\title{
A Taphrina strain infecting the model plant Arabidopsis thaliana.
}

Margaretta Christita ${ }^{1,2}$, Agate Auzane $^{1}$, Kai Wang ${ }^{1}$, Timo Sipilä1,3, Petri Auvinen4, Lars Paulin ${ }^{4}$, Jarkko Salojärvi ${ }^{1,5}$, Kirk Overmyer ${ }^{1, ~ *}$

${ }^{1}$ Organismal and Evolutionary Biology Research Program, Faculty of Biological and Environmental Sciences, and Viikki Plant Science Centre, University of Helsinki, Finland.

${ }^{2}$ Environment and Forestry Research and Development Institute of Manado, Indonesia.

${ }^{3}$ Current address: Finnish Institute of Molecular Medicine, P.O. Box 20, University of Helsinki, FI-00014 Helsinki, Finland.

${ }^{4}$ Institute of Biotechnology, University of Helsinki, Helsinki, Finland.

${ }^{5}$ Population Genomics and System Biology, School of Biological Sciences, Nanyang Technological University, 60 Nanyang Drive, SBS-01n-21, Singapore 637551, Singapore.

*Corresponding author: kirk.overmyer@helsinki.fi 


\section{Abstract}

Yeasts are important plant-associated organisms that can modulate host immunity to either promote or prevent disease. Mechanisms of plant-yeast interactions, specifically of yeast perception by the plant innate immune system, remain unknown. Progress has been hindered by the scarcity of yeast species associated with the model plant Arabidopsis thaliana (Arabidopsis). We have previously isolated Taphrina strain M11 from wild Arabidopsis in the field. Taphrina are poorly studied dimorphic yeast-like fungi that are plant pathogens, often producing plant hormones and causing tumourlike and leaf deformation symptoms on their hosts. Here we characterize the interaction of M11 with Arabidopsis. Infection of Arabidopsis with the birch pathogen T. betulina, used as a non-host control, shows early HR, enhanced ROS accumulation, and limitation of growth, demonstrating that Arabidopsis had immunity against nonadapted yeasts. M11 triggered limited cell death, an attenuated ROS response, and grew in planta, as well as subtle but clear leaf deformation symptoms, demonstrating it is pathogenic. Hormone responsive promoter-reporter analysis demonstrated activation of cytokinin signalling during infection. Mutant infection assays indicate jasmonate and ethylene were required for immunity against M11. Analysis of the Taphrina M11 genome was used to mine evidence for yeast specific PAMPs which may underlie host immune responses against yeast-like fungi.

\section{Introduction}

Pathogens are specifically adapted to overcome specific host and non-host resistance mechanisms utilized by the host to limit their access or growth (Pieterse et al., 2012, Dodds and Rathjen, 2010, Cui et al., 2015; Lee et al., 2017). Plants possess a twotiered innate-immune system (Jones and Dangl, 2006). The first level is termed basal 
or non-host resistance and consists of multiple mechanisms (Lee et al., 2017), including pattern recognition receptors (PRRs), which recognize conserved pathogen associated molecular patterns (PAMPs) to induced PAMP-triggered immunity (PTI) (Jones and Dangl, 2006). To overcome PTI, adapted pathogens have evolved effectors, which are toxins or short secreted proteins that interfere with plant immune signalling. To counter this plants deploy nucleotide-binding, leucine-rich repeat (NLR) immune receptors, which are activated by effector action leading to recruitment of immune signalling pathways, termed effector triggered immunity.

Non-pathogenic yeast species, such as Saccharomyces cerevisiae and Schizosaccharomyces pombe have been used as model system for genetics and molecular biology because of their easy genetics, rapid growth, and ease of cultivation. These model systems have been invaluable reference organisms in fungal genetics; for instance in definition of the unique components found in yeast cell walls (Perez et al., 2018). Human pathogenic yeasts such as Candida albicans have been important systems for understanding yeast-host interactions and have resulted in definition of the human PRRs responsible for monitoring the presence of pathogenic yeasts (Jouault et al., 2009). There are very few known phytopathogenic species among the true yeasts in subphylum Saccharomycotina, with a few examples in the genus Eremothecium (Wendland and Walther, 2011). However, there are a large number of phytopathogenic yeast-like fungi with dimorphic lifecycles, for instance in the Ascomycete subphylum Taphrinomycotina and the Basidiomycete subphylum Ustilaginomycotina (Begerow et al., 2017; Lachance and Walker, 2018).

Species belonging to the genus Taphrina (Ascomycota, Taphrinomycotina, Taphrinomycetes, Taphrinales, Taphrinaceae) are little studied pathogens of primarily woody plant species, although some Taphrina are pathogens of herbaceous host 
species; including for example, Curcuma, Potentilla, and some ferns (Mix, 1949; Ahmed and Kulkarni, 1968; Fonseca and Rodrigues, 2011; Rodrigues and Fonseca, 2003). Protomyces is the sister genus to Taphrina; members of this genus are pathogenic mostly on herbaceous hosts in the Umbelliferae and Compositae and have similar lifecycles and virulence strategies to the Taphrina (Wang et al., 2021). Taphrina are dimorphic, with dikaryotic infectious filamentous phase, which invades host tissues, and an easy to culture haploid yeast phase, which resides in the phyllosphere of the host between infection cycles. The Taphrina infection process has been shown to be dependent on cold and moist conditions during the infection window in spring while host buds opening (Giosuè et al., 2000; Rossi et al., 2006). Thus, infections do not necessarily occur on a yearly basis and it is held that Taphrina can survive as a yeast in the host phyllosphere indefinitely (Mix, 1949). Most Taphrina isolates have been isolated from their respective hosts, in a diseased state (Mix, 1949). Some Taphrina have been isolated in their yeast states from inert surfaces or plants without disease symptoms, suggesting that some Taphrina may be specialized in atypical lifestyles, such as endoliths or non-pathogenic phyllosphere residents (Selbmann et al., 2014; Inacio et al., 2004; Moore, 1998). Much of the previous work on members of the genus Taphrina is quite old; however, recent genome sequencing projects have opened this genus to modern molecular approaches (Cissé et al., 2013; Tsai et al., 2014; Wang et al., 2020).

Most Taphrina cause tumour-like symptoms on their hosts, as are typified by the witches' brooms caused by the birch pathogen, T. betulina (Dingley, 2012; Bacigálová et al., 2005; Mix, 1949; Kern and Naef-Roth, 1975), or the leaf deformations caused by the peach pathogen, T. deformans (Mix, 1949; Fonseca \& Rodrigues, 2011). Taphrina species are known for the ability in produce plant hormones auxin and 
cytokinin, but the role of these hormones in Taphrina pathogenicity has not been confirmed. Production of auxins and cytokinins by T. betulina was first reported in 1975 (Kern and Naef-Roth, 1975), while auxin production by T. wiesneri was first reporedt in 1966 (Matuyama and Misawa, 1961). The IAA biosynthesis pathways utilized in several Taphrina and Protomyces species have been addressed in several publications including genome studies (Cissé et al., 2013; Tsai et al, 2014; Wang et al., 2019). Additionally, secondary metabolite biosynthesis gene clusters have also been identified in the $T$. deformans genome (Cissé et al., 2013).

Arabidopsis thaliana (referred to here as Arabidopsis) is a widely used genetic model plant, which has accelerated definition of the plant immune system. Many studies have utilized the genetic model plant Arabidopsis to investigate the relationship of the plant innate immune system facing diverse microbes, including fungi, bacteria, oomycetes, but not yeasts. While PRRs and NLRs involved in immunity against other pathogen classes are well defined, the immune receptors detecting yeasts remain unknown. The investigation of yeast-plant interaction by utilizing Arabidopsis has been slowed by a lack of Arabidopsis associated yeasts. We have previously isolated Taphrina strains from wild Arabidopsis (Wang et al., 2016) opening the possibility to study Arabidopsis interactions with a pathogenic yeast. Previous studies have used T. betulina to study the non-host interaction with Arabidopsis (Gehrmann, 2013) and Protomyces arabidopsidicola to probe Arabidopsis immune activation by a phyllosphere resident non-pathogenic yeast (Wang et al., 2019; Wang et al., 2021).

Arabidopsis has not been previously known to be a host for Taphrina. In this study we describe Taphrina strain M11 isolated from wild Arabidopsis and compare it to known Taphrina species.. We describe Arabidopsis infection symptoms and potential 
interaction mechanisms with Arabidopsis immunity, such as alteration of plant hormone levels.

\section{Materials and Methods}

\section{Plants and cultivation conditions}

Wild type Col-0 accession and mutant seeds of Arabidopsis (Arabidopsis thaliana) were obtained from the Nottingham Arabidopsis stock centre (NASC; http://arabidopsis.info/). The mutant lines used where; coi1-16 (coronatine insensitive 1-16), cyp79 b2/b3 (cytochrome p450, family 79, subfamily b polypeptide 2 and 3 double mutant), ein2 (ethylene insensitive2), jar1 (jasmonate resistant1), npr1 (non-expresser of pathogenesis-related genes1), pad 4 (phytoalexin deficient4), sid2 (salicylic acid induction deficient2). All mutant alleles are in the Col-0 accession.

Standard plant cultivation conditions were as follows. For soil grown plants, seeds were sown on a well watered 1:1 mix of peat (Kekkilä; www.kekkila.fi) and vermiculite, stratified in the dark at $4^{\circ} \mathrm{C}$ for $72 \mathrm{hrs}$, then transferred to a growth chamber (Fitotron SGC120, Weiss Technik; www.weiss-technik.com) with 8/16 light hours of $150 \mathrm{uM} \mathrm{M}^{-}$ 2 illumination, at $23^{\circ} \mathrm{C}$ and constant humidity (ca. 60\%). For sterile plant cultivation, seeds were sterilized with chlorine gas for $5 \mathrm{~h}$, sown on $0.5 \times \mathrm{MS} 0.8 \%$ agar, and stratified in the dark at $4^{\circ} \mathrm{C}$ for $72 \mathrm{hrs}$. One-week-old seedlings were transplanted into 6 -well plates with $4 \mathrm{ml}$ of $0.5 x M S 0.8 \%$ agar. The medium and roots were separated from the shoots using tight fitting polypropylene disks with a $4 \mathrm{~mm}$ hole in the middle. Plants were grown in the Fitotron SGC120 growth chamber with 12/12 h light/dark cycle at $\sim 170 \mu \mathrm{mol} \mathrm{m} \mathrm{m}^{-2} \mathrm{~s}^{-1}$ light, $+23 /+18^{\circ} \mathrm{C}$, and $65 / 75 \%$ relative humidity.

\section{Microbe strains and culture conditions}


Taphrina strain M11 was previously isolated from the phyllosphere of wild growing Arabidopsis (Wang et al., 2016). Strain M11 has been deposited in the HAMBI Helsinki Microbial Domain Biological Resource Centre - under the accession number HAMBI: H3698 and in the DSMZ - The German Collection of Microorganisms and Cell Cultures - under the accession number DSM 110146. All other Taphrina strains were obtained from the Portuguese yeast culture collection (PYCC; https://pycc.bioaware.com/). T. betulina (strain PYCC 5889=CBS 119536) is not adapted to Arabidopsis and was used as a non-host response control. Two T. tormentillae strains (strain CBS 332.55=PYCC 5705 and strain PYCC 5727), are the strains most closely related to M11. T. tormentillae strain PYCC 5705/CBS 332.55 (formerly named T. carnea) was originally isolated from birch and thought to be a birch pathogen, but later shown to be conspecific with T. tormentillae (Fonseca and Rodrigues, 2011). All yeast strains were grown on 0.2 x potato dextrose agar (PDA) made with $15 \mathrm{~g} / \mathrm{l}$ agar in potato dextrose broth (PDB; BD Biosciences; https://www.bd.com). Pseudomonas syringae pv. tomato strain DC3000 (Pst DC300) transgenically bearing the AvrB avirulence gene was cultured in NYGA media.

\section{Arabidopsis infections}

For infections of soil grown plants seven-day-old Taphrina cells were collected using an inoculation loop, washed in $2 \mathrm{ml} 10 \mathrm{mM} \mathrm{MgCl}_{2}$ and resuspended in the same at OD $=0.3$. Leaf halves from four-week-old soil-grown Arabidopsis were hand inoculated with yeast suspensions using a needleless syringe, then returned to standard growth conditions, covered at high humidity for the first 24 hours. Similarly prepared suspensions $(\mathrm{OD}=0.1)$ from a one-day-old culture of Pst DC300 AvrB were used as a positive control for $\mathrm{HR}$ induction. Mock treatments with $10 \mathrm{mM} \mathrm{MgCl}$ were used as a negative control in all infection experiments. Experiments with Arabidopsis immune 
signaling mutants were photographed at $10 \mathrm{dpi}$ to document symptoms, visually evaluated, and cell death was visualized by trypan blue staining.

For Taphrina growth tests on sterile plants freshly grown cells of all strains were harvested, washed, and suspended in $10 \mathrm{mM} \mathrm{MgCl}_{2}$ with $0.04 \%$ wetting agent Silwet L77. Yeast suspensions $\left(\mathrm{OD}_{600}=0.02\right)$ and control solution were applied onto 24 -dayold plants of wild type Col-0 using sterile plastic spray bottles. To ensure uniform yeast distribution onto plants, all wells except one were covered with sterile aluminum foil and the spray bottle was kept at a constant distance from plates. Half of the plants were harvested immediately and the rest at 9 dpi. Harvested plants were put in tared tubes with $1 \mathrm{ml}$ of $10 \mathrm{mM} \mathrm{MgCl}$, weighed, cooled on ice, and ground in a tissue homogenizer (Precellys 24; https://www.bertin-instruments.com) with $3 \mathrm{~mm}$ silica beads $(2 \times 30 \mathrm{~s}$ at $5000 \mathrm{rpm}$, with cooling on ice between runs). Dilutions of homogenized plant samples were plated on 0.2x PDA and Taphrina colonies were counted after 4 days. Additionally, the gnotobiotic status of the seedlings was periodically checked by plating ground uninfected leaf samples on LB media and 1XPDA.

\section{Histological staining}

Biofilm formation was quantified using the crystal violet staining method as in (Wilson et al., 2017). Four-day-old cells of the indicated Taphrina strains were harvested from 0.2x PDA media, washed, and suspended at $\mathrm{OD}_{600}=0.02 .200 \mu \mathrm{l}$ of yeast suspension were added to $800 \mu$ l of $0.2 x$ PDB (final $O_{600}=0.004$ ) and grown in polystyrene 48well plates (CELLSTAR® Cell Culture Multiwell Plates, TC treated, Greiner Bio-One) without shaking. To prevent contamination, each yeast species was separated by empty wells containing only media. After 8 and 16 days, wells were rinsed to remove loosely adherent cells, stained for $15 \min$ with $1 \%$ crystal violet solution, and 
photographed. Subsequently, biofilm-bound dye was dissolved in $100 \%$ ethanol and quantified spectrophotometrically $(\lambda 600)$.

Crystal violet staining was used, as in Valadon et al (1962), to visualize M11 cells and biofilms in and on infected leaves; briefly, $0.5 \%$ crystal violet staining solution was prepared in aqueous $20 \%$ methanol. Leaves of wild type Arabidopsis that had been infiltrated with Taphrina strain M11 at 3-7 dpi were cleared in 90\% acetone, placed on a slide, and stained with a drop of the staining solution for 5-10 sec at room temperature, destained with $\mathrm{ddH}_{2} \mathrm{O}$ as required, and mounted in $60 \%$ glycerol. Samples were observed under a Leica compound microscope ( $M Z$ 2500; https://www.leica-microsystems.com)with a magnification of 200x-400x. Trypan blue staining was used to visualize hypersensitive response-like cell death in infected soil grown plants. Whole leaves were stained by boiling for ca. 1 minute in a 1:1 dilution of trypan blue staining solution (0:05\%) in lactophenol $(1: 1: 1$, glycerol:85\% lactic acid: phenol) in 95\% ethanol. Samples were cleared at room temperature in chloral hydrate ( $2.5 \mathrm{~g}$ chloral hydrate per $1 \mathrm{ml} \mathrm{ddH_{2 } 0}$ ) with several changes of destaining solution until clear.

DAB (3,3'-Diaminobenzidine; Sigma; www.sigmaaldrich.com) staining was used to visualize the in planta accumulation of $\mathrm{H}_{2} \mathrm{O}_{2}$ (Jambunathan, 2010). DAB stain solution $(0.1 \% \mathrm{w} / \mathrm{v})$ was prepared fresh and protected from light. Four-week-old Arabidopsis were hand inoculated and stained for $2 \mathrm{hrs}$ in a closed container in the dark at high humidity. DAB solution was infiltrated into the leaves by vacuum infiltration. The staining reaction was stopped by immersing samples in clearing solution (3:1 solution of $95 \%$ ethanol in lactophenol). 
$\beta$-Glucuronidase (GUS) staining was used to investigate activation of host plant auxin and cytokinin transcriptional responses during infection using transgenic Col-0 Arabidopsis with the following promoter-reporter systems; the auxin-responsive DR5 promoter or the cytokinin responsive TCS promoted fused to the GUS reporter; denoted as DR5::GUS and TCS::GUS, respectively. Four-week-old Arabidopsis were infected by hand infiltration. Positive controls for DR5::GUS were treated with 2, 5, and $10 \mu \mathrm{M}$ indole acetic acid (IAA), for TCS::GUS controls were 2, 5, and $10 \mu \mathrm{M}$ 6benzylaminopurine (BAP), all negative controls were mock infected with $\mathrm{MgCl}_{2}+$ silwet. GUS staining solution contained $1 \mathrm{mM}$ 5-bromo- 4-chloro-3-indolyl b-Dglucuronide dissolved in methanol, $5 \mathrm{mM}$ potassium ferricyanide and $5 \mathrm{mM}$ potassium ferrocyanide in $50 \mathrm{mM}$ sodium phosphate buffer and adjusted to $\mathrm{pH}$ 7.2. For histochemical staining, seedlings were fixed with ice-cold $90 \%$ acetone for $1 \mathrm{~h}$, washed two times with ice-cold wash solution (50 mM sodium phosphate buffer, $\mathrm{pH} 7.2$ ), 30 min for each wash. Seedlings were vacuum infiltrated for 5 minutes and kept at room temperature in GUS staining solution. Stained seedlings were washed two times with absolute ethanol, then cleared and stored in $70 \%$ ethanol.

\section{Leaf symptom assays}

Leaf symptom assays included quantification of leaf curling and leaf bending. To investigate leaf curling, Col-0 leaves were infected with strain M11, and $T$. betulina at 14 dpi were transversely cross sectioned half way between the leaf base and tip by hand using razor blade and photographed. Curling index was measured from photos of leaf sections using Image $\mathrm{J}$ (https://imagej.nih.gov/ij/), as in Booker et al.(2004), and as illustrated in Figure S1.

To quantify leaf bending, M11 and $T$. betulina infected Col-0 leaves were photographed at $14 \mathrm{dpi}$ then leaf bending was measured using Image J. Leaf bending 
was quantified by measuring the angle between the base of the petiole and the leaf tip, as illustrated in Figure S1, were a greater the angle indicates a higher level of leaf bending.

\section{Genome sequencing, assembly, and analysis}

DNA extraction, genome sequencing, and assembly were performed as previously described in Wang et al. (2019). In short, chromosomal DNA was extracted according to the protocol of Hoffman (1997). DNA quantity and quality was assessed using qubit fluorometer (Thermo Fisher Scientific, USA) and Nanodrop ND-1000 (Thermo Scientific, USA). Following the Paired-End Sample Preparation Guide (Illumina) DNA libraries were prepared for sequencing with MiSeq System (Illumina, California USA). Sequencing was performed at the DNA Sequencing and Genomics Laboratory, Institute of Biotechnology, University of Helsinki. Resulting reads were assembled with SPAdes v. 3.1.1 pipeline (Bankevich et al., 2012). Assembly quality was determined using the QUAST tool version 5.0 (http://quast.sourceforge.net/).

Genome annotation was performed using Augustus version 2.5.5 (Stanke et al., 2008) which was trained on RNA sequencing results from Taphrina betulina genome sequencing project (Bioproject: PRJNA188318). For further details on the automated annotation pipeline see Wang et al. (2019).

To analyse the distribution of orthologous proteins in Taphrina M11 and selected members of the Taphrinomycotina the OrthoVenn2 platform (Xu et al., 2019) was used with an $E$-value cut-off $E<0.01$. Proteomes from the following whole genome sequencing projects were included: T. deformans JCM22205, BAVV01; T. wiesneri JCM22204, BAVU01; T. populina JCM22190, BAVX01; T. flavorubra JCM22207, BAVW01; S. pombe 972h-, ASM294v2. Proteomes of $P$. arabidopsidicola strain C29, 
QXMI01; P. lactucaedebilis YB-4353, QXDS01; P. gravidus Y-17093, QXDP01; P. macrosporus Y-12879, QXDT01 were from (Wang et al., 2019).

Conserved domains in annotated proteins of M11 were identified using HMMER software versions v3.2.1 and v3.3 by searching against Pfam database with $E<1$ 30 cut-off (Finn et al., 2016).

To identify candidate effector-like proteins, open reading frames (ORFs) in the size range 80-333 amino acids (aa) were selected for screening with SignalP 4.1 tool for the presence of a secretion signal (Petersen et al., 2011), and defined as short secreted proteins (SSPs). SSP sequence secretion signals were trimmed and mature SPP peptides with $\geq 4$ cysteine residues were categorized as cysteine-rich SSPs (CSSPs).

Orthologs for enzymes of interest were identified using BLASTp tool to search the M11 and other Taphrina genomes with the query sequences provided in the supplemental files. The identity of proteins was further confirmed by performing BLASTp search against Swiss-Prot database (default parameters). For the alignment of chitin synthases Clustal Omega multiple sequence alignment program was used (Madeira et al., 2019).

\section{Results}

\section{Taphrina M11 growth on Arabidopsis}

We have previously isolated a collection of yeasts from the phyllosphere of wild growing Arabidopsis in the field (Wang et al., 2016). These yeast species were screened for the ability to cause disease on Arabidopsis, including OTU3, which had two Taphrina strains, M11 and M12 with ITS sequences (LT602860) that are identical 
to each other and most closely related (99\% similarity) to T. tormentillae, which is pathogenic on members of the herbaceous host plant genus the Potentilla (Wang et al., 2016; Fonseca \& Rodrigues, 2011). Hand infiltration of Arabidopsis leaves with Taphrina strain M11 cell suspensions resulted in disease symptoms in Arabidopsis (Figure 1A), including leaf deformations and chlorosis. Based on this result, Taphrina strain M11 was targeted for genome sequencing and further characterization of its interaction with Arabidopsis.

As Taphrina species have dimorphic lifecycles, we probed the morphology of strain M11 cells in Arabidopsis leaves using microscopic observation of crystal violet stained infected tissues. Comparison of uninfected control to infected leaf tissue revealed clusters of M11 yeast cells at 24 hpi (Figure 1B-C). In some tissues at slightly later time points (3 dpi) the growth of infectious hyphae was detected (Figure $1 \mathrm{D}-\mathrm{E})$. The stain used here can also visualize biofilms (Wilson et al., 2017). In some infected Arabidopsis leaves, dark staining cell aggregates with the appearance of a biofilm were observed (Figure 1F).

M11 growth on Arabidopsis was then quantified from spray infections of axenic 24day-old plants (Figure 2A) compared to the two closely related T. tormentillae strains (CBS 332.55 and PYCC 5727) and non-host response control, T. betulina. Strain M11 grew to the highest levels, closely followed by the two other T. tormentillae strains, which both grew to similar levels, while $T$. betulina showed little to no growth.

To further explore the possibility of biofilm formation by strain M11 the ability of Taphrina species to form biofilms was quantitatively assayed in vitro. T. tormentillae strain CBS 332.55 demonstrated strong ability to form biofilms on polystyrene surfaces (Figure 2B). In comparison, T. tormentillae strain PYCC 5727 showed medium biofilm formation on polystyrene and M11 started forming small, adherent biofilm-like patches 
only after 16 days of growth. The non-host control, T. betulina, was not able to form biofilms under the tested conditions.

\section{Response to infection}

As shown in Figure 3A-D, the activation of cell death upon Taphrina infection was monitored visually (left) and with trypan blue staining at $48 \mathrm{hpi}$ (right). Treatment of Arabidopsis leaves with M11 resulted in chlorosis and leaf deformation symptoms that were associated with a very low level of cell death (Figure 3A) compared to mock infected control leaves (Figure 3D). Activation of hypersensitive response (HR)-like cell death was observed in leaves challenged with the non-adapted $T$. betulina (Figure 3B); however, this was less than in leaves treated with avirulent Pst strain DC3000 transgenically bearing the $A v r B$ avirulence gene, which was used as a control for a strong HR (Figure 3C).

To monitor the accumulation of $\mathrm{H}_{2} \mathrm{O}_{2}$ caused by challenge with Taphrina, DAB staining was performed; stained and cleared leaves were photographed (Figure 3E) and brown colored pixels were quantified using ImageJ (Figure 3F). Compared to the mock treatment there was a small but significant increase in DAB staining in Arabidopsis infected with M11. In T. betulina inoculated Arabidopsis accumulation of DAB stain was significantly $(p=2.106 e-10)$ higher and covered a wider leaf area than in $M 11$ infected plants (Figure 3E-F).

At later time points, Arabidopsis leaves infected with strain M11, also exhibited additional leaf symptoms, more subtle, but reminiscent of the leaf deformations caused by other Taphrina species; these late responses presented in the form of leaf curing and leaf bending (Figure 5). A leaf curling response was quantified using a curvature 
index as used previously (Booker et al., 2004), which is the ratio of the leaf width to the total leaf width (Figure S1A), where a smaller curling index value indicates a higher degree of leaf curvature (epinasty). Plants infected with the M11 strain exhibited visibly enhanced leaf curling compared to mock treated controls (Figure 4A), and quantified as a curling index $50 \%$, while mock was $75 \%$ (Figure 4B). This phenotype was specific to strain M11, as infection with the non-host control, T. betulina, was indistinguishable from control both visually and quantitatively, with a curling index of $75 \%$ (Figure 4 AB).

Infection with M11 also caused leaf bending (Figure 4C-D), which was monitored visually and quantified using a leaf bending index, measured as the angle between two lines, one defined by points on the base and mid-point of the petiole and the other by points at mid-point and tip of the leaf (Figure S1B). Significant leaf bending was observed in response to infection with M11 in comparison to mock (Figure 4C), quantified as bending index values of $40.6^{\circ}$ and $9.8^{\circ}$, respectively (Figure 4D). This phenotype was also specific to M11 infection, as the non-host control $T$. betulina had a bending index of $12.1^{\circ}$, which was not significantly different from the mock infected control (Figure 4D).

\section{Activation of host plant hormone responses}

There is evidence of plant hormone production in many Taphrina species, including Taphrina M11 (see below; Wang et al., 2016). Plant hormones originating from Taphrina cells are widely presumed to modulate host plant hormone signalling during pathogenesis; however, this has not been formally tested. To address this, the activation of host hormone transcriptional responses were monitored during infection using two Arabidopsis lines transgenically bearing either a cytokinin-responsive 
(TCR::GUS) or auxin-responsive (DR5::GUS) promoter-reporter construct. These reporter lines underwent various treatments, including infiltration with Taphrina strain M11, followed by histological staining of GUS activity to visualize hormone response activation (Figure 5A-B). IAA and BAP were used at three different concentrations as positive controls. The results of the GUS staining experiment showed that both M11 and $T$. betulina were able to activate Arabidopsis auxin (Figure 5A) and cytokinin (Figure 5B) transcriptional responses. The IAA response was similar in extent and spatial distribution; localized to the leaf periphery and secondary vasculature in response to both $\mathrm{M} 11$ and $T$. betulina (Figure 5A). However, the cytokinin transcriptional response to M11 infection was both stronger and involved more tissues, especially around the base of the leaf, while infection with $T$. betulina resulted in only a small response along the primary leaf vein (Figure 5B).

To determine the role of known plant defence signalling pathways, including immune signalling hormones, a reverse genetics approach was used (Figure 6). Seven knockout mutants were challenged with M11 infection, namely; the jasmonateinsensitive mutants coi1-16 and jar1; the cyp79 b2/b3 double mutant, which is deficient in both indolic glucosinolates and the indole alkaloid phytoalexin, camalexin; the ethylene-insensitive ein2 mutant; the pad4 mutant, which is deficient in both camalexin and salicylic acid induction, and the sid2 and npr1 mutants, which are deficient in salicylic acid biosynthesis and signalling, respectively. Each mutant was treated both with M11 and mock treatment and evaluated both visually and after trypan blue staining (Figure 6). Upon visual examination, compared to Col-0, cyp79 b2/b3, coi116, pad4, and ein2 exhibit enhanced disease susceptibility (EDS) phenotypes expressed as extensive damage and tissue collapse in the leaves inoculated with M11 (Figure 6). The npr1 and sid2 mutants had more moderate EDS, with sid2 showing 
enhanced leaf deformations. These symptoms did not always correlate with increased cell death, as only ein2 and cyp79 b2/b3 exhibited strongly increased cell death that spread out of the infected half of the leaf (Figure 6).

\section{Taphrina M11 genome assembly and protein annotations}

In order to gain insight into its biology, the genome of Taphrina strain M11 was sequenced, resulting in a high quality draft genome assembly of $13.6 \mathrm{Mbp}$ in 234 contigs (Table 1). Characteristics of the Taphrina M11 genome were consistent with those of other sequenced Taphrina species (Table S3). A total of 5808 proteins were annotated, which is similar to proteomes identified in other previously sequenced Taphrina species (Table S1). Ortholog distribution was monitored across M11 and several other species of Taphrina, for which genome data is available (Figure 7): additionally several species of the closely related genus Protomyces were used for comparison, and $S$. pombe was used as an outgroup to define Taphrinomycotina specific and conserved eukaryotic proteins. On average $38.5 \%$ of all proteins were common across the subphylum Taprhinomycotina; however these were not specific to the Taphrinomycotina as they included conserved eukaryotic housekeeping genes. The genera Taphrina and Protomyces shared $14.9 \%$ of their genes, while $5.3 \%$ were unique to the genus Taphrina (Figure 7). The genus Protomyces had slightly more genus specific proteins $-7.1 \%$. Only 151 proteins (2.6\%) were found to be unique to Taphrina strain M11. Taphrina M11 shared a sizable portion (132 proteins, $2.3 \%$ ) of orthologous proteins with Taphrina species pathogenic on Prunus species, but not with the T. populina, which is pathogenic on Populus (20 proteins, $0.3 \%$ ).

\section{Candidate effector-like proteins and plant-associated conserved domains}


To identify candidate effector-like proteins in M11 genome, a total of 18660 short (80333 aa) ORFs were identified, 767 of which contained a secretion signal and were defined as short secreted proteins (SSPs; Table 2A). Of the SSPs, 337 contained 4 or more cysteine residues and were defined as cysteine-rich SSPs (CSSPS). This number of CSSPs was consistent with those present in genomes of other Taphrina species (Table 2A). Conserved domains present in these CSSPs were identified (Table 2B). Notably, no LysM domain containing SSPs and CSSPs were detected this domain is common in effectors from chitin-containing fungi (Table 2B).

We also queried all the Taphrina M11 annotated proteins for conserved domains previously identified as being typical of plant-associated microorganisms by (Levy et al., 2017). Proteins containing RNA recognition motif were common in the M11 genome (Table S5), which is a typical characteristic of biotrophic pathogens (Pandaranayaka et al., 2019). The most common domain, however, was the protein tyrosine kinase domain.

\section{Putative plant hormone biosynthesis pathways}

Genes involved in indole acetic acid (IAA) and cytokinin production (Table 4) were identified in the M11 genome using known biosynthesis genes from other species, which represented four possibly routes for IAA biosynthesis in microbes; specifically, the indole-3-acetamide (IAM), indole-3-pyruvate (IPyA), indole-3-acetonitrile (IAN), and tryptamine (TAM) pathways. Remarkably, the Taphrina M11 genome contained complete enzymatic machinery for IAA production via three different routes - the IAM, IPyA, and TAM pathways (Table 4). Enzymes involved in these pathways were also conserved in T. deformans (Table S6). 
Two key enzymes of cytokinin biosynthesis were also identified in M11 genome (Table 4) - tRNA-isopentenyltransferase and cytokinin phosphoribohydrolase. However, the presence of other enzymes involved in this pathway cannot be excluded, as no query sequences for other steps of the pathway were available from closely related fungi.

\section{Biosynthesis of potentially immunoactive cell wall polysaccharides}

Microbial cell walls are a major source of PAMPs such as chitin and linear $\beta-1,3-$ glucan, which are recognized by plant immune receptors. To predict potential PAMPs present in Taprhina M11 cell walls we looked for putative cell wall biosynthesis proteins in Taphrina M11 genome and compared them with biochemical evidence for presence of different cell wall polysaccharides from other studies (Table 3). Despite biochemical studies indicating that yeast cells of Taphrina deformans contain little to no chitin (Petit and Schneider, 1983), we identified two conserved chitin synthases in the Taphrina M11 genome and three conserved chitin synthases in $T$. deformans (Figures S3, S4, and S5). Additionally, a putative chitin deacetylase homolog was found, which could potentially be used by M11 to transform chitin into chitosan (Table 3).

The M11 genome contains homologs of proteins necessary for production of $\beta$ glucans both with $\beta-1,3$-linkages and $\beta$-1,6-linkages (Table 3). The presence of these polysaccharides was also supported by previous biochemical analysis (Petit and Schneider, 1983). Another glucose polysaccharide potentially present in M11 cell walls is a-glucan. We identified two $\alpha-1,3-$ glucan/ $\alpha-1,4$-glucan synthase genes in $M 11$ genome (Table 3). According to biochemical evidence, similar to Schizosaccharomyces pombe Taprhina species contain predominantly a-1,3-glucan (Petit and Schneider, 1983). 


\section{Discussion}

\section{M11 causes disease on Arabidopsis}

Infection of Arabidopsis with the species T. betulina, a Taphrina not adapted to Arabidopsis -- used here as a control for the non-host defence response, resulted in accumulation of $\mathrm{H}_{2} \mathrm{O}_{2}$, activation of rapid $\mathrm{HR}$-like cell death, no growth in planta, and no late leaf deformation or other symptoms. These results indicate that Arabidopsis has immunity against $T$. betulina and likely other Taphrina species. However, the activation of HR-like cell death observed here was in contrast to most forms of nonhost resistance (Lee et al., 2017). This type of non-host resistance appears to share similarities to effector triggered immunity (ETI), normally conditioning host immunity to adapted pathogens. There are several known examples of this; however, the mechanisms and roles of ETI-like resistance in non-host resistance remain poorly understood (Stam et al., 2014); (Lee et al., 2017). Infections with Taphrina strain M11, which was isolated from wild Arabidopsis in the field, resulted in an attenuated ROS response compared to $T$. betulina, a small amount of cell death that was consistent with symptom development, successful multiplication on Arabidopsis, and leaf symptom development including chlorosis and late presentation of leaf deformations. These findings support that strain M11 is adapted to, and pathogenic on Arabidopsis. M11 having the lifestyle of a plant pathogen was also supported by several of its genomic features, such as; a full complement of candidate effector proteins, similar to those found in other Taphrina species; and the presence of conserved protein domains previously shown to be specific to plant associated microbes. There are currently no resistance mechanisms against Taphrina known at the mechanistic level; although several studies have begun to address the possibility of such resistance. Evidence of 
genetic resistance against witches' broom disease caused by $T$. betulina segregating in natural populations of birch (Christita and Overmyer, 2021). Taphrina resistance has also been addressed in peach (Goldy et al., 2017), where Taphrina causes significant economic losses and chemical fungicides are the only available means of control.

Taphrina strain M11 was found to have an ITS sequence that was $99 . \%$ similar to the ITS of $T$. tormentillae (Wang et al., 2016); exceeding the $98.4 \%$ threshold determined for delimitation of yeast species (Vu et al., 2016). This suggests that M11 is a strain of T. tormentillae. However, as has been previously noted, ITS sequences do not always offer good resolution to the species level in the genera Taphrina and Protomyces (Rodrigues and Fonseca, 2003; Wang et al., 2021). Further studies with other phylogenetic markers will be required before the relationship between $\mathrm{M} 11$ and $T$. tormentillae can be determined. The actin1 gene was found to function well as a lineage specific secondary phylogenetic marker for species determination in the closely related genus Protomyces (Wang et al., 2021). Although it remains to be tested, this nuclear gene DNA marker may also function well for the genus Taphrina. Remarkably, the two other tested Taphrina strains -- T. tormentillae strain PYCC 5727 and the closely related strain CBS 332.55, which is also most likely a strain of $T$. tormentillae-- were also able to grow on Arabidopsis, but to slightly lower levels. Further infections with these two strains will be required to determine if pathogenicity on Arabidopsis is a common feature of all strains related to T. tormentillae. Reciprocal infections of these three strains on Potentilla species known to be hosts for $T$. tormentillae will also be required in future studies to fully address host range of this Taphrina species. 


\section{Plant defenses, candidate effectors, and yeast PAMPs}

Infection of known immune signaling mutants of Arabidopsis suggested that ethylene and jasmonate signaling are required for resistance against Taphrina M11. Previous studies with other related systems have shown similar results. A strain (strain C29) of Protomyces, the sister genus to Taphrina, was isolated from Arabidopsis and named P. arabidopsidicola (Wang et al., 2021). Strain C29 was not pathogenic, but persisted in the Arabidopsis phyllosphere and activated enhanced immunity against the fungal necrotrophic pathogen Botrytis, which was associated with activation of MAPK signalling and markers of camalexin biosynthesis and salicylic acid signalling (Wang et al., 2019) Additionally, treatment of plants with yeast cell wall preparations, yeast extract, or autoclave killed $S$. cerevisiae have been shown to activate resistance and activate defence signalling pathways (Raache et al., 2006; Khokon et al., 2010). The above results indicate that yeast induce defence signalling pathways similar to those responding to other pathogenic fungi. However, yeasts and dimorphic yeast-like fungi present a different set of surface molecules compared to other fungi and the major yeast PAMPs remain uncharacterized.

To address the possibility of unique PAMPs in Taphrina, analysis of potential cell wall carbohydrate biosynthesis genes in the M11 genome was undertaken. Although conserved chitin synthases were found in M11 and T. deformans genome (Figures S3-S5), biochemical studies done in the past on Taphrina and the closely related Protomyces cell walls do not indicate the presence of chitin (Petit and Schneider, 1983; Valadon et al., 1962). However, in those studies the cell walls were isolated only from the yeast-like cells of Taphrina and Protomyces. As indicated by studies on other dimorphic fungi, cell wall composition can change depending on the growth form and hyphae can contain substantially more or less chitin than the yeast-like cells (Díaz- 
Jiménez et al., 2012). Also in the cell walls of $S$. pombe - the best studied yeast from the subphylum Taphrinomycotina - chitin can only be detected in ascospores (Arellano et al., 2000). Thus, the presence of conserved chitin synthases in Taphrina M11 and T. deformans genomes suggests that Taphrina could have detectable chitin in other growth forms or produce it only during ascospore formation like $S$. pombe.

Notably, similar to the closely related species from Protomyces genus (Wang et al., 2019), Taphrina M11 genome lacks effector-like proteins containing LysM domain. LysM domain containing effectors are a common strategy among fungi for hiding chitin from plant pattern recognition receptors (Gong et al., 2020). The lack of LysM effectors suggests that chitin is of lesser importance in host interactions or that Taphrina yeasts might use different strategies for masking chitin such as non-LysM effectors, chitin deacetylation, or chitin inaccessibility mediated by layers of other polysaccharides, such as $\beta$-glucans or non-degradable $\alpha-1,3$-glucan. In support of the latter two potential strategies, a putative chitin deacetylase and two $\alpha$-glucan synthases were found in M11 genome.

$\beta$-glucans are known to elicit immune responses in a wide range of plants (Fesel and Zuccaro, 2016), including Arabidopsis (Melida et al., 2018; Rebaque et al., 2021). In Taphrina strain M11 we identified the necessary machinery for production of $\beta$-glucans with $\beta-1,3-$ and $\beta-1,6$ - linkages. The presence of these polysaccharides in Taphrina is also supported by biochemical studies (Petit and Schneider, 1983). Interestingly, Taphrina M11 genome contains only one $\beta-1,3-$ glucan synthase FKS homolog. $S$. pombe, which has a similar cell wall composition to Taphrina (Perez et al., 2018), has four FKS homologs with different functions and regulation. In the dimorphic plant pathogen Ustilago maydis and other species having only one FKS homolog, the gene 
is essential for survival and is constitutively expressed (Ruiz-Herrera and OrtizCastellanos, 2019).

Apart from chitin and $\beta-1,3$-glucans that have been described to trigger immune response in Arabidopsis (Xue et al., 2019; Melida et al., 2018), cell walls of M11 could contain glycoproteins with immunoactive glycans. From cell wall monosaccharide analysis, it is known that Taphrina walls contain mannose, rhamnose, and galactose (Petit and Schneider, 1983; Sjamsuridzal et al., 1997). These could be arranged in galactomannans and rhamnomannans as seen in the filamentous plant-pathogenic ascomycete Rhynchosporium secalis (Pettolino et al., 2009). Both galactomannans and rhamnomannans are recognized by innate immunity of animals (Barreto-Bergter and Figueiredo, 2014) and could possibly be also recognized by plants. Taphrina cell walls could also contain simple mannose polysaccharides. Mannopeptides (protease digested mannan glycoproteins) have been previously demonstrated to elicit immune response in tomato cell cultures (Grosskopf et al., 1991).

\section{Plant Hormones in plant-Taphrina interactions}

Taphrina are well documented as producers of the plant hormones auxin and cytokinin (Kern and Naef-Roth, 1975; Cissé et al., 2013; Tsai et al., 2014; Streletskii et al., 2016, Streletskii et al., 2019; Wang et al., 2016). Auxin and cytokinin production is widely believed to be responsible for the dramatic leaf deformation and tumour symptoms typical of the plant pathogens belonging to the genus Taphrina, although this has never been formally tested. Previous studies have examined in vitro plant hormone production by Taphrina species, including Taphrina Strain M11. Here, taking advantage of the genetic tools available with the model plant Arabidopsis, activation of plant hormone response was monitored during infection with M11 Taphrina. Auxin 
response was activated slightly and non-specifically, in response to both pathogenic and non-pathogenic Taphrina species. In Ustilago maydis, a pathogen that shares many similarities with the Taphrina, reduced auxin production by $60 \%$ by loss of function in multiple biosynthesis genes had no effect on tumour formation during infection of its host maize, suggesting that auxin may not be required for tumour formation. In contrast to IAA responses, Arabidopsis cytokinin response was specifically activated in response to the pathogenic M11 strain, but not the non-host control. Cytokinins are key plant developmental hormones that promote cell divisions (Argueso et al., 2009) and are also known to be produced by several plant associated microorganisms, including other tumor inducing pathogens (Pertry et al., 2010). In Ustilago, cytokinin production was required for full induction of tumors (Morrison et al., 2015). Several studies have presented evidence of cytokinin production in Taphrina species (Sommer, 1961; Barthe and Bulard, 1974; Streletskii et al., 2019). Further studies will be required to test the role of auxin and assess if cytokinins from M11 Taphrina are associated with phenotypic changes in response to pathogenic infections.

To further explore the ability for plant hormone production in Taphrina, the auxin and cytokinin biosynthesis genes were examined the M11 genome and revaluated from the genome of $T$. deformans. Both of these Taphrina species have the necessary enzymes for auxin production through three different pathways - IAM pathway, IPyA pathway, and TAM pathway (Table 4, Table S6). To our knowledge, this is the first study in which tryptophan monooxygenase and indole acetamide hydrolase (IAM pathway) have been found in Taphrina genomes. In previous studies enzymes involved in IAM pathway have not been detected in Taphrina species (Tsai et al, 2014). In another study, only TAM and $L A D$ genes of the IPyA pathway were found in the 
genome of $T$. deformans (Cissé et al., 2013). In comparison, the closely related Protomyces species, which have been demonstrated to secrete auxin into culture media, have only one conserved IAA biosynthesis pathway - IPyA pathway (Wang et al., 2019). These results raise the question of the need for these multiple IAA biosynthesis pathways and their function. A model for future testing is suggested by the multiple roles played by auxin in microbes (Spaepen and Vanderleyden, 2011). Auxin is used by pathogens to subvert host immunity and promote infection (Naseem and Dandekar, 2012; Ma and Ma, 2016; Fu and Wang, 2011); in beneficial microbes to promote host growth (Ahmad et al., 2008; Contreras-Cornejo et al., 2009). Additionally, auxin functions in fungal development (Chanclud and Morel, 2016), and is an important adaptation promoting survival in the phyllosphere (Vorholt, 2012; Kemler M., 2017). The various IAA biosynthesis pathways in Taphrina species may be functionally divergent as has been seen in bacterial systems. Pantoea agglomerans pv gypsophilae has dual IAA biosynthesis pathways that are differentially expressed and differentially required; the IAM pathway for pathogenesis, infection and gall formation and the IPyA pathway for fitness in the phyllosphere (Manulis et al., 1998; Chalupowicz et al., 2009).

In Taphrina M11 we identified key enzymes necessary for cytokinin production, thus further supporting the hypothesis that observed increase in cytokinin levels of arabidopsis might be coming from yeast-produced cytokinin (Table 4).

\section{Acknowledgement}


Authors thanks to Tuomas Puukko, and Leena Grönholm, for excellent technical support. MC is a member of the University of Helsinki Doctoral Program in Plant Science (DPPS); AA is a member of the University of Helsinki Microbiology and Biotechnology Doctoral Program (MBDP). This work was supported by the following grants: The Academy of Finland Center of Excellence in Primary Producers 20142019 (decisions \#271832 and 307335); a research grant to MC from the Finnish Society for Forestry Sciences; a research grant to AA from the Kuopio Nature Friends' Association (Kuopion Luonnon Ystäväin Yhdistys); research allocations to AA and MC from the University of Helsinki YEB graduate school, the MBDP, and DPPS; a PhD Fellowship from MPDP granted to AA, and a PhD Fellowship from The Indonesian Fund for Education (LPDP) granted to MC. Computing resources provided by the Finnish IT Center for Science (CSC; www.csc.fi) are gratefully acknowledged. The authors declare no conflict of interest related to this work.

\section{Figure legends}

Figure 1. Host symptoms and Taphrina cell morphology in infected Arabidopsis. (A) Four-week-old control and infected Arabidopsis were photographed at seven days post infection (dpi). Taphrina strain M11 infiltration (M11), mock infiltration using $\mathrm{MgCl}_{2}$ (mock). Scale bars $=1 \mathrm{~cm}$. (B-F) Visualization of the morphology of Taphrina strain M11 cells in the leaf of Arabidopsis after hand infiltration using a needless syringe with four-week-old Arabidopsis. Observations were made at one dpi and show a control mock infected leaf (Scale bar $=10 \mu \mathrm{m})(\mathbf{B})$, and yeast cells (Scale bar $=10 \mu \mathrm{m})$. (C), Hyphal cells were observed at three dpi (Scale bar $=5 \mu \mathrm{m}$ ). (D), close up of hyphal cells (Scale bar $=2 \mu \mathrm{m}$ ). (E), and biofilm formation observed on the leaf surface at three dpi, as shown, or later (Scale bar $=30 \mu \mathrm{m})(\mathbf{F})$. 
Figure 2. Taphrina growth and biofilm formation in vitro. Taphrina growth in the phyllosphere of in vitro Arabidopsis plants (A). Taphrina yeast suspensions were sprayed onto the surface of 24-day-old, sterile wild type Col-0 accession Arabidopsis plants. Strains used were M11 Taphrina, the birch pathogen T. betulina used here as a non-host response control, and two strains of $T$. tormentillae - PYCC 5727/CBS339.55 (T. tormentillae) and PYCC 5705/CBC332.55 ( T. carnea) which was originally assigned the name $T$. carnea but later shown to be a strain of $T$. tormentillae).Yeast growth was quantified through cultivation based technique immediately after spraying and at 9 dpi (days post infection). Combined data are presented from three independent experiments $(n=6)$ for each experiment, data points from each experiment are represented with a different shape - circle, triangle, or square. Letters above boxplots represent significance groups from a Tukey's test performed on linear mixed model computed in $\mathrm{R}$ with biological repeats as a random effect. Means $\alpha \geq 0.05$ share a common letter. (B) Biofilm formation by Taphrina species using the same strains as described above. The presence of adherent, biofilmforming cells were monitored by spectrophotometric quantification of released crystal violet stain after treatment with a with $1 \%$ solution and ethanol extraction. Pooled data from four independent biological repeats is presented $(n=6$ for each biologcal repeat, total $n=24$ ), data points from each experiment are plotted with a different shape. Letters above boxplots represent significance groups as described above.

Figure 3. Cell death and ROS accumulation in infected Arabidopsis. Various cell suspensions were hand infiltrated using a needless syringe into leaf halves of fourweek-old soil grown Arabidopsis. At 48 hours post infection (hpi), infected leaves were photographed (left) and trypan blue histological staining was used to visualize cell death (right). Leaves were infected with: (A) Taphrina strain M11, which was isolated from wild Arabidopsis (B) T. betulina, a birch pathogen used here as a control for a non-host response. (C) Avirulent Pseudomonas syringae pv. tomato DC3000 transgenically expressing $A v r B$, used as a positive control for the hypersensitive response (D) Mock (10 $\mathrm{mM} \mathrm{MgCl}_{2}$ ). (E-F) ROS accumulation during infection of Arabidopsis with Taphrina strain M11 or T. betulina was monitored at 48 hpi by histologically visualizing $\mathrm{H}_{2} \mathrm{O}_{2}$ accumulation with 3,3'-diaminobenzidine (DAB) staining. Leaf halves of four-week-old soil grown Arabidopsis were hand infiltrated with a needless syringe. Stained and cleared leaves were photographed (E) and stain was 
quantified digitally by counting brown pixels in ImageJ (F). One repeat representative of three independent biological repeats is shown. Letters above boxplots represent significance groups determined with ANOVA and Tukey HSD post-hoc test.

Figure 4. Leaf deformation phenotypes. Subtle leaf deformation phenotypes observed in response to infection with Taphrina species. Leaves of four-week-old soil grown Col-0 accession Arabidopsis were hand infiltrated with using a needless syringe delivering cell suspensions of $\mathrm{M} 11, T$. betulina, or mock treatment with $10 \mathrm{mM} \mathrm{MgCl}_{2}$. Observations were made at $14 \mathrm{dpi}(\mathbf{A})$ Leaf curling was seen in primary infected leaves and in new leaves that developed after infection. Leaves were photographed on the adaxial side (top), abaxial side (middle) and hand sectioned at their mid-point. The ca. $1 \mathrm{~mm}$ hand section was placed on its side and photographed to reveal its curvature (bottom). Scale bars $=0.5 \mathrm{~cm}$. (B) Leaf curing was quantitatively measured from the hand section photographs with ImageJ and the leaf curling index was calculated as the ratio of the leaf with and the total width (Figure S1A; (Booker et al., 2004), which results in lower scores for leaves with greater curvature. Box plots depict pooled results from three independent biological repeats $(n=5$ per biological repeat, total $n=15)$. Letters above the box plots indicate significance groups calculated with ANOVA and Tukey HSD post-hoc test. (C) Leaf bending phenotypes were documented in photographs of primary infected leaves. (D) Leaf bending phenotypes were quantitatively measured from photographs with ImageJ and the leaf curling index was calculated as the angle between a line defined by the petiole and a second line defined by the leaf mid-point and tip, as shown (Figure S1B). Box plots depict pooled results from three independent biological repeats $(n=5$ per biological repeat, total $n=15)$. Letters above the box plots indicate significance groups calculated with ANOVA and Tukey HSD post-hoc test.

\section{Figure 5. Activation of host hormone responses during Taphrina infections.}

Activation of the Arabidopsis auxin and cytokinin transcriptional responses in response to infection with Taphrina strain M11 or $T$. betulina. Infections of four-week-old soil grown Arabidopsis was by hand infiltration of Taphrina cell suspensions using a needless syringe. Left hand leave halves were infiltrated and histologically stained to visualize GUS activity at $48 \mathrm{hpi}$. (A) Activation of the plant auxin response to various treatments, as indicated, using plants transgenically bearing the auxin responsive 
pDR5::GUS promoter-reporter construct. As a positive control, treatments with the auxin, indole acetic acid (IAA), were used at the concentrations, 2, 5, and $10 \mathrm{uM}$ and the negative control was mock infected with $10 \mathrm{mM} \mathrm{MgCl}_{2}$. (B) Activation of the plant cytokinin response to various treatments, as indicated, using accession Col-0 plants transgenically bearing the cytokinin responsive pTCS::GUS promoter-reporter construct. As a positive control, treatments with the cytokinin, benzylaminopurine (BAP), were used at the concentrations, 2, 5, and $10 \mathrm{uM}$ and the negative control was mock infected with $10 \mathrm{mM} \mathrm{MgCl}$.

Figure 6. M11 infection of defence signalling mutants. Seven known plant immune signalling mutants were infected with $\mathrm{M} 11$ and symptoms were evaluated visually and by visualizing cell death with trypan blue staining. Genotypes used were: wild type Col-0 accession; the jasmonate insensitive jar1-1 and coi1-16 mutants; npr1 and sid2, which are deficient in salicylic acid perception and biosynthesis, respectively; cyp 79 b2/b3 double mutant deficient in both indolic glucosinolates and camalexin; the ethylene insensitive ein2 mutant; and pad4, which is deficient in the accumulation of salicylic acid and camalexin. (A) The left hand halves of leaves from four-week-old soil-grown plants were hand infiltrated with suspensions of M11 cells or mock infected with $10 \mathrm{mM} \mathrm{MgCl}_{2}$ and then photographed and trypan blue stained seven days post infection. All scale bars $=1 \mathrm{~cm}$. All leaves were photographed individually against a black background or mounted on microscope slides and the composite figure was assembled in Corel Draw. (B) Infections of sterile immune signalling mutants with Taphrina M11. Taphrina M11 was sprayed onto 24-day-old sterile plants. Yeast growth was quantified through cultivation based technique after nine days. Combined data from three independent experiments is presented; data points from each experiment are represented with a different shape. Pairwise comparison of means ( $\alpha=0.05$, Tukey test, linear mixed model with biological repeat as a random effect) indicated no differences among genotypes. All scale bars $=1 \mathrm{~cm}$. The abbreviation cyp $79^{\star}$ denotes the cyp79 b2/b3 double mutant.

Figure 7. Ortholog distribution in M11 and other Taphrinomycotina yeasts. Ortholog analysis was performed using OrthoVenn2, with $\mathrm{E}<0.01$ cut-off for ortholog calling. Fission yeast (Schizosaccharomyces pombe) was used as an outgroup. 
Figure S1. Leaf curling index and leaf bending index measurement. Leaf curling (A) was measured as in (Booker et al., 2004), briefly this calculates the ratio of the leaf width $\left(\mathrm{W}_{\mathrm{L}}\right)$ to the total width $\left(\mathrm{W}_{\mathrm{T}}\right)$, so that leaves with greater curling will have smaller values for the leaf curling index. Leaf bending (B) was quantified by measuring the angle between a line following the base of the petiole and a second line defined by points at the middle and tip of the leaf, such that leaves with greater bending will have higher values.

Figure S2. Phylogeny of chitin synthase genes. Chitin synthase genes were identified from Taphrina species and fungal model organisms from the phylum Ascomycota and aligned using the Clustal Omega multiple sequence alignment tool. Species abbreviations used: TM11, Taphrina species strain M11; Tdef, Taphrina deformans, Bcin, Botrytis cinerea; Foxy, Fusarium oxysporum; Ncra, Neurospora crassa, Cgra, Colletotrichum graminicola; Afum, Aspegillus fumigatus; Anid, Aspegillus nidulans.

Figure S3. Sequence conservation in class I CHSs from Taphrina species. Multiple sequence alignment was performed with Clusal Omega. Conserved protein domains from the pfam database are higlighted as follows: pink, chitin synthase $1 \mathrm{~N}$ terminal (pfam08407); yellow, chitin synthase1 (pfam01644); blue, partial chitin synthase2 (pfam03142). The start and end point of the domains pfam08407 and pfam01644 are from the NCBI database. The coordinates of chitin synthase 2 are from $\mathrm{Li}$ et al. (2016), as the coordinates from the NCBI database were supported by alignment of only seven sequences. Red boxes indicate conserved functional motifs listed in Li et al. (2016): 1, ligand binding; 2, metal ion binding site; 3, donor saccharide binding; 4, acceptor saccharide binding; 5, product binding. Blue boxes indicate conserved sequence patterns defined by Li et al., 2016. Blue coloured amino acids in CHS sequences from Taphrina spp. do not match the conserved sequence patterns. Species abbreviations used: TM11, Taphrina species strain M11; Tdef, Taphrina deformans, Bcin, Botrytis cinerea; Foxy, Fusarium oxysporum; Ncra, Neurospora crassa, Cgra, Colletotrichum graminicola; Afum, Aspegillus fumigatus; Anid, Aspegillus nidulans, Scer, Saccharomyces cervisiae.

Figure S4. Sequence conservation in class II CHSs from Taphrina deformans. Multiple sequence alignment was performed with Clusal Omega. Conserved protein 
domains from the Pfam database are higlighted as follows: pink, chitin synthase $1 \mathrm{~N}$ terminal (pfam08407); yellow, chitin synthase 1 (pfam01644); blue, partial chitin synthase 2 (pfam03142). The start and end point of the domains pfam08407 and pfam01644 are from the NCBI database. The coordinates of chitin synthase 2 are from $\mathrm{Li}$ et al. (2016), as the coordinates from the NCBI database were supported by alignment of only seven sequences. Red boxes indicate conserved functional motifs listed in Li et al. (2016): 1, ligand binding; 2, metal ion binding site; 3, donor saccharide binding; 4, acceptor saccharide binding; 5, product binding. Blue boxes indicate conserved sequence patterns defined by Li et al. 2016. Blue coloured amino acids in the CHS sequence from Taphrina deformans do not match the conserved sequence patterns. Species abbreviations used: Tdef, Taphrina deformans, Bcin, Botrytis cinerea; Foxy, Fusarium oxysporum; Ncra, Neurospora crassa, Afum, Aspegillus fumigatus; Anid, Aspegillus nidulans, Scer, Saccharomyces cervisiae.

Figure S5. Sequence conservation in class III CHSs from Taphrina species. Multiple sequence alignment was performed with Clusal Omega. Conserved protein domains from the Pfam database are higlighted as follows: pink, chitin synthase $1 \mathrm{~N}$ terminal (pfam08407); yellow, chitin synthase 1 (pfam01644); blue, partial chitin synthase 2 (pfam03142). The start and end point of the domains pfam08407 and pfam01644 are from the NCBI database. The coordinates of chitin synthase 2 are from $\mathrm{Li}$ et al. (2016), as the coordinates from the NCBI database were supported by alignment of only seven sequences. Red boxes indicate conserved functional motifs listed in Li et al. (2016): 1, ligand binding; 2, metal ion binding site; 3, donor saccharide binding; 4, acceptor saccharide binding; 5, product binding. Blue boxes indicate conserved sequence patterns defined by Li et al. 2016. Blue coloured amino acids in the CHS sequence from Taphrina species do not match the conserved sequence patterns. Species abbreviations used: TM11, Taphrina species strain M11; Tdef, Taphrina deformans, Bcin, Botrytis cinerea; Foxy, Fusarium oxysporum; Ncra, Neurospora crassa, Cgra, Colletotrichum graminicola; Afum, Aspegillus fumigatus; Anid, Aspegillus nidulans.

Table S1. Ortholog distribution in selected Taphrinomycotina species. Protein annotations of selected species were analyzed using OrthoVenn2 web platform. Taphrina strain M11 and Protomyces arabidopsidicola were isolated from wild Arabidopsis thaliana plants. Other included Protomyces species are known to infect 
Compositae and Umbelliferae plants. T. deformans, T. wiesneri, and T. flavorubra are pathogenic to Prunus species. Host of $T$. populina is Populus nigra. Schizosaccharomyces pombe is phylogenetically most distant to other species and has a non-pathogenic lifestyle.

Table S2. Conserved domains in Taphrina strain M11 annotated proteins. Data was generated using HMMER v3.3 (E value 1e-30) through homology searches against the Pfam database. For the full explanation of HMMER output see the HMMER User's Guide at www.hmmer.org

Table S3. Comparison of genome statistics and candidate effector proteins. Analysis was performed with Taphrina strain M11 and other fungi from subphyla Taphrinomycotina and Saccharomycotina. Used strains and genome assemblies: Taphrina deformans PYCC 5710, CAHR02; T. deformans JCM 22205, BAVV01; T. flavorubra JCM 22207, BAVW01; T. populina JCM 22190, BAVX01; T. wiesneri JCM 22204, BAVU01; Neolecta irregularis DAH-3, LXFE01; Pneumocystis murina B123, AFWA02; Schizosaccharomyces pombe 972h-, ASM294v2; S. cryophilus OY26, ACQJ02; S. japonicus yFS275, AATM02; S. octosporus yFS286, ABHY03; Saitoella complicata NRRL Y-17804; Saccharomyces cerevisiae S288c, R64; Yarrowia lipolytica CLIB122, ASM252v1; Candida albicans SC5314, ASM18296v3. Secretion signal was identified using SignalP 4.1 tool.

Table S4. Conserved domains in short secreted proteins (SSPs). Table depicts the full data from the searches for the conserved protein domain hits found in SSPS from Taphrina strain M11 and reported in Table 2b. Data was generated using HMMER v3.2.1 (E value 1e-30) through homology searches against the Pfam database. For the full explanation of HMMER output see The HMMER User's Guide at www.hmmer.org

Table S5. Conserved plant-associated domains in the annotated proteins of Taphrina species strain M11. Plant associated domains were previously defined from plant associated prokaryotes (Levy et al., 2017).

Table S6. Indole-3-acetic acid (IAA) biosynthesis pathways in two Taphrina species. Analysis compares IAA biosynthesis genes of Taphrina species strain M11 and T. deformans. Genes were first identified in strain M11 (Table 4) using potential IAA biosynthesis genes from other fungal species as BLAST search terms, as in 
(Wang et al., 2019). The genes of IAA biosynthesis enzymes found in M11 genome were then used as search terms with the BLAST tool against the T. deformans genome. Pathway name abbreviations are the indole-3-acetamide (IAM), indole-3pyruvate (IPyA), indole-3-acetonitrile (IAN), and tryptamine (TAM) pathways.

Table S7. Putative cell wall biosynthesis genes from Taphrina M11. Blast protein search was performed with default search parameters against the Taphrina M11 genome using the well characterized cell wall biosynthesis genes from model fungal species as queries. Known conserved protein domains found in such genes were also used as queries. Query genes and conserved domains used are listed in Table S8.

Table S8: Cell wall biosynthesis query sequences and conserved domains used. Queries used to identify putative proteins involved in M11 cell wall polysaccharide biosynthesis. Conserved domains (Pfam database) are indicated in blue. Gene accession numbers are from UniProt database. NA - not applicable 


\section{Tables}

Table 1. Taphrina strain M11 genome assembly statistics. Genome assembly quality was analyzed using QUAST tool, version 5.0. For additional explanation of QUAST output see (http://quast.sourceforge.net/).

\begin{tabular}{lr} 
BioProject $^{\mathrm{a}}$ & PRJNA487587 \\
\hline BioSample $^{\mathrm{a}}$ & SAMN09906266 \\
\hline SRA $^{\mathrm{a}}$ & SRX4936057 \\
\hline Total length (bp) & 13601285 \\
\hline Number of contigs ( $\geq 0 \mathrm{bp})$ & 382 \\
\hline Total lenght of contigs ( $\geq 0 \mathrm{bp})$ & 13654843 \\
\hline Number of contigs $(\geq 1000 \mathrm{bp})$ & 147 \\
\hline Total length of contigs $(\geq 1000 \mathrm{bp})$ & 13544983 \\
\hline Total number of contigs & 234 \\
\hline Largest contig (bp) & 514056 \\
\hline Average GC $(\%)$ & 48.83 \\
\hline N50 & 277880 \\
\hline N75 & 157923 \\
\hline L50 & 19 \\
\hline L75 & 34 \\
\hline \# N's per $100 \mathrm{kbp}$ & 0.02 \\
\hline Annotated genes/orfs & 6496 \\
\hline Number of orfs $>100$ aa & 14561 \\
\hline Density (no. of orfs $>100$ aa/kbp) & 1.07
\end{tabular}

aSequencing data is available at the NCBI under the given accession numbers. 
Table 2. Candidate effector proteins. (A) Comparison of identified candidate effector proteins in Taphrina strain M11 and other fungi from subphyla Taphrinomycotina and Saccharomycotina ${ }^{a}$. Number of open reading frames (ORFs), short secreted proteins (SSPs) and cysteine rich SSPs (CSSPs) is shown. (B)The conserved protein domains were identified from Taphrina strain M11 SSPs using HMMER v3.2.1 (E value 1e-30) homology searches against the Pfam database. The presented E-values and scores are for full sequences.

A

\begin{tabular}{lcccc}
\multicolumn{1}{c}{ Species/Strains } & $\begin{array}{c}\text { Small } \\
\text { ORFs }\end{array}$ & SSPs & $\begin{array}{c}\text { CSSPs } \\
(\mathbf{C} \geq \mathbf{4})\end{array}$ & Lifestyle $^{\text {b }}$ \\
Taphrina strain M11 & 18660 & 767 & 337 & $\mathrm{PP}$ \\
T. deformans PYCC 5710 & 18081 & 881 & 421 & $\mathrm{PP}$ \\
T. deformans JCM 22205 & 18421 & 909 & 431 & $\mathrm{PP}$ \\
T. flavorubra & 21829 & 1097 & 513 & $\mathrm{PP}$ \\
T. populina & 14424 & 799 & 378 & $\mathrm{PP}$ \\
T. wiesneri & 15314 & 756 & 334 & $\mathrm{PP}$ \\
Neolecta irregularis & 17954 & 892 & 354 & $\mathrm{~S} / \mathrm{RA}$ \\
Pneumocystis murina & 5154 & 136 & 26 & $\mathrm{MP}$ \\
Schizosaccharomyces pombe & 6077 & 248 & 65 & $\mathrm{~S}$ \\
S. cryophilus & 6543 & 271 & 68 & $\mathrm{~S}$ \\
S. japonicus & 10507 & 511 & 195 & $\mathrm{~S}$ \\
S. octosporus & 6465 & 255 & 60 & $\mathrm{~S}$ \\
Saitoella complicata & 24552 & 1018 & 322 & IA \\
Saccharomyces cerevisiae & 6367 & 440 & 100 & $\mathrm{~S}$ \\
Yarrowia lipolytica & 26526 & 1499 & 541 & $\mathrm{~S}$ \\
Candida albicans & 5756 & 392 & 126 & $\mathrm{MP}$
\end{tabular}

B

$\begin{array}{llll}\text { Pfam ID } & \text { Pfam description } & \text { Score } & \text { E-value } \\ \text { PF09362.10 } & \text { Domain of unknown function (DUF1996) } & 214.6 & 1.90 \mathrm{E}-63 \\ \text { PF04063.14 } & \text { Domain of unknown function (DUF383) } & 192.2 & 7.00 \mathrm{E}-57 \\ \text { PF06682.12 } & \text { SOCE-associated regulatory factor of calcium } & 101.5 & 7.20 \mathrm{E}-29 \\ & \text { homoeostasis } & 172.8 & 1.20 \mathrm{E}-50 \\ \text { PF01204.18 } & \text { Trehalase } & 117.9 & 4.30 \mathrm{E}-34 \\ \text { PF09792.9 } & \text { Ubiquitin 3 binding protein But2 C-terminal } & & \\ & \text { domain } & 122.5 & 6.10 \mathrm{E}-36 \\ \text { PF01247.18 } & \text { Ribosomal protein L35Ae } & 110 & 1.80 \mathrm{E}-31 \\ \text { PF00128.24 } & \text { Alpha amylase, catalytic domain } & 217.3 & 3.20 \mathrm{E}-64 \\ \text { PF02127.15 } & \text { Aminopeptidase I zinc metalloprotease (M18) } & 148.5 & 1.30 \mathrm{E}-43 \\ \text { PF00025.21 } & \text { ADP-ribosylation factor family } & 147.8 & 3.10 \mathrm{E}-43 \\ \text { PF01105.24 } & \text { emp24/gp25L/p24 family/GOLD } & 226.6 & 3.30 \mathrm{E}-67 \\ \text { PF11790.8 } & \text { Glycosyl hydrolase catalytic core } & 207.3 & 3.10 \mathrm{E}-61 \\ \text { PF02089.15 } & \text { Palmitoyl protein thioesterase } & 140.4 & 8.00 \mathrm{E}-41 \\ \text { PF09531.10 } & \text { Nucleoporin protein Ndc1-Nup } & 145 & 2.30 \mathrm{E}-42 \\ \text { PF01105.24 } & \text { emp24/gp25L/p24 family/GOLD } & & \end{array}$




$\begin{array}{llrr}\text { PF04756.13 } & \text { OST3 / OST6 family, transporter family } & 234.5 & 1.60 \mathrm{E}-69 \\ \text { PF01735.18 } & \text { Lysophospholipase catalytic domain } & 122.7 & 1.40 \mathrm{E}-35 \\ \text { PF11790.8 } & \text { Glycosyl hydrolase catalytic core } & 232.9 & 3.70 \mathrm{E}-69 \\ \text { PF10681.9 } & \begin{array}{l}\text { Chaperone for protein-folding within the ER, } \\ \text { fungal }\end{array} & 256.7 & 1.40 \mathrm{E}-76 \\ \text { PF13668.6 } & \text { Ferritin-like domain } & 147.3 & 2.90 \mathrm{E}-43 \\ \text { PF13883.6 } & \text { Pyridoxamine 5'-phosphate oxidase } & 109.1 & 2.20 \mathrm{E}-31 \\ \text { PF13668.6 } & \text { Ferritin-like domain } & 106.4 & 1.30 \mathrm{E}-30 \\ \text { PF01328.17 } & \text { Peroxidase, family 2 } & 128.8 & 3.40 \mathrm{E}-37 \\ \text { PF16655.5 } & \text { PhoD-like phosphatase, N-terminal domain } & 110.4 & 4.80 \mathrm{E}-32 \\ \text { PF04622.12 } & \text { ERG2 and Sigma1 receptor like protein } & 280.4 & 6.60 \mathrm{E}-84 \\ \text { PF01735.18 } & \text { Lysophospholipase catalytic domain } & 136.3 & 1.00 \mathrm{E}-39\end{array}$

a Strains and genome assemblies used: Taphrina deformans PYCC 5710, CAHR02; T. deformans JCM 22205, BAVV01; T. flavorubra JCM 22207, BAVW01; T. populina JCM 22190, BAVX01; T. wiesneri JCM 22204, BAVU01; Neolecta irregularis DAH-3, LXFE01; Pneumocystis murina B123, AFWA02; Schizosaccharomyces pombe 972h, ASM294v2; S. cryophilus OY26, ACQJ02; S. japonicus yFS275, AATM02; S. octosporus yFS286, ABHY03; Saitoella complicata NRRL Y-17804, GCA_001661265.1; Saccharomyces cerevisiae S288c, R64; Yarrowia lipolytica CLIB122, ASM252v1; Candida albicans SC5314, ASM18296v3. aLifestyle abbreviations used: PP, plant pathogen; RA, rhizosphere associated; S, saprotroph; MP, mammalian pathogen; IA, insect associated, 
Table 3. Putative cell wall biosynthesis genes in Taphrina strain M11. Potential cell wall components were predicted based on the putative cell wall biosynthesis genes and biochemical evidence presented in Petit and Schneider, 1983. Sequences of well-described homologs from $S$. cerevisiae, $S$. pombe, and $A$. nidulans were used as protein blast queries. Additionally, all predicted genes containing conserved protein domains specific for the cell wall biosynthesis genes were analyzed to confirm their identity. For additional information on query sequences, putative homolog sequences, and protein blast results see Tables S6 and S7.

\begin{tabular}{ccrl}
$\begin{array}{c}\text { Wall } \\
\text { component }\end{array}$ & Gene & Gene accession & $\begin{array}{c}\text { Function (inferred from } \\
\text { homology) }\end{array}$ \\
\hline ChS1 & TM11_g683.t1 & $\begin{array}{l}\text { Chitin synthase, class I. } \\
\text { Polymerizes UDP-N- } \\
\text { acetylglucosamine into } \\
\text { chitin. }\end{array}$ \\
& & & $\begin{array}{l}\text { Chitin synthase, class III. } \\
\text { Polymerizes UDP-N- } \\
\text { acetylglucosamine into } \\
\text { chitin. }\end{array}$
\end{tabular}

Biochemical evidence $^{1}$

\begin{tabular}{|c|c|c|c|c|}
\hline Chitosan & CDA1 & TM11_g2542.t1 & Chitin deacetylase. & not tested \\
\hline \multirow{2}{*}{ a-glucan } & AGS1 & TM11_g3195.t1 & $\begin{array}{l}\alpha-1,3 \text {-glucan/a-1,4-glucan } \\
\text { synthase. }\end{array}$ & \multirow{2}{*}{$\begin{array}{c}\text { yes } \\
\text { (a-1,3-glucan) }\end{array}$} \\
\hline & AGS2 & TM11_g396.t1 & $\begin{array}{l}\alpha-1,3-\text { glucan/ } \alpha-1,4-\text { glucan } \\
\text { synthase. }\end{array}$ & \\
\hline \multirow{6}{*}{$\begin{array}{l}\beta-1,3 \text {-linked } \\
\text { glucan }\end{array}$} & GAS1 & TM11_g1673.t1 & \multirow{4}{*}{$\begin{array}{l}\beta-1,3- \\
\text { glucanosyltransferase. } \\
\text { Elongation of } \beta-1,3 \text {-glucan } \\
\text { chains. }\end{array}$} & \multirow{6}{*}{ yes } \\
\hline & GAS2 & TM11_g762.t1 & & \\
\hline & GAS3 & TM11_g2885.t1 & & \\
\hline & GAS4 & TM11_g1143.t1 & & \\
\hline & FKS1 & TM11_g3331 & $\begin{array}{l}\text { Catalytic subunit of } \beta-1,3- \\
\text { glucan synthase complex }\end{array}$ & \\
\hline & $\mathrm{RHO} 1$ & TM11_g2469.t1 & $\begin{array}{l}\text { Regulatory subunit of } \beta-1,3- \\
\text { glucan synthase complex }\end{array}$ & \\
\hline \multirow{3}{*}{$\begin{array}{l}\beta-1,6 \text {-linked } \\
\text { glucan }\end{array}$} & $\begin{array}{l}\text { SKN1/ } \\
\text { KRE6 }\end{array}$ & TM11_g4026.t1 & $\begin{array}{l}\text { Required for } \beta-1,6 \text {-glucan } \\
\text { biosynthesis, } \\
\text { glucolsyltransferase }\end{array}$ & \multirow{3}{*}{ yes } \\
\hline & $\begin{array}{l}\text { BIG1- } \\
\text { like }\end{array}$ & TM11_g912.t1 & $\begin{array}{l}\text { Required for } \beta-1,6 \text {-glucan } \\
\text { biosynthesis }\end{array}$ & \\
\hline & $\begin{array}{l}\text { KRE9- } \\
\text { like }\end{array}$ & TM11_g138.t1 & $\begin{array}{l}\text { Involved in } \beta-1,6 \text {-glucan } \\
\text { assembly }\end{array}$ & \\
\hline
\end{tabular}

${ }^{1}$ Biochemical evidence on presence of poly- and mono- saccharides constituting cell walls is from study by Petit and Schneider, 1983. *Very small amount of glucosamine was detected, but it constituted less than $0.2 \%$ of wall monosaccharides and thus could have originated from cell wall glycoproteins. 
Table 4. Auxin and cytokinin biosynthesis pathways in Taphrina strain M11.

\begin{tabular}{|c|c|c|c|}
\hline Hormone & Pathway $^{a}$ & Enzymes & $M 11^{b}$ \\
\hline \multirow{6}{*}{ IAA } & IAM pathway & $\begin{array}{l}\text { Trp2-monooxygenase (TMO/laaM) } \\
\text { IAM hydrolase (laaH) }\end{array}$ & $\begin{array}{l}1 \\
2\end{array}$ \\
\hline & IAN pathway & $\begin{array}{l}\text { Unknown enzymes } \\
\text { Nitrilase (NIT) }\end{array}$ & $\begin{array}{c}\text { NA } \\
3\end{array}$ \\
\hline & IPyA pathway & $\begin{array}{l}\text { Trp aminotransferase (TAM) } \\
\text { IPyA decarboxylase (IPDC) } \\
\text { IAAld dehydrogenase (IAD) }\end{array}$ & $\begin{array}{l}1 \\
1 \\
2 \\
\end{array}$ \\
\hline & TSO pathway & $\begin{array}{l}\text { Tryptophan side-chain oxidase (TSO) } \\
\text { IAAld dehydrogenase (IAD) }\end{array}$ & $\begin{array}{c}\text { NA } \\
2 \\
\end{array}$ \\
\hline & TAM pathway & $\begin{array}{l}\text { Tryptophan decarboxylases (TDC) } \\
\text { Amine oxidase (AOX) } \\
\text { IAAld dehydrogenase (IAD) } \\
\text { Flavin monooxygenase (YUC) } \\
\end{array}$ & $\begin{array}{l}2 \\
3 \\
2 \\
1\end{array}$ \\
\hline & other proteins & $\begin{array}{l}\text { Auxin efflux carrier (1) } \\
\text { Auxin efflux carrier (2) }\end{array}$ & $\begin{array}{l}1 \\
1\end{array}$ \\
\hline Cytokinin & $\begin{array}{l}\text { Isopentenyladenine } \\
\text { dependent }\end{array}$ & $\begin{array}{l}\text { tRNA- isopentenyltransferase } \\
\text { Cytokinin phosphoribohydrolase }\end{array}$ & $\begin{array}{l}1 \\
1\end{array}$ \\
\hline
\end{tabular}

a. Pathway name abbreviations are the indole-3-acetamide (IAM), Tryptophan side chain oxidase (TSO), indole-3-pyruvate (IPyA), indole-3-acetonitrile (IAN), and

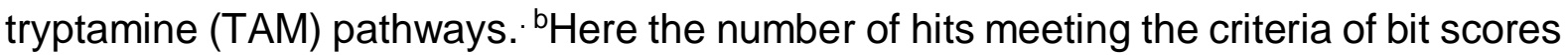
$>120$, E-values $>0.05$, and identities $>50 \%$ are presented. 


\section{References}

AHMAD, F., AHMAD, I. \& KHAN, M. S. 2008. Screening of free-living rhizospheric bacteria for their multiple plant growth promoting activities. Microbiological Research, 163, 173-181.

AHMED, L. \& KULKARNI, N. B. 1968. Studies on Taphrina maculans Butler, inciting leaf spot of turmeric (Curcuma longa L.). I. Isolation of the pathogen. Mycopathologia et mycologia applicata, 34, 40-46.

ARELLANO, M., CARTAGENA-LIROLA, H., HAJIBAGHERI, M. A. N., DURÁN, A. \& VALDIVIESO, M. H. 2000. Proper ascospore maturation requires the chs1+ chitin synthase gene in Schizosaccharomyces pombe. Molecular microbiology, 3, 79-89.

ARGUESO, C. T., FERREIRA, F. J. \& KIEBER, J. J. 2009. Environmental perception avenues: the interaction of cytokinin and environmental response pathways. Plant Cell Environ, 32, 114760.

BACIGÁLOVÁ, K., MUŁENKO, W. \& WOŁCZAŃSKA, A. 2005. Parasitic microfungi of the Tatra Mountains. 1. Taphrinales. Polish Botanical Studies, 50, 185-207.

BANKEVICH, A., NURK, S., ANTIPOV, D., GUREVICH, A. A., DVORKIN, M., KULIKOV, A. S., LESIN, V. M., NIKOLENKO, S. I., PHAM, S., PRJIBELSKI, A. D., PYSHKIN, A. V., SIROTKIN, A. V., VYAHHI, N., TESLER, G., ALEKSEYEV, M. A. \& PEVZNER, P. A. 2012. SPAdes: a new genome assembly algorithm and its applications to single-cell sequencing. J Comput Biol, 19, 455-477.

BARRETO-BERGTER, E. \& FIGUEIREDO, R. T. 2014. Fungal glycans and the innate immune recognition. Frontiers in cellular and infection microbiology, 4, 1-17.

BARTHE, P. \& BULARD, C. 1974. Identification d'une cytokinine par chromatographic en phase gazeuse à partir de cultures pures de Taphrina cerasi. Canadian Journal of Botany, 52, 15151518.

BEGEROW, D., KEMLER, M., FEIGE, A. \& YURKOV, A. 2017. Parasitism in Yeasts. In: BUZZINI, P., LACHANCE, M.-A. \& YURKOV, A. (eds.) Yeasts in Natural Ecosystems: Ecology. Cham: Springer International Publishing.

BOOKER, F. L., BURKEY, K. O., OVERMYER, K. \& JONES, A. M. 2004. Differential responses of G-protein Arabidopsis thaliana mutants to ozone. New Phytologist, 162, 633-641.

CHALUPOWICZ, L., BARASH, I., PANIJEL, M., SESSA, G. \& MANULIS-SASSON, S. 2009. Regulatory interactions between quorum-sensing, auxin, cytokinin, and the Hrp regulon in relation to gall formation and epiphytic fitness of Pantoea agglomerans pv. gypsophilae. Mol Plant Microbe Interact, 22, 849-56.

CHANCLUD, E. \& MOREL, J. B. 2016. Plant hormones: a fungal point of view. Mol Plant Pathol, 17, 1289-97.

CISSÉ, O. H., ALMEIDA, J. G. C. F., FONSECA, Á., KUMAR, A. A., ALOJÄRVI J, OVERMYER, K., HAUSER, P. M. \& PAGNI, M. 2013. Genome sequencing of the plant pathogen Taphrina deformans, the causal agent of peach leaf curl. mBio, 4, e00055-13.

CONTRERAS-CORNEJO, H. A., MACIAS-RODRIGUEZ, L., CORTES-PENAGOS, C. \& LOPEZBUCIO, J. 2009. Trichoderma virens, a plant beneficial fungus, enhances biomass production and promotes lateral root growth through an auxin-dependent mechanism in Arabidopsis. Plant Physiol, 149, 1579-92.

CUI, H., TSUDA, K. \& PARKER, J. E. 2015. Effector-triggered immunity: from pathogen perception to robust defense. Annu Rev Plant Biol, 66, 487-511.

DÍAZ-JIMÉNEZ, D. F., PÉREZ-GARCÍA, L. A., MARTÍNEZ-ÁLVAREZ, J. A. \& MORAMONTES, H. M. 2012. Role of the Fungal Cell Wall in Pathogenesis and Antifungal Resistance. Current Fungal Infection Reports, 6, 275-282.

DINGLEY, J. M. 2012. Records of fungi parasitic on plants in New Zealand 1966-68. New Zealand Journal of Agricultural Research, 13, 325/337.

DODDS, P. N. \& RATHJEN, J. P. 2010. Plant immunity: towards an integrated view of plantpathogen interactions. Nat Rev Genet, 11, 539-48.

FESEL, P. H. \& ZUCCARO, A. 2016. beta-glucan: Crucial component of the fungal cell wall and elusive MAMP in plants. Fungal Genet Biol, 90, 53-60. 
bioRxiv preprint doi: https://doi.org/10.1101/2021.09.16.460675; this version posted September 19, 2021. The copyright holder for this preprint (which was not certified by peer review) is the author/funder, who has granted bioRxiv a license to display the preprint in perpetuity. It is made available under aCC-BY-NC-ND 4.0 International license.

FINN, R. D., COGGILL, P., EBERHARDT, R. Y., EDDY, S. R., MISTRY, J., MITCHELL, A. L., POTTER, S. C., PUNTA, M., QURESHI, M., SANGRADOR-VEGAS, A., SALAZAR, G. A., TATE, J. \& BATEMAN, A. 2016. The Pfam protein families database: towards a more sustainable future. Nucleic Acids Res, 44, D279-85.

FONSECA, Á. \& RODRIGUES, M. G. 2011. Taphrina fries (1832). In: KURTZMAN, C. P., FELL, J. W. \& BOEKHOUT, T. (eds.) The Yeasts Elsevier.

FU, J. \& WANG, S. 2011. Insights into auxin signaling in plant-pathogen interactions. Front Plant Sci, $2,74$.

GEHRMANN, F. 2013. Non-host and induced resistance in the Taphrina-Arabidopsis model system. Master's Thesis, University of Helsinki.

GIOSUÈ, S., SPADA, G., ROSSI, V., CARLI, G. \& PONTI, I. 2000. Forecasting infections of the leaf curl disease on peaches caused by Taphrina deformans. European Journal of Plant Pathology, 106, 563-571.

GOLDY, C., SVETAZ, L. A., BUSTAMANTE, C. A., ALLEGRINI, M., VALENTINI, G. H., DRINCOVICH, M. F., FERNIE, A. R. \& LARA, M. V. 2017. Comparative proteomic and metabolomic studies between Prunus persica genotypes resistant and susceptible to Taphrina deformans suggest a molecular basis of resistance. Plant Physiol Biochem, 118, 245-255.

GONG, B. Q., WANG, F. Z. \& LI, J. F. 2020. Hide-and-Seek: Chitin-Triggered Plant Immunity and Fungal Counterstrategies. Trends Plant Sci, 25, 805-816.

GROSSKOPF, D. G., FELIX, G. \& BOLLER, T. 1991. A Yeast-Derived Glycopeptide Elicitor and Chitosan or Digitonin Differentially Induce Ethylene Biosynthesis, Phenylalanine AmmoniaLyase and Callose Formation in Suspension-Cultured Tomato Cells. Journal of Plant Physiology, 138, 741-746.

HOFFMAN, C. S. 1997. Preparation of yeast DNA. Current protocols in molecular biology, 39, 1311.

INACIO, J., RODRIGUES, M., SOBRAL, P. \& FONSECA, L. 2004. Characterisation and classification of phylloplane yeasts from Portugal related to the genus and description of five novel species. FEMS Yeast Research, 4, 541-555.

JAMBUNATHAN, N. 2010. Determination and detection of reactive oxygen species (ROS), lipid peroxidation, and electrolyte leakage in plants. Methods Mol Biol, 639, 292-8.

JONES, J. D. \& DANGL, J. L. 2006. The plant immune system. Nature, 444, 323-9.

KEMLER M., W. F., BEGEROW D., YURKOV A. 2017. Phylloplane Yeasts in Temperate Climates. In: BUZZINI P., L. M., YURKOV A. (ed.) Yeasts in Natural Ecosystems: Diversity. Cham.: Springer International Publishing

KERN, H. \& NAEF-ROTH, S. 1975. Zur Bildung von Auxinen und Cytokininen durdh TaphrinaArten. Phytopath, 1, 193-222.

KHOKON, M. A., HOSSAIN, M. A., MUNEMASA, S., URAJI, M., NAKAMURA, Y., MORI, I. C. \& MURATA, Y. 2010. Yeast elicitor-induced stomatal closure and peroxidase-mediated ROS production in Arabidopsis. Plant Cell Physiol, 51, 1915-21.

LACHANCE, M. \& WALKER, G. M. 2018. Yeasts. In eLS.

LEE, H. A., LEE, H. Y., SEO, E., LEE, J., KIM, S. B., OH, S., CHOI, E., CHOI, E., LEE, S. E. \& CHOI, D. 2017. Current Understandings of Plant Nonhost Resistance. Mol Plant Microbe Interact, 30, 5-15.

LEVY, A., SALAS GONZALEZ, I., MITTELVIEFHAUS, M., CLINGENPEEL, S., HERRERA PAREDES, S., MIAO, J., WANG, K., DEVESCOVI, G., STILLMAN, K., MONTEIRO, F., RANGEL ALVAREZ, B., LUNDBERG, D. S., LU, T. Y., LEBEIS, S., JIN, Z., MCDONALD, M., KLEIN, A. P., FELTCHER, M. E., RIO, T. G., GRANT, S. R., DOTY, S. L., LEY, R. E., ZHAO, B., VENTURI, V., PELLETIER, D. A., VORHOLT, J. A., TRINGE, S. G., WOYKE, T. \& DANGL, J. L. 2017. Genomic features of bacterial adaptation to plants. Nat Genet, 50, 138-150.

MA, K. W. \& MA, W. 2016. Phytohormone pathways as targets of pathogens to facilitate infection. Plant Mol Biol, 91, 713-25.

MADEIRA, F., PARK, Y. M., LEE, J., BUSO, N., GUR, T., MADHUSOODANAN, N., BASUTKAR, P., TIVEY, A. R. N., POTTER, S. C., FINN, R. D. \& LOPEZ, R. 2019. The 
EMBL-EBI search and sequence analysis tools APIs in 2019. Nucleic Acids Res, 47, W636W641.

MANULIS, S., HAVIV-CHESNER, A., BRANDL, M. T., LINDOW, S. E. \& BARASH, I. 1998. Differential involvement of indole-3-acetic acid biosynthetic pathways in pathogenicity and epiphytic fitness of Erwinia herbicola pv. gypsophilae. Mol Plant Microbe Interact, 11, 63442.

MATUYAMA, N. \& MISAWA, T. 1961. Anatomical studies on the leaf curl of peach caused by Taphrina deformans Tul. . Tohoku Journal of Agricultural Research, 12.

MELIDA, H., SOPENA-TORRES, S., BACETE, L., GARRIDO-ARANDIA, M., JORDA, L., LOPEZ, G., MUNOZ-BARRIOS, A., PACIOS, L. F. \& MOLINA, A. 2018. Non-branched beta-1,3-glucan oligosaccharides trigger immune responses in Arabidopsis. Plant J, 93, 3449.

MIX, A. J. 1949. A monograph of the genus Taphrina. University of Kansas Science Bulletin, 33.

MOORE, R. 1998. Lalaria RT Moore. The Yeasts. Elsevier.

MORRISON, E. N., EMERY, R. J. \& SAVILLE, B. J. 2015. Phytohormone Involvement in the Ustilago maydis- Zea mays Pathosystem: Relationships between Abscisic Acid and Cytokinin Levels and Strain Virulence in Infected Cob Tissue. PLoS One, 10, e0130945.

NASEEM, M. \& DANDEKAR, T. 2012. The role of auxin-cytokinin antagonism in plant-pathogen interactions. PLoS Pathog, 8, e1003026.

PANDARANAYAKA, E. P., FRENKEL, O., ELAD, Y., PRUSKY, D. \& HAREL, A. 2019. Network analysis exposes core functions in major lifestyles of fungal and oomycete plant pathogens. BMC Genomics, 20, 1020.

PEREZ, P., CORTES, J. C. G., CANSADO, J. \& RIBAS, J. C. 2018. Fission yeast cell wall biosynthesis and cell integrity signalling. Cell Surf, 4, 1-9.

PERTRY, I., VÁCLAVÍKOVÁ, K., GEMROTOVÁ, M., SPÍCHAL, L., GALUSZKA, P., DEPUYDT, S., TEMMERMAN, W., STES, E., DE KEYSER, A., RIEFLER, M., BIONDI, S., NOVÁK, O., SCHMÜLLING, T., STRNAD, M., TARKOWSKI, P., HOLSTERS, M. \& VEREECKE, D. 2010. Rhodococcus fascians impacts plant development through the dynamic fas-mediated production of a cytokinin mix. Molecular Plant-Microbe Interactions, 23, 1164-1174.

PETERSEN, T. N., BRUNAK, S., VON HEIJNE, G. \& NIELSEN, H. 2011. SignalP 4.0: discriminating signal peptides from transmembrane regions. Nat Methods, 8, 785-6.

PETIT, M. \& SCHNEIDER, A. 1983. Chemical analysis of the wall of the yeast form of Taphrina deformans. Archives of microbiology, 135, 141-146

PETTOLINO, F., SASAKI, I., TURBIC, A., WILSON, S. M., BACIC, A., HRMOVA, M. \& FINCHER, G. B. 2009. Hyphal cell walls from the plant pathogen Rhynchosporium secalis contain $(1,3 / 1,6)$-beta-D-glucans, galacto- and rhamnomannans, $(1,3 ; 1,4)$-beta-D-glucans and chitin. FEBS J, 276, 3698-709.

PIETERSE, C. M., VAN DER DOES, D., ZAMIOUDIS, C., LEON-REYES, A. \& VAN WEES, S. C. 2012. Hormonal modulation of plant immunity. Annu Rev Cell Dev Biol, 28, 489-521.

REBAQUE, D., DEL HIERRO, I., LOPEZ, G., BACETE, L., VILAPLANA, F., DALLABERNARDINA, P., PFRENGLE, F., JORDA, L., SANCHEZ-VALLET, A., PEREZ, R., BRUNNER, F., MOLINA, A. \& MELIDA, H. 2021. Cell wall-derived mixedlinked beta-1,3/1,4-glucans trigger immune responses and disease resistance in plants. Plant $J$.

RODRIGUES, M. G. \& FONSECA, Á. 2003. Molecular systematics of the dimorphic ascomycete genus Taphrina. Int J Syst Evol Microbiol, 53, 607-616.

ROSSI, V., BOLOGNESI, M., LANGUASCO, L. \& GIOSUĖ, S. 2006. Influence of environmental conditions on infection of peach shoots by Taphrina deformans. Phytopathology,, 9, 155-163.

RUIZ-HERRERA, J. \& ORTIZ-CASTELLANOS, L. 2019. Cell wall glucans of fungi. A review. Cell Surf, 5, 100022.

SELBMANN, L., TURCHETTI, B., YURKOV, A., CECCHINI, C., ZUCCONI, L., ISOLA, D., BUZZINI, P. \& ONOFRI, S. 2014. Description of Taphrina antarcticaf. a. sp. nov., a new anamorphic ascomycetous yeast species associated with Antarctic endolithic microbial 
communities and transfer of four Lalaria species in the genus Taphrina. Extremophiles, 18, 707-721.

SJAMSURIDZAL, W., TAJIRI, Y., NISHIDA, H., THUAN, T. B., KAWASAKI, H., HIRATA, A., YOKOTA, A. \& SUGIYAMA, J. 1997. Evolutionary relationships of membrers of the genera Taphrina, Protomyces, Schizosaccharomyces, and related taxa within the archiascomycetes: Integrated analysis of genotypic and phenotypic characters. Mycoscience, 38, 267-280.

SOMMER, N. F. 1961. Production by Taphrhia deformans of Substances Stimulating Cell Elongation and Division. Physiologia Plantarum, 14, 460-469.

SPAEPEN, S. \& VANDERLEYDEN, J. 2011. Auxin and plant-microbe interactions. Cold Spring Harb Perspect Biol, 3.

STAM, R., MANTELIN, S., MCLELLAN, H. \& THILLIEZ, G. 2014. The role of effectors in nonhost resistance to filamentous plant pathogens. Front Plant Sci, 5, 582.

STANKE, M., DIEKHANS, M., BAERTSCH, R. \& HAUSSLER, D. 2008. Using native and syntenically mapped cDNA alignments to improve de novo gene finding. Bioinformatics, 24, 637-44.

STRELETSKII, R. A., KACHALKIN, A. V., GLUSHAKOVA, A. M., DEMIN, V. V. \& CHERNOV, I. Y. 2016. Quantitative determination of indole-3-acetic acid in yeasts using high performance liquid chromatography—tandem mass spectrometry. Microbiology, 85, 727-736.

STRELETSKII, R. A., KACHALKIN, A. V., GLUSHAKOVA, A. M., YURKOV, A. M. \& DEMIN, V. V. 2019. Yeasts producing zeatin. PeerJ, 7, e6474.

TSAI, I. J., TANAKA, E., MASUYA, H., TANAKA, R., HIROOKA, Y., ENDOH, R., SAHASHI, N. \& KIKUCHI, T. 2014. Comparative genomics of Taphrina fungi causing varying degrees of tumorous deformity in plants. Genome Biol Evol, 6, 861-72.

VALADON, L. R. G., MANNERS, J. G. \& MYERS, A. 1962. Studies on the life-history and taxonomic position of Protomyces inundatus Dangeard. Transactions of the British Mycological Society, 45, 573-IN5.

WANG, K., SIPILA, T. \& OVERMYER, K. 2021. A novel Arabidopsis phyllosphere resident Protomyces species and a re-examination of genus Protomyces based on genome sequence data. IMA Fungus, 12, 8.

WANG, K., SIPILÄ, T., RAJARAMAN, S., SAFRONOV, O., LAINE, P., AUZANE, A., MARI, A., AUVINEN, P., PAULIN, L., KEMEN, E., SALOJÄRVI, J. \& OVERMYER, K. 2019. A novel phyllosphere resident Protomyces species that interacts with the Arabidopsis immune system. bioRxiv, 594028.

WANG, K., SIPILÄ, T. P. \& OVERMYER, K. 2016. The isolation and characterization of resident yeasts from the phylloplane of Arabidopsis thaliana. Scientific reports, 6, 1-13.

WANG, Q., SUN, M., ZHANG, Y., SONG, Z., ZHANG, S., ZHANG, Q., XU, J. R. \& LIU, H. 2020. Extensive chromosomal rearrangements and rapid evolution of novel effector superfamilies contribute to host adaptation and speciation in the basal ascomycetous fungi. Mol Plant Pathol, 21, 330-348.

WENDLAND, J. \& WALTHER, A. 2011. Genome evolution in the eremothecium clade of the Saccharomyces complex revealed by comparative genomics. G3 (Bethesda), 1, 539-48.

WILSON, C., LUKOWICZ, R., MERCHANT, S., VALQUIER-FLYNN, H., CABALLERO, J., SANDOVAL, J., OKUOM, M., HUBER, C., BROOKS, T. D., WILSON, E., CLEMENT, B., WENTWORTH, C. D. \& HOLMES, A. E. 2017. Quantitative and qualitative assessment methods for biofilm growth: A mini-review. Research \& reviews. Journal of engineering and technology, 6.

VORHOLT, J. A. 2012. Microbial life in the phyllosphere. Nature Reviews Microbiology, 10, 828840.

VU, D., GROENEWALD, M., SZOKE, S., CARDINALI, G., EBERHARDT, U., STIELOW, B., DE VRIES, M., VERKLEIJ, G. J., CROUS, P. W., BOEKHOUT, T. \& ROBERT, V. 2016. DNA barcoding analysis of more than 9000 yeast isolates contributes to quantitative thresholds for yeast species and genera delimitation. Stud Mycol, 85, 91-105.

XU, L., DONG, Z., FANG, L., LUO, Y., WEI, Z., GUO, H., ZHANG, G., GU, Y. Q., COLEMANDERR, D., XIA, Q. \& WANG, Y. 2019. OrthoVenn2: a web server for whole-genome 
comparison and annotation of orthologous clusters across multiple species. Nucleic Acids Res, 47, W52-W58.

XUE, D. X., LI, C. L., XIE, Z. P. \& STAEHELIN, C. 2019. LYK4 is a component of a tripartite chitin receptor complex in Arabidopsis thaliana. J Exp Bot, 70, 5507-5516. 
Figure 1.
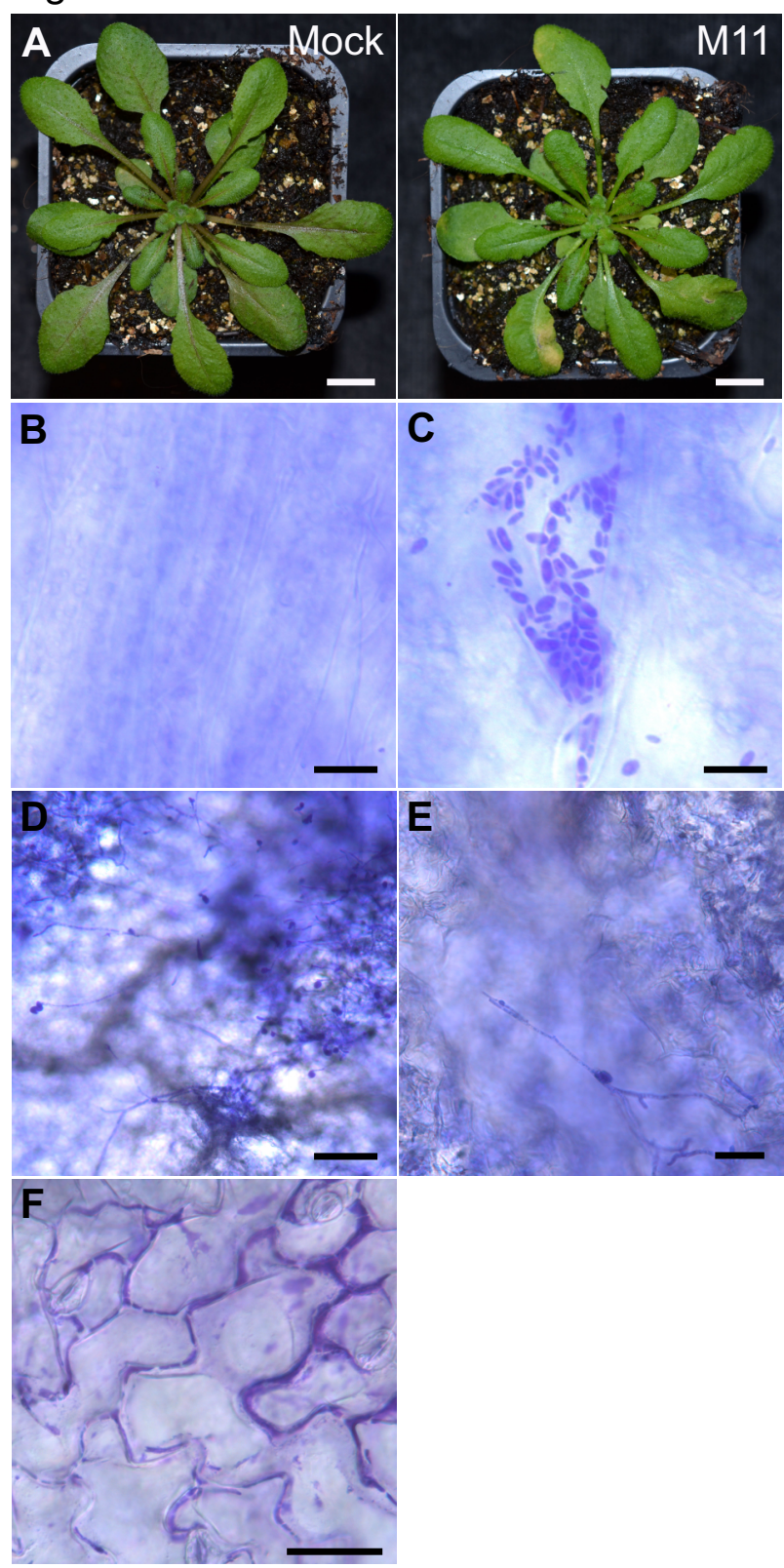
Figure 2.
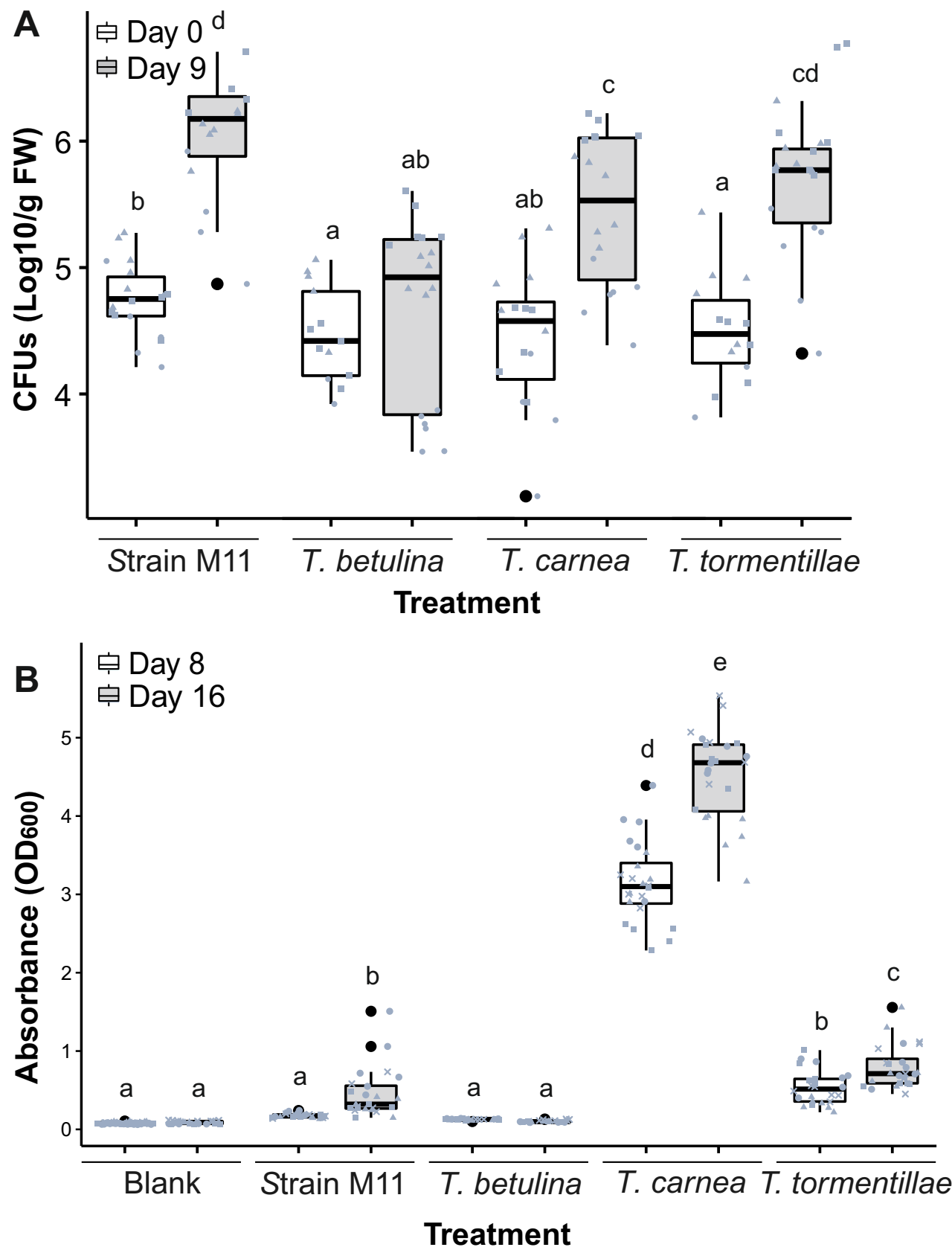
bioRxiv preprint doi: https://doi.org/10.1101/2021.09.16.460675; this version posted September 19, 2021. The copyright holder for this preprint (which was not certified by peer review) is the author/funder, who has granted bioRxiv a license to display the preprint in perpetuity. It is made available under aCC-BY-NC-ND 4.0 International license.

\section{Figure 3}

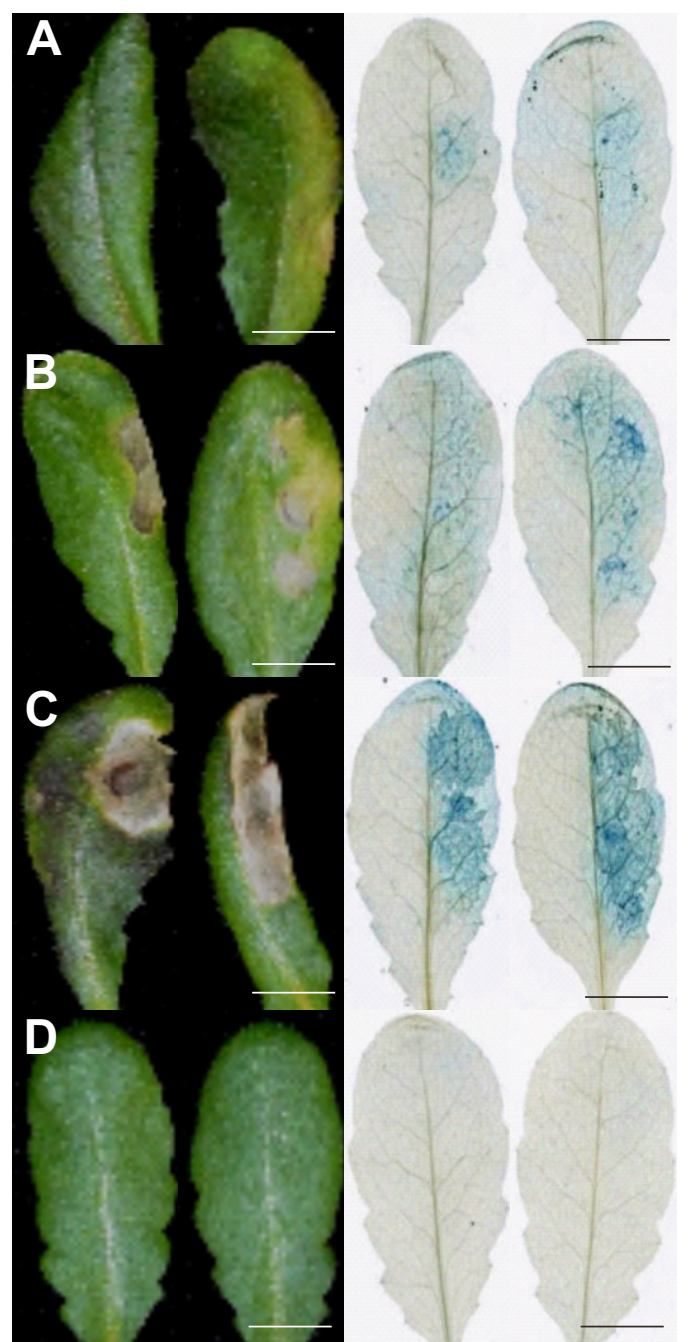

\section{E}
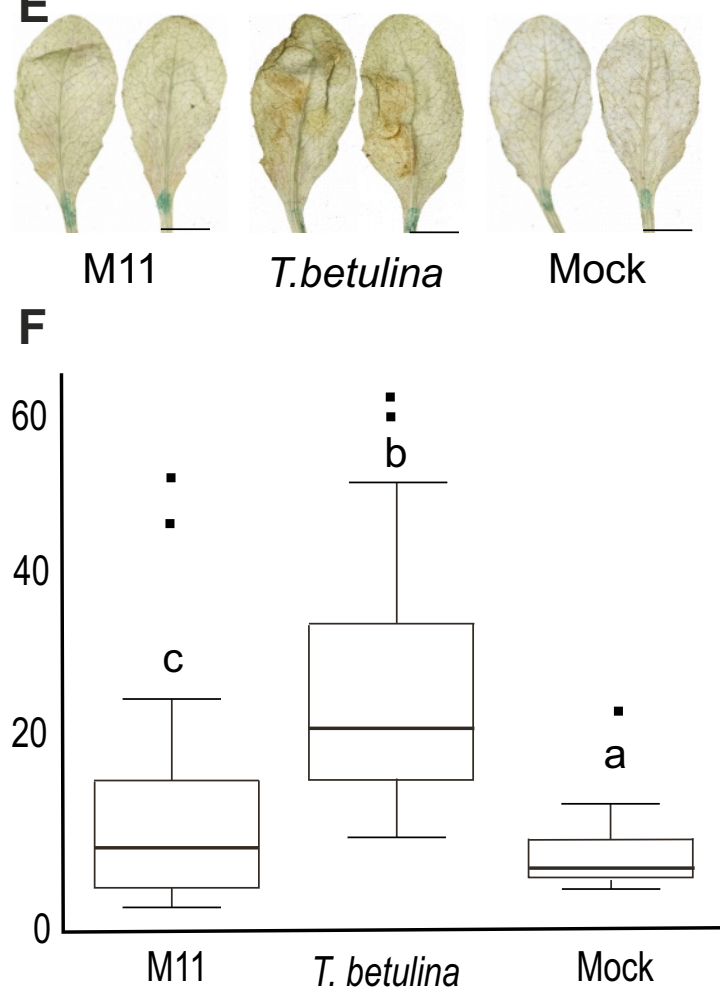
Figure 4.

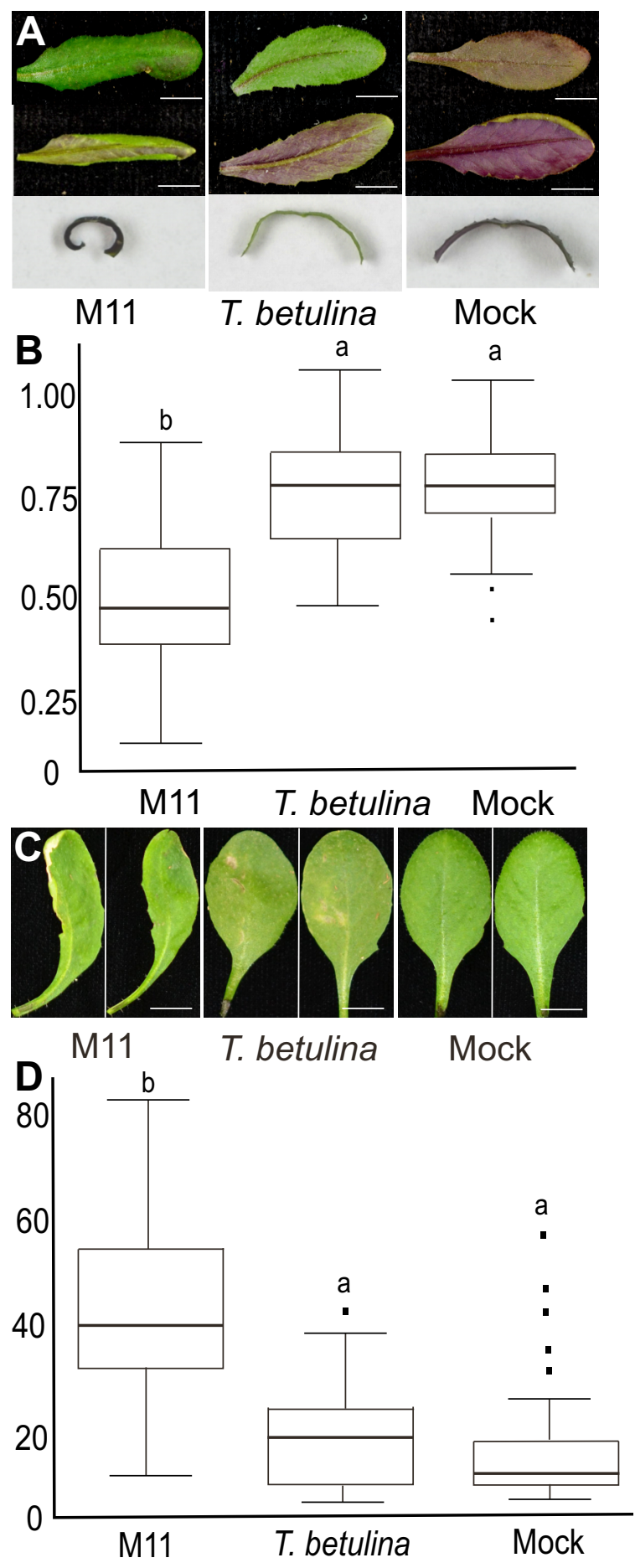




\section{Figure 5.}

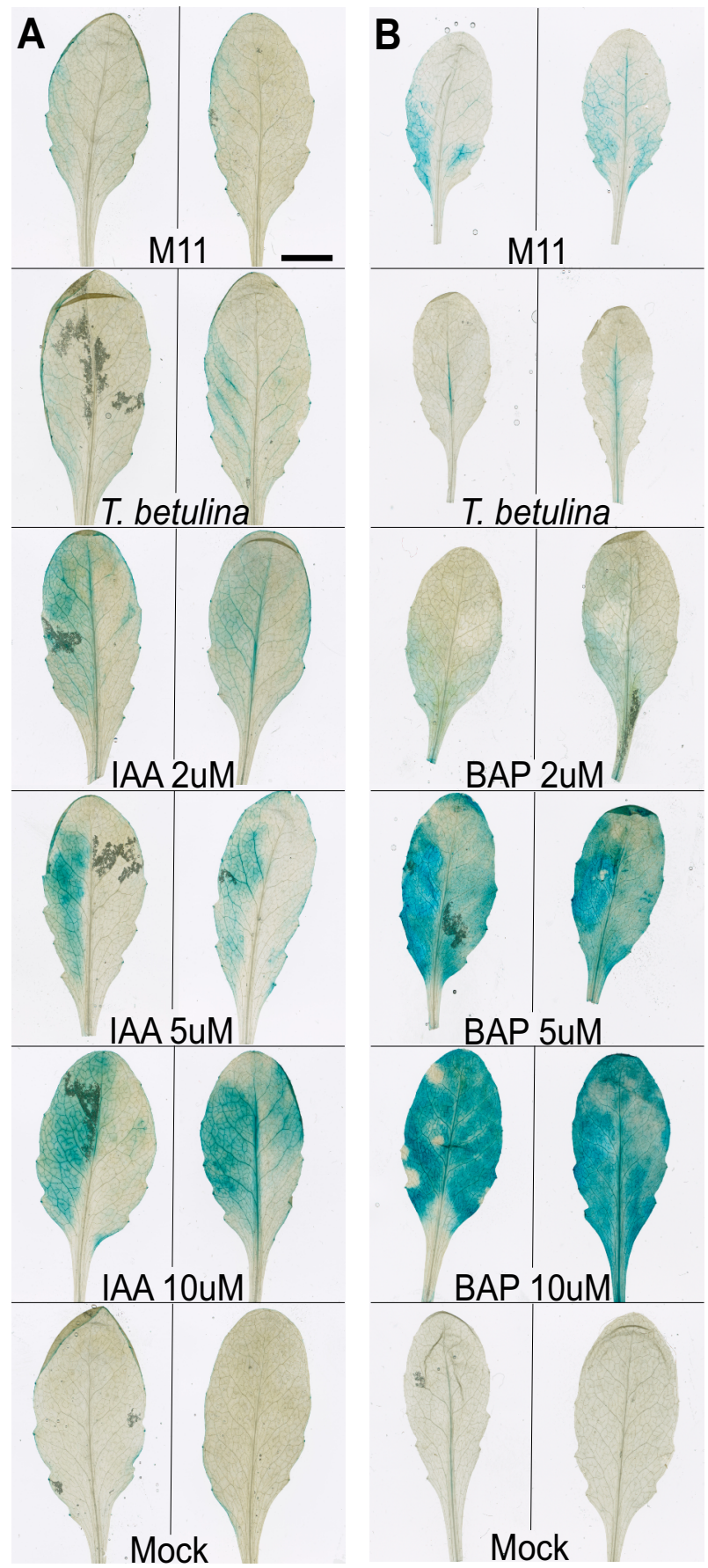


bioRxiv preprint doi: https://doi.org/10.1101/2021.09.16.460675; this version posted September 19,2021 . The copyright holder for this preprint (which was not certified by peer review) is the author/funder, who has granted bioRxiv a license to display the preprint in perpetuity. It is made available under aCC-BY-NC-ND 4.0 International license.

Figure 6

A Col-0
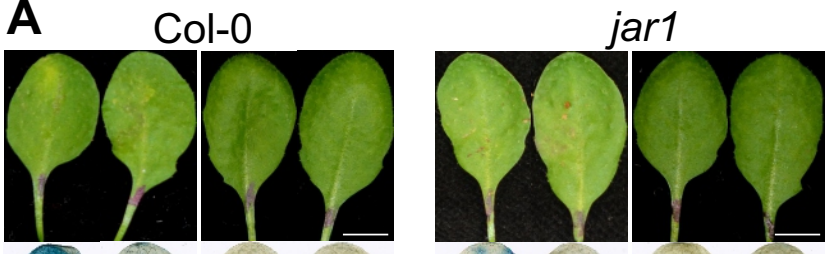

M11 Mock 1

coi1-16
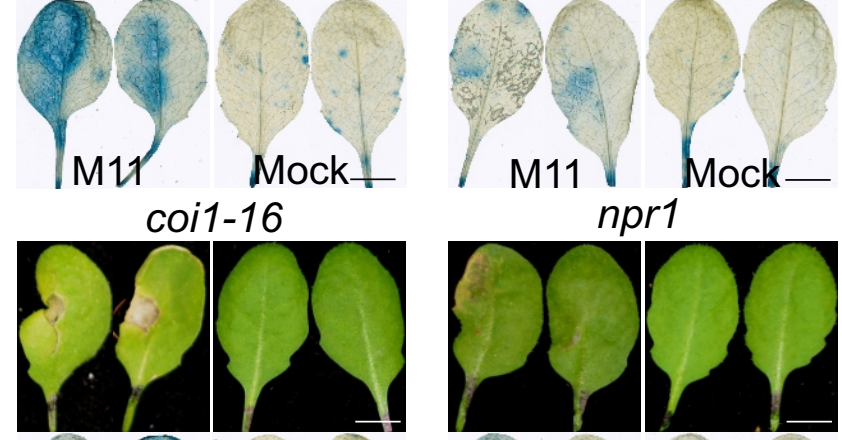

npr1
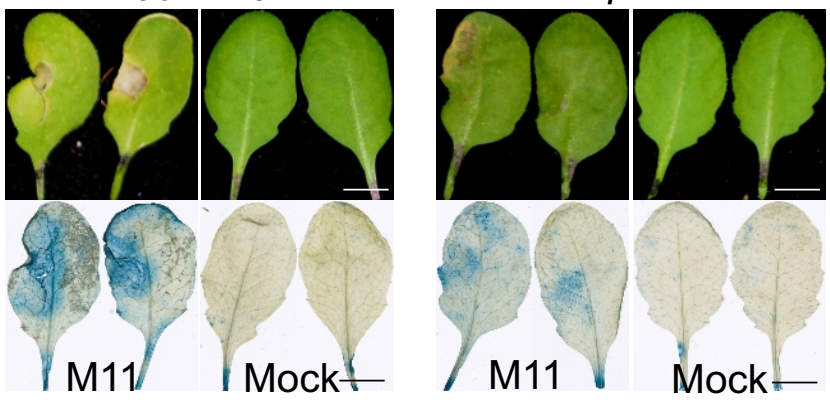

cyp79 b2/b3
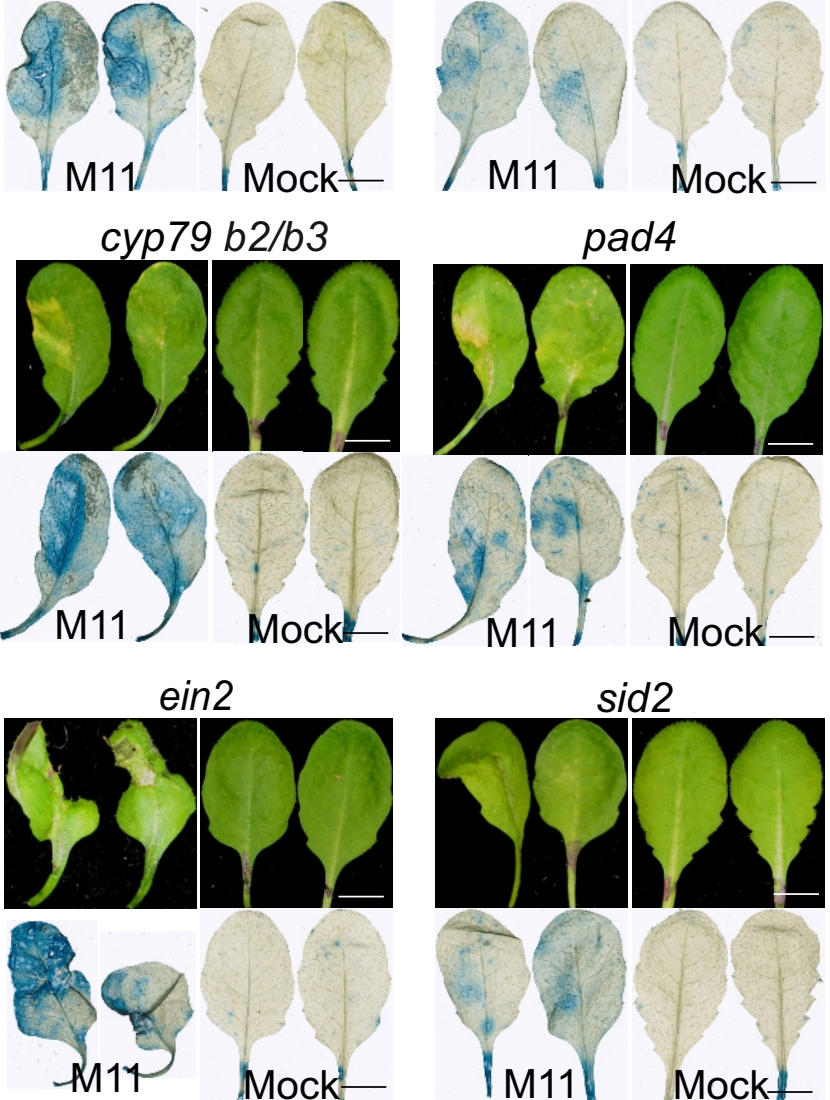

Mock $\mid$ M11 Mock
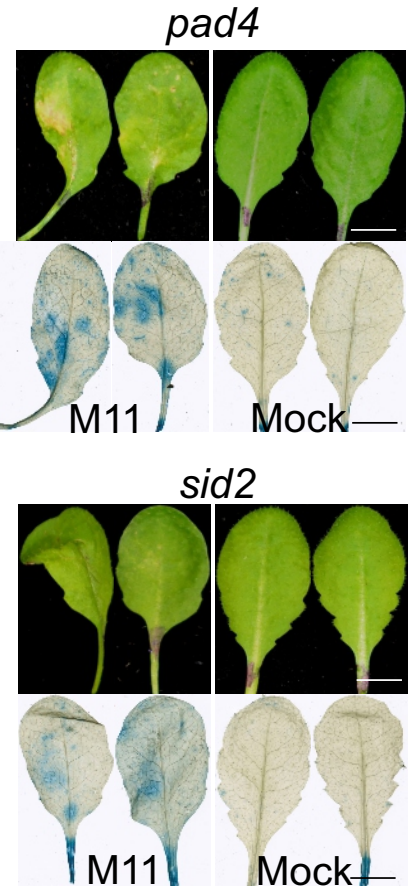
Figure 7.

\section{Strain M11}

T. deformans

T. wiesneri

T. populina

T. flavorubra

P. arabidopsidicola

$P$. lactucaedebilis

$P$. gravidus

$P$. macrosporus

S. pombe

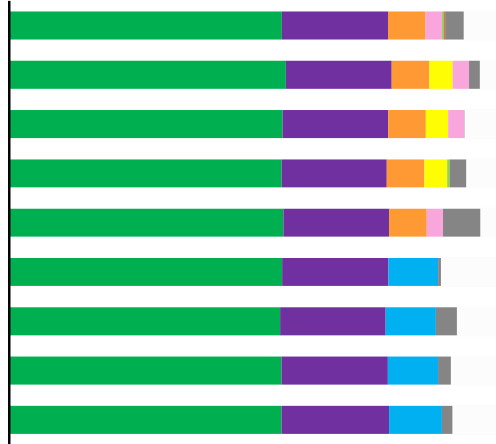

0
12234

Number of proteins (x 1000)
Present in:

- All species

- Taphrinales order

- Protomyces spp.

Taphrina spp.

Prunus pathogens

- M11 and Prunus pathogens

M11 and Populus pathogens

- Species isolated from $A$. thaliana

- Species specific

Other 
bioRxiv preprint doi: https://doi.org/10.1101/2021.09.16.460675; this version posted September 19, 2021. The copyright holder for this preprint (which was not certified by peer review) is the author/funder, who has granted bioRxiv a license to display the preprint in perpetuity. It is made available under aCC-BY-NC-ND 4.0 International license.

Figure S1.
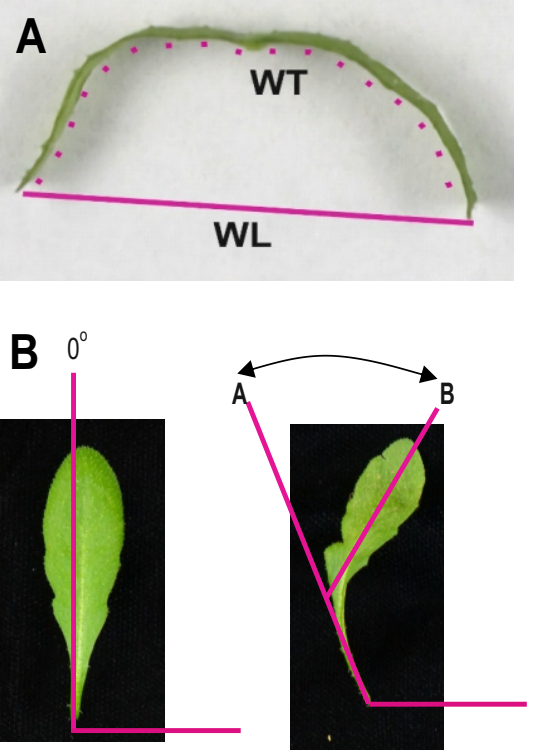
bioRxiv preprint doi: https://doi.org/10.1101/2021.09.16.460675; this version posted September 19, 2021. The copyright holder for this preprint (which was not certified by peer review) is the author/funder, who has granted bioRxiv a license to display the preprint in perpetuity. It is made available under aCC-BY-NC-ND 4.0 International license.

\section{Figure S2}

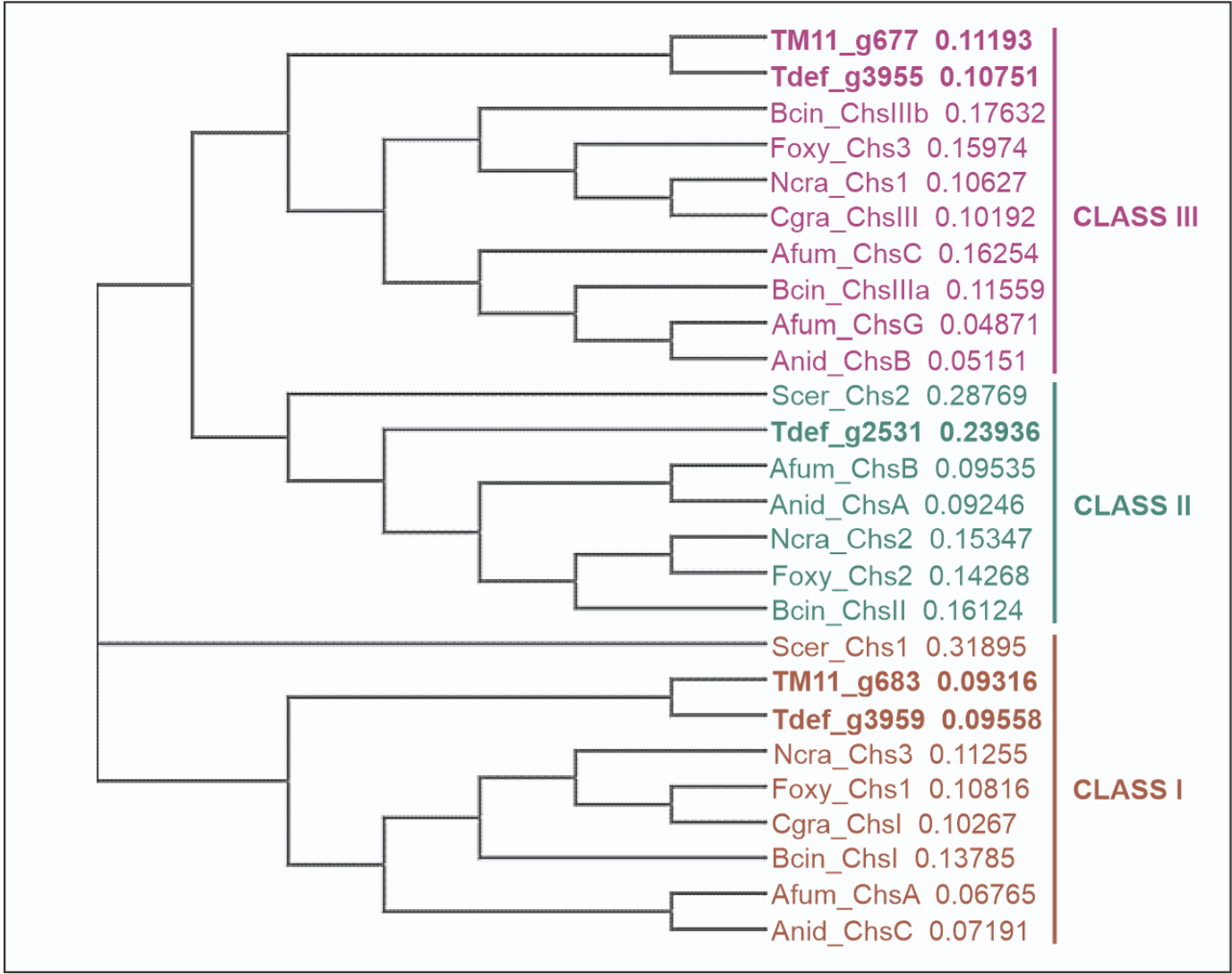


bioRxiv preprint doi: https://doi.org/10.1101/2021.09.16.460675; this version posted September 19, 2021. The copyright holder for this preprint (which was not certified by peer review) is the author/funder, who has granted bioRxiv a license to display the preprint in perpetuity. It is made available under aCC-BY-NC-ND 4.0 International license.

\section{Figure S3}

S cer Chs 1 T_M11_g683 T_def_g3959 $\mathrm{N}$-cra_Chs 3 F-oxy Chs 1 C gra Chs I A fum ChsA A nid_ChsC B_cin_Chs I

S_cer_Chs 1 T_M11_g683 T-def g3959 $\mathrm{N}$ Cra Chs 3 F_oxy-Chs 1 C gra Chs I A fum ChsA A nid ChsC B_cin_Chs I

S_cer_Chs 1 T_M11_g683 T_def_g3959 $N$ cra Chs 3 $\mathrm{F}^{-} \mathrm{Oxy} \mathrm{Chs}^{-}$ C-gra_Chs I A fum ChsA A nid ChsC B ${ }^{-}$Cin ${ }^{-}$Chs I

S_cer_Chs 1 T ${ }^{-} 11-\mathrm{g} 683$ T-def g3959 $\mathrm{N}$ cra Chs 3 $\mathrm{F}^{-} \mathrm{Oxy} \mathrm{Chs}^{-}$ C_gra_Chs I A fum ChsA A nid ChsC B_cin_chs I

S cer Chs 1

T M11 g683

T_def_g3959

$\mathrm{N}$ Cra Chs 3

F_oxy_Chs 1

C-gra-Chs I

A fum ChsA

A nid $\mathrm{ChsC}$

B_cin_Chs I

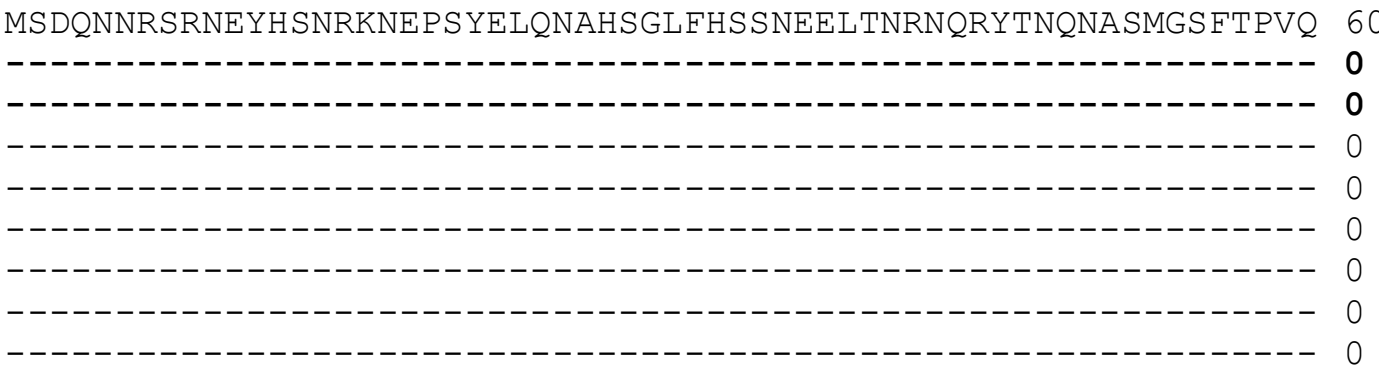

SLQFPEQSQQTNMLYNGDDGNNNTINDNERDIYGGFVNHH-RQR-PPP---ATAEYNDVF 115

--------MSNLNWPDTD--YR---RN-N-----------------RSP-GVYNNNY 25 -MSWQNGQ--YS---DG-GHYDNGHN---------PNYPQ-TQYDQHY 31

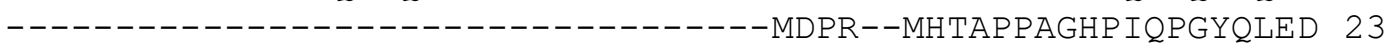
-MDPRYG---AQ-----PQQHPH--PHRTPSPGQPLQQGYQLDD 33 -----------------------------------MDPR--YHRTPSPGQPLQHGYQLED 23 -----------MSYNRLD-HYG---ED-GDRSPTMNPQHLADRTPSPGRPL-NTYQLSD 42 -MSYNRLGDPYG---DDRDARSPIMNPSSLSNRSPSPGRPL-DGYQLSD 44 -MSYNRLDPA-G---QGQDDYYN-MN-----NRHQS--PHP-QGYQLED 35 *:

N---TNS--QQLPSEHQYNNVPSYPLPSINVIQTTPELIHNGSQTMATPIERPFENENDY 170 GPYDPYRPENHSSTS--ENH-VT-----DPYAPYSQQQHNQSNSSFGYTPS-----------------V--------------- 55 NPYHHQQ----------------------------------GFDIPAGP------- 38

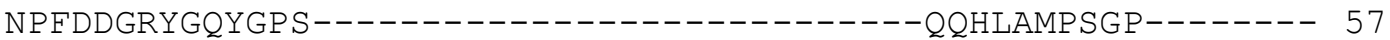
NPENNNAAYQPPPQHDPYGHTSP-------------------HQQLDVPMGP-------- 56

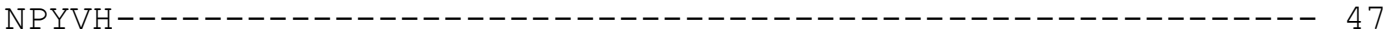
APYGHH---------------- - - - - - - - - - - - - - - - - - - - - - - 50 APYGRPNTTSPGPG----------------------------MHNLEIPMGP-------- 59

YYNNRNSRTSPSIASSSDGYADQEARPILEQPNNNMNS-----GNIPQYHDQPFGYNNGY 225 --------PI-YDAHD--PLNEAYPLQSYPQGLTASHPY------DATPSPGGMDPYT 87 ---------AR-YTLED--PQEESYPLQQYPQGLTASNPY------THTPSPGGMSPYG 96 --------GR---YSPGDALHIQTPQPIEGMGG---------YNAPGQHYTPDYAVNPEE 78 --------DQHRLPTPSDHLNLNAAQSVDNLSG---------YGPP-----GDYAVNPEA 95 --------P-ARYGTPS DQLPLNAAHSVSNLSG---------YDTPVNH--GDYGVNPEA 96 --------DHLQMPSS DRLAEQPTYSVERIPNSYGHNEAYEQRHHEQYPAYDYAVNPEA 98 --------HHIEMPSS DRLAEQPTYSVERI PQSYGHNEAYEAQ-HQHYPGYEYSVDPEA 100 -------GAHRIGTPS DQLQAQP SYSVEHLDQNQYHQRMSL--NPSQSYDSEYSLDPNA 109

HGLQAKDYYDDPEGGYIDQRGDDYQINSYLGRNGEMVDPYDYENSLRHMTPMERREYLHD 285 HP-NDS-YFH-------DQG--ADLGYG---Q----PH---I------------QDE 111 HG-HDSSYFH--------DG----DLGYQTGHD----PS---R--------------PDD 122 H---HDAYYNQPYEPQVGHDPYAAAP-----TP----PVAGYQ--------------AHD 112 H---HDAYYNQPYEPRPQQQPYDQG-------Y----DQEYDQ--------------PYD 127 H---HDAYYNQPYEPSPHDPSVPYD-------Q----PTG-YS--------------EYD 127 H---HDAYYTQPYEPTVTPQ-DDYDLGQYHEQH----QPY----------------QD 132 H---HDAYYTQPYQPTVTPGHDDYDLGQYPGHQ----HSY-----------------QD 135 H---HDAYYQPPYQPSPHEEH---PLQNYAPGQ----DPYAYN--------------DDD 145 $\star \quad . *$ : 
S cer Chs 1

T_M11_g683

T_def_g3959

N Cra Chs 3

F oxy Chs 1

C-gra- Chs I

A fum Chs A

A_nid_ChsC

B_cin_ChsI
DSRPVNDGKEELDSVKSGYSHRDLGEYDKDDFSRDDEYDDLNT I DKLQFQANGVPASSSV

MQSPLLDQFP--------------------------------K-----SL---HDGL

MQSPLLEQFP------------------------------K-----EL---HDGP

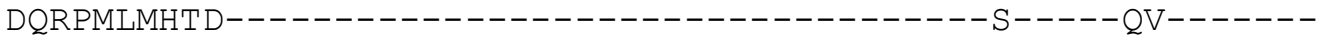

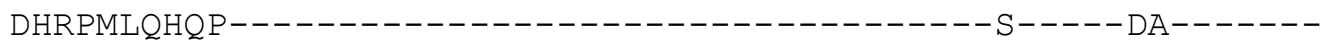

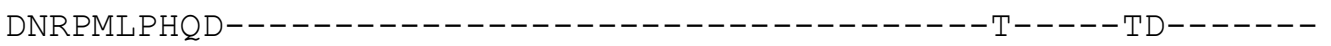

DQVPI LQPEN-- - - - - - - - - - - -

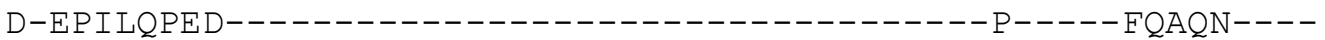

DHQPI LQSHE-----------------------------P-----YGPDPHSAS

*:

S cer Chs 1

T_M11_g683

T_def_g3959

N Cra Chs 3

F oxy Chs 1

C_gra_ChsI

A fum ChsA

A_nid_ChsC

B_cin_ChsI

S cer Chs 1

T_M11_g683

T_def_g3959

N Cra Chs 3

F_oxy_Chs 1

C_gra_ChsI

A_fum_ChsA

A nid_ChsC

B_cin_ChsI

S cer Chs 1

T_M11_g683

T_def_g3959

$\mathrm{N}$ Cra Chs 3

$\mathrm{F}^{-} \mathrm{oxy}{ }^{-} \mathrm{Chs} 1$

C gra Chs I

A fum ChsA

A nid ChsC

${ }^{-}$cin Chs I $^{-}$

S cer Chs 1

T M11 g683

T def g3959

$\mathrm{N}$ Cra Chs 3

F oxy Chs 1

C_gra_Chs I

A fum ChsA

$\mathrm{A}^{-}$nid $\mathrm{ChsC}$

$\mathrm{B}^{-} \mathrm{Cin}^{-} \mathrm{Chs}$

SS I GS KESDI IVSNDNLTANRALKRS GTEIRKFKLWNGNFVFDSPISKTLLDQYATTTEN

PSPGE PDPVMT-PYAQVPPVGAHPRRWKT IKRVEL YNGNLVLDCPVPQKLLATLPIK---

PTPGSVTRHTT-GYAQP PPMGAQPRRYKTMKRVELYKGNLVLDCPIPPKLLATLPIK---

--GQSDPYHDE-PQ--P PTNNAPIKRWKTVKQVLLYRGNLVLDCP I P PKLLNQLPHG---

--P-SEPYQD------QPQQGGGIKRWKTVKQVLLYRGNLVLDCPVPPVLLQQNPHG---

--G-Y-QDNP------TPQPAGGLKRWKTVKQVLLYRGNLVLDCPVP PRLLNQI PHG---

--PYSEEYHDD-PAAVPTPS PAPIRRWKTVKEVQLFHGNLVLDCPIAPKLLSQVPHAE--

--PYSDDYQED-MTIAPTPS PAPLRRWKTVKEVQLFQGNLVLDCPIAPKLLNQ I PHAE--

GTDYKGGYDGT-VQSPSATPVPALRRYKTVKEVQLFNGNLVLDCP I P PKLLNQVNHAP--

$$
: \quad:: \ldots{ }^{\star}:{ }^{\star}{ }^{\star}:{ }^{\star}:{ }^{\star}{ }^{\star}:{ }^{\star} *
$$

1.

ANTLPNEFKFMRYQAVTCEPNQLAEKNFTVRQLKYLTPRETELMLVVTMY NEDHI LLGRT

---EGREFTHMRYTAATGDPSEFVSRGFTLRQKLYQPSRQTELFIVITMYNENEILFART -DGREFTHMRY TAATGD PSDFARKGFTLRQALYQPQRQTELFIVITMY NENEI LFART

---ERDEFTHMRYSAATCDPSEFYEENFTLRQKLFSKPRHTELFIVVTMYNEDEILFART

---ERDEFTHMRY SAATCDPNDFY DHDFTLRQRLFTKPRHTELFIVVTMYNEDDI LFART

---ERDEFTHMRYTAATCDPNYFYDDNFTLRQKLFSKPRHTELFIVVTMYNEDEILFART

- PPGRDEFTHMRYSAATCDPADFYEERFTLRQKLFAKPRHTELFIVITMYNEDDFLFART

-NGQRDEFTHMRYSAATCDPKDFFEERFTLRQKLFAKPRHTELFIVVTMYNEDDFLFART

- PPERDEFTHMRYSAATCDPSEFFEERFTLRQKLFAKPRHTELFIVVTMYNEDDVLFART

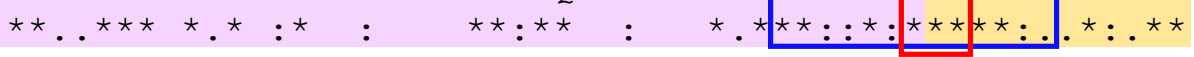

LKG IMDNVKYMVKKKNSS TWG PDAWKKIVVC I IS DGRSK INERS LALLSS LGCYQDGFAK

MIGVFKNIEYMCKRTESKTWGKDAWKKIVVCVVSDGR AK INPRTRALLAGMGVYQEGIAK MTGVFKNIEYMCNRPNSKTWGKDAWKKIVVCVVSDGR SK INPRTKALLAGMGVYQEGIAK MIGVLKNVEYMCNRKESKTWGKDAWKKIVVCVVSDGRAK INPRTRALLAGMGVYQEGIAK LIGVFKNIEYMCNRTQSKTWGKDAWKKIVVCVISDGRAKINPRTRAVLAGLGVYQDGIAK MVGVFKNIEHMCSRTRSKTWGKDAWKKIVVCVISDGRAK INPRTRAVLAGLGCYQDGIAK MHGVFKNIE FMCTRKDSKTWGKDAWKKIVVCVVSDGR AK INPRTRAVLAGLGVYQDGIAK

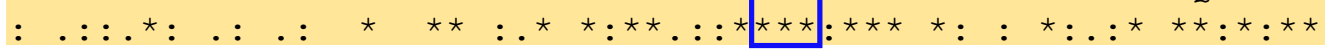

\section{5}

241

234

245

244

261

264

281

DE INEKKVA MHVYEHTTMINI TNI SE SEVSLECNQGTVP IQLLFCLKEQNDKKIN SHRWA 585 NVVNNEPVT AHLYEYTTQISINAD--LTF-KGSDRGIVPVQML FCLKEKNQKKINSHRWF 358 NVVNNEPVTAHLYEYTTQISINSD--LTF-KGSDRGIVPVQML FCLKEKNQKKINSHRWF 369 QQVNGKDVTAHIYEYTTQVGMTIK--NDVVQLI PK-QQPVQML FCLKEKNDKKIN SHRWF QQVNGKDVTAHIYEYTTQTHLQIK--NDVVQLVHR-RQPVQML FCLKEKNAKKIN SHRWF QQVNGKDVTAHIYEYTSQVGMMIK--NDVVTLVPK-QQPVQMLFCLKEKN QKKINSSHRWF QQVNGKDVT AHIYEYTTQVGLELK--GTQVH I KGRSACPVQMI FCLKEKN QKKINSSHRWF QQVNGKDVTAHIYEYTTQVGMELK--GNQVHLKPRSGVPVQMI FCLKEKN QKKINSHRWF QQVNGKDVTAHIYEYTTQVGISLK--KDIVTLTPK-QQPVQLLFCLKEKNDKKINSSHRWF 
S_cer Chs 1 $T^{-}$M11_-g683 T_def_g3959 $\mathrm{N}$ Cra Chs 3 F_oxy-Chs 1 C-gra Chs I A_fum_ChsA A nid_ChsC B_cin_Chs I

S_cer_Chs 1 T_M11_g683 T_def_g3959 $\mathrm{N}$ Cra Chs 3 $\mathrm{F}$ oxy Chs 1 C_gra_Chs I A fum ChsA A_nid_ChsC B_cin_Chs I

S_cer_Chs 1 T-M11_g683 T_def_g3959 N_cra_Chs 3 F oxy Chs 1 C_gra Chs I A_fum_chsA A nid_ChsC B_cin_ChsI

S_cer_Chs 1 T_M11_g683 T_def_g3959 $\mathrm{N}$ Cra Chs 3 $\mathrm{F}$ oxy Chs 1 C gra Chs I A fum ChsA A nid ChsC B_cin_Chs I

S cer Chs 1 T M11 g683 T-def g3959 $\mathrm{N}$ cra Chs 3 Foxy Chs 1 C_gra_Chs I A fum ChsA A nid ChsC B Cin Chs I
2.

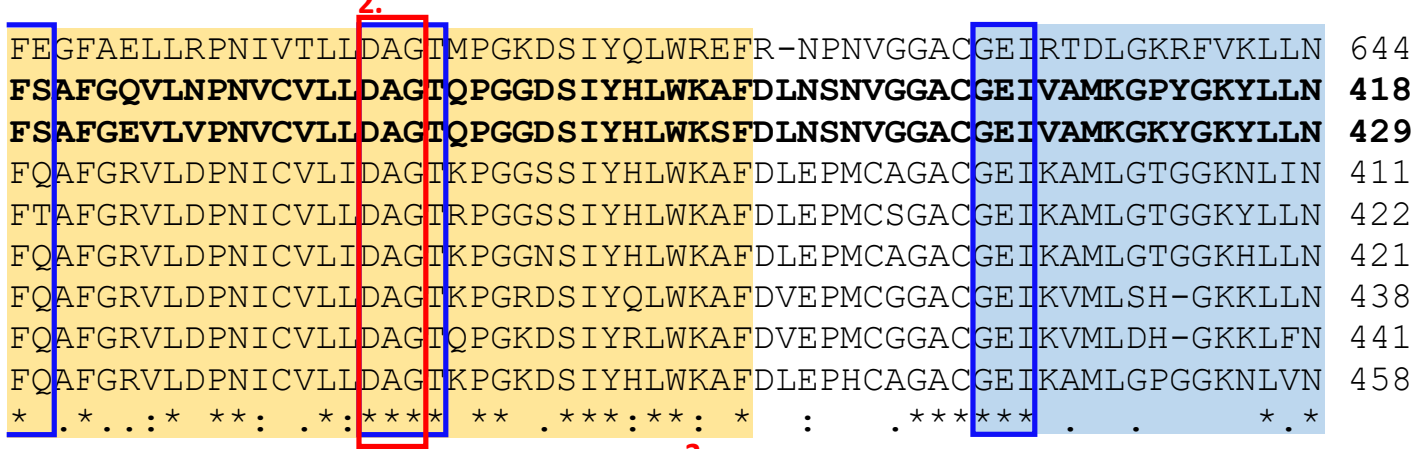
3.

PLVAS QNFEYKMSNILDKTTESNF GF ITVLP GAFSAYRFEAVR-----GQPLQKYFYGEI PLVAA QNEEYKMSNILDKPLESVF GF ISVLP GAFSAYREAALQNDSVGQGPLAQY FKGEK PLVAA QNFEYKMSNILDKPLESVF GF ISVLP GAFSAYREAALQNDSVGQGPLAQY FKGES PLVATQNFEYKMSNILDKPLESAF GF ISVLP GAF SAYRYVALQNDKNGQGPLEKY FAGEK PLVAA QNFEYKMSNILDKPLESAF GF ISVLP GAFSAYRYVALQNDKNGKGPLEKY FLGET PLVAT QNFEYKMSN ILDKPLESAF GF I SVLP GAFSAYRYVALQNDKNGQGP LEKYFAGEK PLVAGQNFEYKLSN ILDKPLESA F G ISVLP GAFSAYRYVALQNDKNGQGPLERY FLGEK PLVAGQNFEYKLSNILDKPLE SAFGF ISVLPGAFSAYRY IALQNDKNGQGPLERY FLGEK PLVAT QNFEYKMSNILDKPLESAF GF ISVLPGA SAYRYVALQNDKTGNGP LEKYYFAGEK

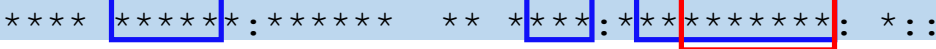

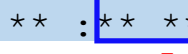
4. 5. MEN-EGFHF F SNMYLAEDRI LEEVVTKKNCNWI LKYCRSSYASTDVPERVPEF I L $\overline{\text { QRR }}$ MHG-ANAGIFEANMYL AEDRI I CFELVAKRKSAWVLHYVKSAYAVTDVPDELPELISQRR MHG-ANAGIFE ANMYLAEDRI L CFELVAKRKSSWVLHYVKSAYAVTDVPDELPELISQRR LHGG-DAG I FTANMYLAEDR I CFELVTKRNCHWI LQYVKSATGETDVPADLTELILQRR LHGGS DAGLFE SNMYLAEDR I LFELVTKRNCHW I LQYVKSATGETDVPPTVTELVLQRR LEG-AGAGIFTSNMYLAEDRI LCEELVTKRNCHWI LQYVKSATGETDVPDTVTELVIQRR MHG-ANAGI FTANMYLAEDRI L CFE IVTKRNCRWLLQYVKSST GETDVP PRMAEF I LQRR MHG-ANAGIFTANMYLAEDRI L FE IVTKRNCRWLLQYVKS STGETDVPDQMAEF I LQRR MHG-ANAGI FTANMYLAEDRI L CEELVSKRNCHWI LQYVKSAT GETDVPPTMAEL I LQRR

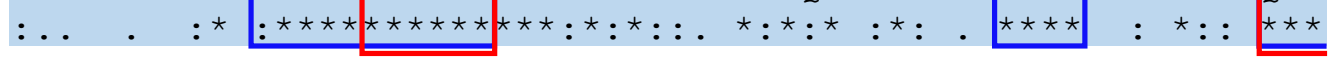
699 478 489 471 482 481 498 501 518

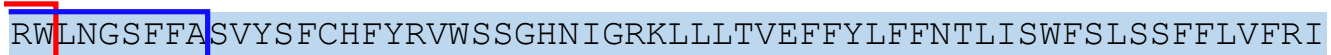
RWLNGSFFA AVYALWHTFAIWRSDHGFFRKI FFHIEFLYQGISMLFSWFGLGNFF IAFSI RWLNGSFFA AVYALWHTFAIWRSDHGIFRKLMFHIEFLYQGISMLFSWFGLGNFF IAFTI RWLNGSFFA AIYA IVHFHQFFRSDHSFLRKIAFFIEFVFQTVNMIFAWFAIGNFFLVFKI RWLNGSFFA A IYA IVHFLDFLRSDHTFLRKFAFFIEFIFNTINMIFAWFAIGNFFLVFKI RWLNGSFFAGIYA IAHFYEFFRSDHSMLRKLMFFVEFVFNTINLIYAWFAIGNFFLVFKI RWLNGSFFA AVYA IAHFYQIWRSDHS FMRKFMLLVEFIYQTINMIFAWFNIGNFFLVFHI RWLNGSFFA AVYA ITHFYQLWRSDHS FIRKFMLLIETIYQTINMLFAWFGIGNFFLVFHI RWLNGSFFAAIYALAHFYQIFRSDHSFLRKIMFLIEFTYQTINMIFAWFALGNFFLVFHI

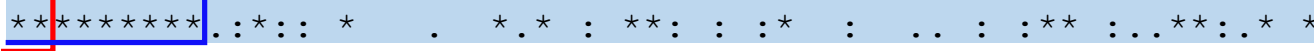

LTVSIALAY-----------HSAFNVLSVIFLWLYGICTLSTF I LSLGNKPKSTEKFYVL LSKALATNKWTIGPRAGKEIFAPGDVLYTVCTWLYAALIVLCEVLSMGNRPQGSKWAYMG LAKALAENKWTSGAKIGRDIFSPGQVLYTVCTWIYAGLVVMCFILSMGNRPQGSKWAYIV 668 LTTGLGDEKL---------LGTVGQ I LGVVFAWAYGVTLITCFVLSMGNRPAGSPRLYMG LTTSLGDDTL---------LGRTGE I LGVVFTWLYGVFLITCFVLSLGNRPAGSGRLYTA LTTSLGDDNL---------LGRTGE I LGVVFTWVYGIALITCFVLAMGNRPAGSGPYYIT LTTYLGDAEL---------LGTTGKVLGVVFEWLYLATLVTCFVLSLGNRPGGSNKFYMT LTTYLGDADL---------LGTAGKVLGVVFEWLYLATLVTCFVLSLGNRP GGSNKLYMT LTTSLGSSDL---------LGNVGVILGVVFEWLYLFTLLTCF ILALGNRPQGTNKVYMS 641 653 651 668 671 688 *: : . : ${ }^{\star}:$ 
S cer Chs 1

T_M11_g683

T_def_g3959

$\mathrm{N}$ Cra Chs 3

F oxy Chs 1

C gra Chs I

A_fum_ChsA

A nid ChsC

B_cin_ChsI

S cer Chs 1

T_M11_g683

T_def_g3959

$\mathrm{N}$ Cra Chs 3

F oxy Chs 1

C gra Chs I

A fum ChsA

A_nid_ChsC

B_Cin_ChsI

S_cer_Chs 1

T_M11_g683

T_def_g3959

N_cra_Chs 3

F_oxy_Chs 1

C_gra Chs I

A_fum_ChsA

A nid_ChsC

B_cin_ChsI

S cer Chs 1

T_M11_g683

T_def_g3959

$\mathrm{N}$ Cra Chs 3

F_oxy_Chs 1

C gra Chs I

A fum Chs A

A nid ChsC

B_cin_ChsI

S cer Chs 1

T M11 g683

T-def g3959

$\mathrm{N}$ cra Chs 3

F oxy Chs 1

C_gra_Chs I

A fum_ChsA

A nid ChsC

B_cin_ChsI
TCVIFAVMMIYMI FCS IFMSVKSFQN I LKN----D----TISFEGLITTEAFRDIVISLG

TMVFFAILMGYMLFAAGFLSYVSIQSLIYTVDATGNKSFESVWAALRADPIFYQLCISLI TMTFFALLMGYMI FAAGFLSYVSIEGLILTIETGGNRSFATIFKAVRSDPIFYQLCISLL MVVFWAIIFIYLMFAA IY IAVVAIQTDVQ-----K----GLSFTDLFRNELFYTLIVSVV MVY FWAFIMIYLLFAAVFIAVKAI IADVH---DSN----GFNI TDLFKNPVFYTLI ISVM MVYFWIGIMIYLTFAA I FVTVKSIQKEVA---D-N----SFSVGQLFSNSQFFS I FVSLG MVYLWVFIMIYLAFAAVFVTVRS IQEEVK---D-G----SFTFSTLFTNSTFFS I IVSLG MVYFWI I IMIYLMFAS I F I TVKS IQTQLA---K-D----EFNWTDI IKNQI FYTLI ISLA $:::{ }^{\star}:{ }^{\star}$ : : : : : : $\quad$ : $:$ : $:$ MCWFWA I IMIYLLFAA I F IAVKA I IADVN---DAN----GFNFADI FKNKVFYMLI ISVM

919

717

728

692

706 704 720 723 740

STYCLYLISS I IYLQPWHMLT SFIQYILLSPSYINVLNIYAFCNVHDLSWGTKGAMAN-- 977 STYGLYLIASVLYFEPWHMITSFVQYMLISPSYINILNVYAFCNTHDISWGTKGDTGVKT 777 STYGLYILSSLLYFEPWHMITSFVQYLLISPSYINILNVYAFCNTHDISWGTKGDSGVKT 788 STYGIWLIASLLMFDPWHMVT SMVQYMLLSPTYTNVLNVYAFCNTHDISWGTKGDDKPDK 752 STFGIWLIASLIMLDPWHMAT SLVQYMLLTPTFTNVLNVYAFCNTHDVSWGTKGDDKVEK 766 STYGIWLIASLLMFDPWHMITSFVQYMLLTPTYTNILNVYAFCNTHDISWGTKGDDKAES 764 STYVMWLLASLIFLDPWHMFT SFIQYMLLTPTYINVLNIYAFCNTHDI TWGTKGDDKAEK 780 STYVMWFIAS I FMDPWHMFTCFIQYILLTPTYINVLNIYAFCNTHDI TWGTKGDDKAEK 783 STYLLWFISSFLFFDPWHMFTSFLQYLLLTPHISIFSTFTLFCNTHDITWGTKG------ 794

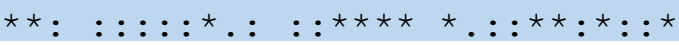

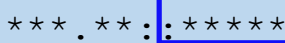

PLGKIN-TTEDGTFKMEVLVSSSEIQANYDKYLKVLNDFDPKSESRPTEPSYDEKKTGYY 1036 DLGVVNVSKTDGKLEMAMPTSEVDVDALYSKALTTLQTKEPEKKS---KRDAQTKQEDYY 834 DLGVVNVSKTDGKLELAMPTSEVDVDELYMKALKTLQVKEPEAKN---KRDAKTKQEDYY 845 LP-SVN-TKDGQGK-TD-LPDEGDLNASYERELQVFSRKYVKPVTAPTSAQLEEKQMDYY 808 LP-SVN-TKDGTGK-TD-LPDEGDLNAQYQRELAVFAQKHVEVKTTPTPSQLQEKQMDYY 822 LP-TVS-TKDGSGK-TD-LPDEADLNAQYERELTVFSTKFVKEVKAPTESQLAEAQMDYY 820 LP-SAN-MKPGGKVDVDIPQDDGDLNAQYEAELAKEAQKPPKETKVI---SEEERQADYY 835 LP-SAN-LKPGGKVDVNIPQDDGDLNAQYEAELMKFAQKPPKEIKTI---SEEERQADYY 838 794

ANVRS LVI IFWVITNFI IVAVVLETGGIADYIAMKS ISTDDTLETAKKAEIPLMTSKASI 1096 KAFRTRVVLFWIFSNGVLIGLILGVGGVDQIDATSG------------STS---ASRASV 879 KAFRTRVVLFWILTNGALVGVVLGVGGVNQIVTGST-----------STS---TSNAST 890

RGVRSMVVLVWMITNFALCAVVLSTAGLERIDPEEG-----------SQEQQTTKRATI 856 RGVRTGVVLIWMVSNFGLAALVLSSAGLDRISPNKD-----------KEAE-QLSRSNI 869 RGVRSVVVLAWMI SNFGLAAVVLSAAGLERINPAAN------------STDD-VDGRANI 867 KGFRSAVVLAWVFCNFALGAVVLSAAGLDRFNSDKN------------ATD---DDRATI 880 KGFRS SVVLVWVFCNFALGAVVLSSAGLDRFSDDAE-----------AAETDRNNRAMI 886
YFNVILWLVALSALIRFIGCS IYMIVRFFKKVTFR 1131

YLSIIFWSVAGLSAFRALGSLAYLVLRLFHGE--- 911

YLSIVFWSVAGLSLFRFIGCILYLIIRLFHGE--- 922

YMSVVLWSVAVLSGFKFVGACWFLVVRMFRGV--- 888 YMS IVLWSVAGLSAFKFIGAMWFLVVRMFRGV--- 901 YMSVVLWSVAGLSSFKFIGAMWFLVVRMFRGV--- 899 YMAVVLWSVAGLS IFKFIGAMWFLVVRMFRGV--- 912 YMAVVLWSVAGLS IFKFLGAMWFLVVRMFRGV--- 918 
bioRxiv preprint doi: https://doi.org/10.1101/2021.09.16.460675; this version posted September 19, 2021. The copyright holder for this preprint (which was not certified by peer review) is the author/funder, who has granted bioRxiv a license to display the preprint in perpetuity. It is made available under aCC-BY-NC-ND 4.0 International license.

\section{Figure S4.}

S_cer_Chs 2

T_def_g2531

A fum ChsB

A nid_ChsA

$\mathrm{N}$ - cra Chs 2

B_cin_ChsII F_oxy_Chs 2

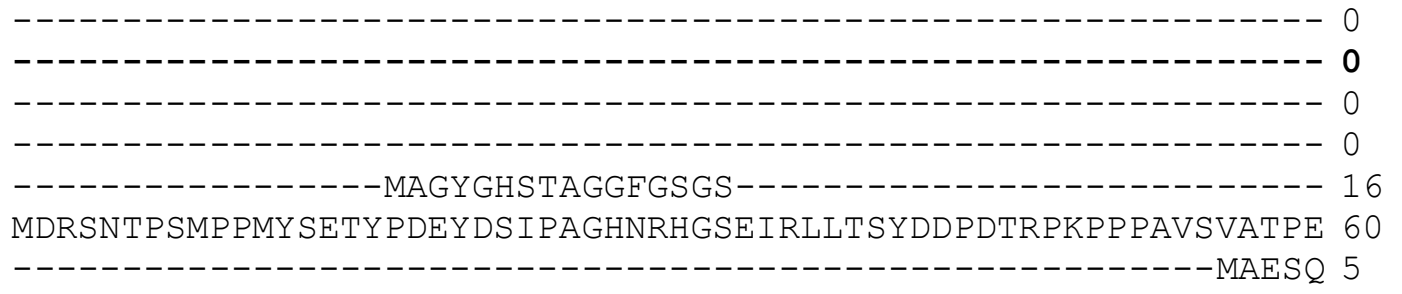

$S$ cer Chs 2 T_def_g2531 A fum ChsB A nid-ChsA N_cra-Chs 2 $\mathrm{B}^{-} \mathrm{Cin}$ - ChsII F_oxy_Chs 2

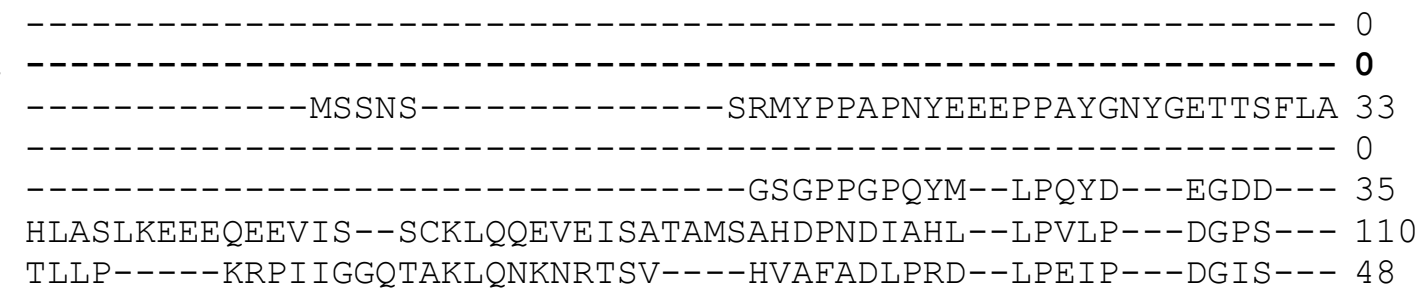

S cer Chs 2

T_def_g2531

A_fum_ChsB

A_nid_ChsA

N_cra_Chs 2

B_cin_ChsII F_oxy_Chs 2

\section{$-$}

DHDSS PRHQGVTMRLLPNSTDVDDDLSVDVERGASHHYGIEYS----------------- 76 ---------------------------MDCQNG--------------------------- 6

PDADA-TPAGQGVRLLTNLDNSSYISVSEITSQSSHRDNIRPSRLRQAYEPSID------ 88 RRRSLRHPVSSP---LSTL------KSQLIGKKSSLLKNISTSSDRRSYQASVMSTDSYD 161 DRRRVHKEQQH-----------------LGLD------------------------- 63
S_cer_Chs 2 T_def_g2531 A fum_ChsB A nid ChsA N_cra_Chs 2 B_cin_ChsII F_oxy_Chs2

S_cer_Chs 2

T_def_g2531

A fum ChsB A_nid_ChsA N_cra-Chs 2 $\mathrm{B}$ - Cin ChsII F_oxy_Chs 2

S_cer_chs 2 T_def_g2531 A_fum_ChsB A_nid_chsA N_cra-Chs 2 B_cin_ChsII F_oxy_Chs 2
-MTRNPEMVE-PSNGSPNRRGASNLSKFYANANSNSR-WANPSEESLEDSYDQSNVFQGL 57 DD---------ESTRANVQ-----YVPYSGNANGGYNR--FYGYNAEESPSRPASSLGNV 120 -------------RRANR-----TVRFARTAESRYPERYSYEYDPEETLSRAAPSMRNA 47 ARTYEPS--------------LDTRTYEPSISDR-RHMYEP-------SIDERSSYMDP 125 DHRRAPSINTYDDHRRPPSMNTYDDHRRPPS INTYDDHRRPPTATTYDDHRRAPSIIDNV 221 ---TTPPVP----PRPLSRLRDVNS HDKLPS IRSPRNLNYQP----SVRSSRSGS IFDDA 112

PASPSRAA--------------------LRYSPDRRHRT-------------QFYRDSAH 84

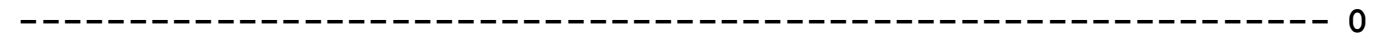

PSIPP PAVSA---VEVPQ-YSSRPASPLRPWSPARAADWTR--PPAPPSVTGSQYERADL 174 PTIPPPTASG---ADEMRYTASRPASPARPWSPTRAADWVR--PPS---AAASYYERADI 99 PRIPPPDGGSYVSSYMG--TESMVSGHGRPWSPESATG--------YRVPPQGRYEPSEI 175 PDLPPPES-AYRPYSPLQYSPSGRASPTRTWSPIREER--NSSEFNVPPPMGYHYEPSDL 278 PSMAP PGG-SYVSYG-----MHDDGSPQRPWTPSSRVSGFTRSDLSRPPPSDGMYEPSDL 166

NSPVAPNRYAANLQESPKRAGEAV-IHL-----SEGSNLYPRDNADLPVDPYHLSPQQQ - 137

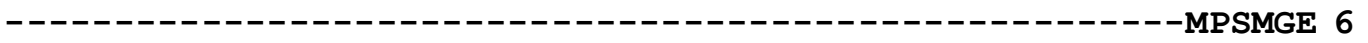

NGSPRPGTPSSRYGGSPRRPLPPAPLFAGPGAAT-------------GQDTSIDIGDGN- 220 NGSPRPGTPSSRYGGSPRRPLPPAPLESKPGTTT--------------QDTKIDIGDG-- 143 DGHARPGTPGSSYGNA-RRPLPSAPAPLHYNSPSRAASHYPRYHGGYADDVTVSMGPDD - 233 NGSPRPGTPSTAYGGSPRRPLPPAPLFAAHGA-R---------SPFGDDATIHIPLEHE 327 NGSPRPGTPSSRYGGSPRRPLPPAPLFSNSRQPV----------PPIADDATISIPLHDT 216 
----PSNNLFGSGRLYSQ------SSKYTMSTTSTTAPSLAEADDEK----EKYLTS-TT 182 T_def_g2531 KTNWVDESPYEMP

-YKGFDVK---AYSVLSDDDDDGGG

-DDDND 45

A_fum_ChsB

----DPEDPFGGGGRTN-NRHEHRGS IRSFMSD-----STMITDEKE------EMA--KI 262

A nid_ChsA

N_cra_Chs 2

-----EEDPFGGGGRTISSRHGPQGSVQSFTSE-----STFIADETD-------LE--KV 184

${ }^{-}$Cin $^{-}$ChsII

----DRTDIFGPETDLSETRHLNDA--YGFRSS-----QITLSEDPHGTHARSRYDDEDD 282

F_oxy_Chs2

$----Y$ YDDVFAPE SDLSDARPHP-----------------------VDRSSYMSSE-- 245

$\mathrm{S}$ cer Chs 2

SYDDQSTIFSADTFNETKFELNH--PTRQQYVRRANSESKRRMVSDLPPPSKKKALLKLD 240 T_def_g2531

A fum_ChsB

A nid_ChsA

DSDRQSLAPTISSKEEGAKTNYGPAPAEPQPRRRHK-----SKT--TEVVNLTEGNLIIE 98

N_Cra_Chs 2

NLN------EDDVVDVD PNMHYGPAPEK--QSRRGVREA--QMS--KKEVQLINGELILE 310 B_cin_ChsII DLDEYEEESNETKSMVDPNLHYGPAPEK--QSRRGVRNA--QMA--KKEVQLVNGELILE 238 VSTTYSSNTGTSASGVDKFEHYGPIPEEGKHERRGVRPP--QMS--RKEVQLINGELVLE 338 F_oxy_Chs2 -QSYS-TFADDMESAKDYEHYGPAPSGKQERRGANRTT--QMK--KREVKLINGELILE 404 --SQDT-LNEGDMEDYDKVEHYGPAPTGAQERRGV-RAP--QMS--RKEVQLINGELVLE 297

S-cer_chs 2 T_def_g2531 A fum ChsB A_nid_ChsA $\mathrm{N}$ Cra Chs 2 $B$ - cin ChsII F_oxy_Chs 2

NPI PKGLLDTLPRRNSPEFTEMRYTACTVEPDDFLREGYTLRFA--EMNREOQIAICITM 298 REVPEKLRNLLIRHDLKEFNQVKYSAVTCDPDDFVNEGFTLRQHA--QGRETEIMVVMTM 156 CKI PT ILHSFLPRRDDREFTHMRYTAVTCDP DDFTQRGYKLRQQIGSTMRETELF ICVTM 370 CKIPTILHSFLPRRDDREFTHMRYTAVTCDPDDFTQRGYKLRQQIGRTMRETELFICITM 298 CKIPT ILYSFLPRRDEVEFTHMRYTAVTCDP DDFVARGYKLRQNIGRTARETELFICVTM 398 CKIPTILYSFLPRRDEIEFTHMRYTAVTCDPDDFVAKGYKLRQNMGVTARETELFICITM 464 CKIPT ILYSFLPRRGEVEFTHMRYTAVTCDPDDFVERGYTLRQTFGKTVRETELFICVTM 357

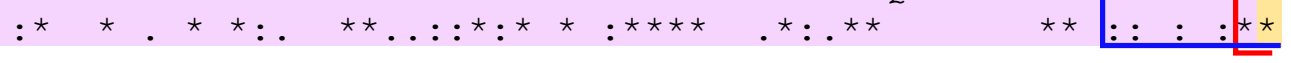

S_cer_Chs 2

YNEDKYSLART IHS IMKNVAHLCKREKSHVWGPNGWKKVSVILIS DGRAKVNQGSLDYLA 358 T_def_g2531 A_fum_ChsB A_nid_ChsA N_cra_Chs2 B_cin_ChsII F_oxy_Chs 2 YNENE KLFTRTLHGVIKNIALLTNRTRSRTWGVDAWQKVVVLIVA DGR KNINPRVLDVLT 216 Y NEDE THFTRTMH G IMRN I SH FCSRS KSRTWGKDGWKKI VVCI I A DGR KKVHPRTLNALA 430 Y NEDE THFTRTMHGVMQNISHFCSRSKSRTWGKDGWKKIVVCI ISDGR KKVHPRTLNALA 358 Y NEDE FGFTRTMHAVMKNISHFCSRNKSRTWGADGWQKIVVCVVSDGREIIHPRTLDALA 458 Y NETE IDFTRTMHAVMKNI SHFCSRS KSRTWGENGWQKIVVAI ISDGRDKI HPRTLDALA 524 Y NEDE I GFTRTMHAVMKNISHFCSRSRSRTWGETGWQKIVVCIVSDGREKI HPRTLDALA 417

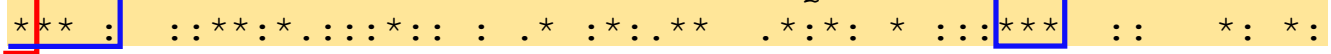

S_cer_Chs2 ALGVYQEDMAKASVNGDPVKAHIFELTTQVS INADLDYV--SKDIVPVQLVECLKEENKK 416 T_def_g2531 A_fum_ChsB A_nid_ChsA N_cra_Chs2 B $^{-}$Cin $^{-}$ChsII F_oxy_Chs2

ALGVYQDGLAQTRVNGNPVTAHLYEYTSQYSMTPDLQFRGAEKNI PPVQIA FLLKEQNQK 276 AMGVYQEGIAKNI VNQKQVTAHVYEYTTQVS LDSDLKFKGAEKGIMPCQVIECLKEHNQK 490 ALGVYQEGIAKNVVNQKQVNAHVYEYTTQVSLDSDLKFKGAEKGIVPCQVIECLKEHNQK 418 AMGVYQHGIAKNFVNQKAVOAHVYEYTTQVS LDSDLKFKGAEKGIVPCQMIECLKEKNDK 518 AMGVYQDGIAKNLVNGREVOAHVYEYTTQVS LDSDLKFKGAEKGIVPCQMLECLKEKNAK 584 AMGVYQHGIAKNFVNNRAVOAHVYEYTTQVSLDSDLKFKGAEKGIVPCQMI FCLKEKNDR 477

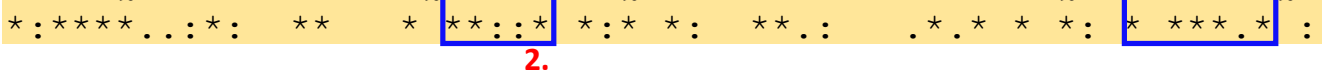

S_cer_Chs2 KIN SHRWLFNAFCPVLQPTVVTLVIVGTRLNNTAIYRLWKVFDMDSNVAGAAGQIKTMKG 476 T_def_g2531 KLNSHRWALQGLAPLLEPNICVLIDVGIRPGPDSIYKLWKAFDMDSRVAGAAGEIRILAG 336 A_fum_ChsB A nid ChsA N_cra_Chs 2 B_cin_ChsII KLN SHRWFFNAFGRALQPNIC ILIDVGIKPEPTALYHLWKAFDQDSNVAGAA GEIKAGKG 550 KLNSHRWF FNAFGRALQPNIC ILIDVGIRPEPTALYHLWKAFDQDSNVAGAA GEIKASKG 478 KLN SHRWF FNAFGKALNPNVC ILIDVGIRPGGTS LYHLWKAFDTDSNVAGACGE IKAMKG 578 F_oxy_Chs2 KLNSHRWFFNAFGKALNPNVCILIDVGTRPSGTSLYHLWKAFDTDSNVAGACGEIKAMKG 537

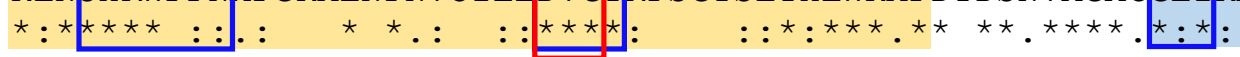


S_cer_Chs2 KWGLKLFNPLVAS QNFEYKISNILDKPLESVF GYISVIP GALSAYRYRALKNHEDGTGPL 536 T_def_g2531 RAWSALLNPLVAS QNFEYKMSNLLDKPCESV FYIGVLPGAFSAYRYRALAGDALGTGPL 396 A_fum_ChsB A_nid_ChsA N_cra_Chs2 B_Cin_ChsII F_oxy_Chs2

KNMMGLLNPLVAS QNFEYKMSNI LDKPLESV F GY I TV LP GALSAYRFFALQNDADGNGPL 610 KNMLGLLNPLVAS QNFEYKMSNILDKPLESV F GY ITVLPGALSAYRFFALQNDAEGNGPL 538 RFGGNLLNPLVAS QNEEY KMSNI LDKPLESV F GY I IV LP GALSAYRY HALQNDETGHGPL 638 KGWMGLLNPLVAS QNFEYKMSNILDKPIESV GYIITVP GALSAYRY HALQNDHTGHGPL 704 RLGANLLNPLVAS QNEEYKMSNILDKPLESVE GY ITVLPGALSAYRYHALQNDETGHGPL 597

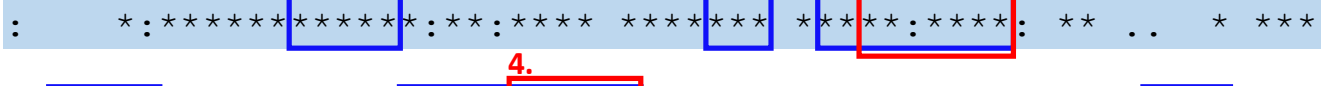

S_cer_Chs2 RSYFLGETQEGRDHDVFTANMYLAEDRILCWELVAKRDAKWVLKYVKEATGETDVPEDVS 596 T_def_g2531 ESYFRGEKID-LEADVFOQNMYLAEDRILAFELIAKRNCNWLLKYVADAYGETDCPNTVA 455 A_fum_ChsB A nid_ChsA N_cra_Chs 2 B_cin_ChsII F_oxy_Chs2 NOYFKGE TLHGKDADVFTANMYLAEDRILCWELVAKREERWVLKFVKSAVGE TDVPDT IP 670 NOYFKGE TLHGKDADVFTANMYLAEDRILCWELVAKREERWVLRFVKSAVGETDVPDSIP 598 SOYFKGE TLHGQHADVFTANMYLAEDRI LCWELVAKRGERWVLKYVKGCTGETDVPDTVP 698 SOYFKGE TLHGQNADVFTANMYLAEDRILCWELVAKRDERWVLKYVKGCTGE TDVPDTVP 764 SOYFKGE PLHGQHADVFTANMYLAEDRI LCWELVAKRGERWVLKYVKGCTGE TDVPDTVP 657

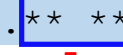
$\star \star \star$

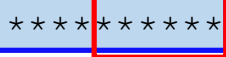

5.

S_cer_Chs 2

EFIS QRRRW LNGAMFA IYAQLHFYQ IWKTKHSVVRKFF LHVEFLYQFIQMLFSWFSIAN 656 T_def_g2531 A fum ChsB A_nid_ChsA N cra Chs 2 B_cin_ChsII F_oxy_Chs2

EI IGQRRRWLNGATFA STYALWNFRRIWSTSHTTRRKLALHVE FLYQAVQLLFTFFGLAN 515 EFISQRRRWLNGAFFA AVYSLVNVKQLWKTDHSVPRKILLQIEAFYQFLNLLFTYFGLAN 730 EFISQRRRW LNGA FFA AVYS IVNVKQLWKTDHSLARKI LLQIESVYQLLQLIFTYFGLAN 658 EFVSQRRRWLNGAFFA AVYSLVHFRQ IWKTDHTFMRKALLHVEFLYHLLQLLFTYFSLAN 758 EFVSQRRRWLNGAFFA AVYSLAHFKQVWHTDHTLGRKILLHIEFIYQFIQLLFTYFSLAN 824 EFISQRRRWLNGAFFA AVYSLVHFKQ IWFTDHTLARKILLHMEFLYQFIQLMFTFFSLAN 717

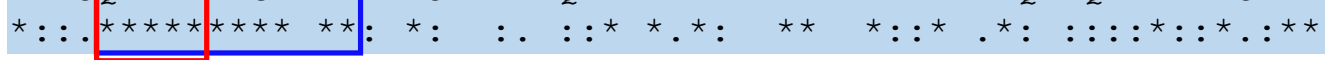

S_cer_Chs 2 T_def_g2531 A_fum_ChsB A_nid_ChsA N cra_Chs 2 B_cin_ChsII F_oxy_Chs 2

S_cer_Chs 2 T_def_g2531 A fum ChsB A_nid_ChsA N_cra_Chs 2 B_cin_ChsII F_oxy_Chs 2

S_cer_Chs 2 T_def_g2531 A_fum_ChsB A nid Chs A N_cra_Chs 2 B_cin_ChsII F_oxy_Chs2
FVLTFYYLAGSMNL-------VIKHGEALFIFFKYLIFCDLASLFI ISMGNRPOGAKHL 708 FYLTFFFIAQS------FGQKFHWASYVFVFLRYLCIMVTAAQFILALGNRPRGAKSL 567 FYLAFFFIAGSLS DERI DP FGH--NMGKY I FFVLRYAC I LVMC LQFI I SMGNRPQGAKKL 788 FYLAFFFIAGSLTDEKIDPFGH--NMGKYIFIVLRYACVLVMC LQFIFSMGNRPQGAKKL 716 FYLAFYFIAGGLADPHVDPFNSDGHVARIIFNILRYVCVLLICTQFILSLGNRPQGAKRM 818 FYLTFYFIAGSLSVDNMDPFGH--S IGKY I FYVLKYVCVLLTATQFILSMGNRPQGARKL 882 FYLTFYFVAGGLTDPKVDPFGH--NIATVIFHILRYACVLLISTQFILSLGNRPQGSKKL 775 ${ }^{\star}{ }^{*}:{ }^{\star}::{ }^{\star}$. $:{ }^{\star} .:{ }^{\star} \cdot{ }^{\star *}:::{ }^{\star * *}:{ }^{\star}:::$

FITSMVILSICATYSLICGFVFAFKS LASGTE---------SHKIFVDIVISLLSTYGLY 759 FLLCL ILYSVIMI YTLGCASYLGVSS ILEGLK---EGGS ILANKQFANIVLSIVATTGIY 624 YMSGI IVYS I IMVYTAFCALY LVVLE LMAKAG-VGKKELAVSDS LFINIVVSLLSTVGLY 847 YLSSMIVYS IVMAYTAFCTLYLIVLELMAKTG-HD-VPITMSDTLFVNIVVSLLSTVGLY 774 YLASMI IYAVIMVYTTFATIF IVVRQ IQP SQKSDDKPDLELGNNVFTNLIVSVASTLGLY 878 YYMSMI IYS I IMVYTLFST IY IVYREVHD-----NAKNLVMGNNLFTNLVVSLCSTLGLY 937 YLISMI IYS I IMVYTTFATFY I I HQLTS-----KDDK I EMGDNVFTNMIVS ILSTIGMY 830 $: \quad::::{ }^{\star}: \quad . \quad: \quad .: \quad \ldots{ }^{\star}::::^{\star}::^{\star}{ }^{\star}{ }^{\star}$

FFSSLMYLDPWHMFTSSIQYFLTLPAFTCT LIFAFCNTHDVSWGTKGSTQESKQLSKAI 819 FVASLMYLDIWHMFTSFLPYMLLVPFYICTLTIFAFCNIHDISWGTKEEDVADLDVVEAK 684 FYSSF LYLDPWHMFTSSAQYFALLPSYICT LQVYAFCNTHDVTWGTKGDNTINNDLGAAR 907 FFTSFMYLDPWHMFTSSAQYFALLPSYICT LCYAFCNTHDVTWGTKGDNTINTDLGTAR 834 FVMSF LYLDPWHMFTSAIQYFVLLPS Y ICT LQIYAFCNT HDV TWGTKGDNVMRTDLGGA - 937 FLMSE LYLDPWHMFTSSGAYFALLPSYICT LQVYAFCNT HDV TWGTKG DNVMSTDLGAA- 996 F IMS I LYLDPWHM ITS SAQYF ILLPS ICT LVYAFCNT HDV TWGTKGDNVMKTDSWGA- 889

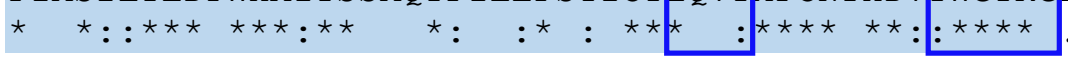


bioRxiv preprint doi: https://doi.org/10.1101/2021.09.16.460675; this version posted September 19, 2021. The copyright holder for this preprint (which was not certified by peer review) is the author/funder, who has granted bioRxiv a license to display the preprint in perpetuity. It is made available under aCC-BY-NC-ND 4.0 International license.

S_cer_Chs2 VVQGPDGKQIVET----DWPQEVDKKFLEIKSRLKEPEFEESSGNEKQSKNDYYRDIRTR 875 T_def_g2531 VLKDDNTKVKIELYQGADAEGSYEDALANLRLRKPVA---EREQDRSRIQEDYFK----- 736 A_fum_ChsB IINGTTVEVEMPS-EQLDIDSGYDAALRNLRDRLEVP---PPPVSENQQQEDYYRAVRTY 963 A-nid-ChsA IINGSIVEVEMPS-EQLDIDSGYDAALRNLRDRLEVP---DPGVSESQQQEDYYRAVRTY 890 N_cra_Chs2 IGKGSTVELEMPS-DQLDIDSGYDECLRNLRDRVMVP---AVPVSEDQLQQDYYKSVRTY 993 B cin ChSII SGKGQTVELEMPS-EQLDIDSGYDEALRNLRDRLEVP---SPPISESQQQEDYYKSVRTY 052 F_oxy_ChS2 VGKGETVELEMPS-EQLDIDSGYDEALRNLRDRLEVP---ESPPSESQLQEDYYKSVRTY 945

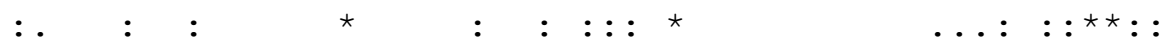

S_cer_Chs2 IVMIWMLSNLILIMSIIQVFTPQD-TDNGYLIFILWSVAALAAFRVVGSMAFLFMKYLRI 934

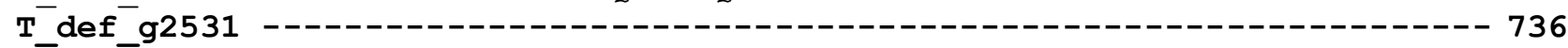
A- fum ChsB MVSIWMVANVILAMSVSEIYGVDSGGTNVYLGIILWSVAVLALIRAVGSTTYAILLVVQK 023 A_nid_ChsA MVSVWMVANVVLAMAVSEVYGVGSSGTNVYLAIILWSVAVLAIIRAIGSTAYAVLYLIQK 950 N_cra_Chs2 MVVSWMVANATLAMAVSEAYGDSEIGDNFYLRFILWAVAALALFRALGSTTFAAINLVSA 053 B_cin_ChSII MVLVWMIANGILAMAVSEAYGPDHLGTNYYLTFLLWAVAALALFRAVGSSAFGIINCVEA 112 F_oxy_Chs2 LVLTWMIGNGILGMAVSEIYSARGIGDNYYLRFLLWSVAALAVFRAIGSTTFAVLNVINM 005

S_cer_Chs2 IVSYRNKVEGS---GSWEVSK---LD--LPNVFHKKG-----------------------963

T_def_g2531

A fum ChsB

IVEGKTKFDAGNIVNSNAATSS-YVSSRSTAQYG-GGTSFKDKVTEAGWTLKRTAGKAMF 081 A-nid-ChsA LVEGKAKFQAGNIASANASAAGSSLGTKSNVSYGSKGLNMTDRINETKWAISRGMQKAMF 010 $\mathrm{N}$-cra_Chs2 LVEGRVRLRLNMKGFRWIKE---KWGDADVKGKF-------EGLGDRARGLARR------097

B_cin_ChSII IVEGRIRVSMT--VPRWMGG----WSSKISEGIS-------EGISSVGNAVKRN------ 153

F_oxy_Chs2 IVEGRVRLSLK--APRWMGG----LKERVNDKMS-------SVSSNLRS-----------041

S_cer_Chs $2---963$

T_def_g2531 --- 736

A fum_ChsB WKK 1084

A_nid_ChsA WKK 1013

$\mathrm{N}^{-} \mathrm{Cra}{ }^{-} \mathrm{Chs} 2$-- 1097

B_cin_ChsII -- 1153

F_oxy_Chs2 --- 1041 


\section{Figure S5.}

T_M11_g677

T_def_g3955

B_cin_ChsIIIb

F_oxy_Chs3

A fum ChsC

N_cra_Chs 1

C_gra_ChsIII

B_cin_ChsIIIa

A fum_Chs

A_nid_ChsB

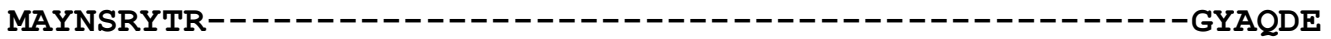

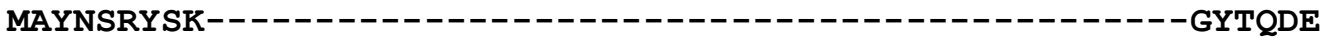

-METSRS----W---------------NSSAENYPMNE

MGFN---PQGQGNGPNYDAPREMQDLPAGQAYHFRESDETAAARVSPVSNPYEPDYDQLS ---------MGT-PRPYSAHS PQESRS--SFYSQPSQ-----------SPTQPTYGRDD MAYH-GR-------GDGYDGHQLQDLPGGHNQGDQ-------------------------

MAYRGGH-------ENDYDGHNMQDLPAGTGRYHLPPQ-------------------DEG

MAYSGNGGY---------DEHKLQDLP PGGGNYHHPQD-------------------EEE

MAYQGSGSHSP P--HYDDNGHRLQDLPH--GSYEEEAS---------------------

MAYHGSGPQSPGE-HTYDDGHQLRDLSHSNTSYEEEAS---------------------

T_M11_g677

T_def_g3955

B Cin Chsilib

F-oxy_Chs 3

A fum ChsC

N_cra_Chs 1

C_gra_ChsIII

B_cin_Chsilia

A fum Chs

A_nid_ChsB

T_M11_g677

T_def_g3955

B_cin_Chsilib

F_oxy_Chs 3

A_fum_ChsC

N_cra_Chs 1

C gra ChsiII

B_cin_ChsIIIa

A fum Chs

A_nid_ChsB

VPINRH-DASDEEEEDLGDVDLNDGMPMQASLNPFSDTAYSG-

APINHY-DLSDD-EEDLGNTQFPEPESLRSGMS PFGDTAYQG

----L-IQHSNNSVT DPAT-QLDNTDH I SDVHHSNDAHDVG-----ESLLSDT SGYHPTT PPP PLGAQRPVPEQNESSRDLLHS SYQGSVGHNSFDGHSF----------------GHN -----------AE DQQQS LLRR-SLAS PNGWSYDDPNVS--------TDSLRRYTL------------HDDAQAPFLS--ENP----MPYDND---RLGTDTPPVRPVSAYSLTE -----------VDDVGQSLLRDPHAP----GPYE-S---HLGPAEVPGRPVSAYS LTE -----------G---ALPLLDSGGHGGPFNS PYDSHSQGGLRANTPPVRPVSAYS LTE ----------------RGLL--SHQQGPFTGPFDDPQQHGS----STTRPVSGYSLSE ------n---n---HGLL--SSQQSPFAGPFDDPHQQRGLTAS PVQRPTSGYSLTE :$$
\text { -YRPGYD- - }
$$
-TELDEPIPYQQSVMHQSHYSERSLVEDLKTPIPSITRTS -YQPSND -DEYEHPTVHDSSSR NANGLELRG-TSRLSTPVQSG----

PYVTGTGQVQR-----------------------------------QRSPTSS----SYGPGAFGHYPADQHGRMPGSPGYEY--PEPEYDVEASRLAESRLSVMHRAPTMQDW--G --------HDP--------GITAFAPPYPESEA--A----------------------SYAPGAGTTRA--------GVAVNPTPPPHGGYGGG---------------------SYAPGAGARTP--------VPGETA---FASGFS-Q----------------------TYANDPQ---P--------YSSDYN---SSHTYNEQ-----------------------TYAPEAAYHDP--------YTQPS----PGSVYSAQ----------------------SYAPDAAYHDP--------YSANQ------SVYS-G-----------------------15 15 18 57 36 27 34 32 34 37

T_M11_g677 T_def_g3955 B_cin_ChsIIb F oxy Chs 3 A fum ChsC N Cra Chs 1 C_gra_ChsIII B cin ChsIIIa A fum Chs A_nid_ChsB

SPYEPSLKERFAGSPELGKQPEVDPEAGFR-ERQQPLRRGHTRKV -FHSPALSTKYGFLEKDPHEIVTTPFSHAESDPEAGFR-ERQ-------QPLKRGHTRRV 145 -----VNGEEFFGDQHHLPDI DQDFYRS---PEDSFNAQDMPSANGARGALRRRATRKI QNGEALSVPDFAHGRP------DST--YQEFDVDESWM-MRQQQNQ-LAGGLGRSKTRKV -DVR----------------SARMSGYSGIEMDAWQ-RRQGV---KPSALRRYGTRKI -GVSSGVDQGYNYGGD---YATDPAYRMSAIDEDDSWL-RRQQPNAAPTGGLKRYATRKV -ELDSDANGGFGYGR----------PASTVDADESWT-RRQQPGH-QAGGLKRYATRKI --LE--DNPY--------PQTDTPLSRAGTTS TEAWR-QRQAPQA---GGLKRYATRKV --SA--ENPAAAFGVP---GRVAS PYARSDTSSTEAWR-QRQAP-GGGPGGLRRYATRKV --HS--ENPAAAFGVP---GRVASPYARSETSSTEAWR-QRQAGAAGGGNGLRRYATRKV KLVQ---GSVLS IDYPVPSAIKNAVEPRYRSGPGSMEEEFTKMRYTAATCDPNDFTLRNG NLVQ---GSVLSVDYPVPSAIQNAIQAEYRDAEEAFHEEFT HMRYTAATCDPDEFTLRNG KLVQ---GSVLSLDYPVPSAIRNAVQPKYR-DEEGNNEEFFKMRYTAATCDPNDFTLKNG 
A_nid_ChsB KLVQ---GSVLSVDYPVPSAIQNAIQAKYRNDLEGGSEEFTHMRYTAATCDPNEFTLHNG

T_M11_g677

1. T_def_g3955

YNLRPALYERNTELLIAVTYYNEDKVLTARTLHGIMENIKDICQDKKSKFWNKGSPAWQN 261 B Cin ChsiIto YNLRPALYQRNTELLIAVTYYNEDK FLTARTLHGVMQNIKDICNDKKSRFWNSTSPAWQN YTLRQHIYNRHTELLIAITYYNEDKVLFARTLHGVMKNIRDIVNLKKSRFWTQGSAAWEK FNLRPKMYNRHTELLIAITYYNEDK VLLARTLHGTMQN IRD IVNLKRSKFWNKGGPAWQK YNLRPAMYNRHTELLIAITYYNEDKVLTARTLHGVMQNVRD IVNLKKSEFWNKGGPAWQK F_oxy_Chs A fum ChsC $\mathrm{N}$ Cra Chs 1 C_gra_ChsiII B_cin_ChsIIIa A-fum_ChsG A-nid_ChsB YDLRPRMYNRHTELLIAITYYNEDK VLLSRTLHSVMTNIRDIVNLKKSS FWNRGGPAWQK YDLRPRMYNRHTELLIAITYYNEDK VLLSRTLHGVMQNIRDIVNLKKSTFWNKGGPAWQK YNLRPAMYNRHTELLIAVTYYNEDKQLTARTLHGVMQN IRD IVNLKKSDFWNVGGPAWQK YNLRPAMYNRHTELLIAITYYNEDK TLTSRTLHGVMQNIRDIVNLKKSEFWNKGGPAWQK YNLRPAMYNRHTELLIAITYYNEDK TLTARTLHGVMQNIRDIVNLKKSEFWNKGGPAWQK

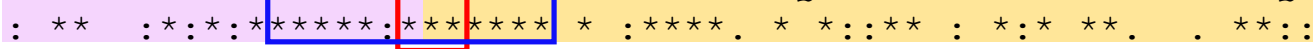

T_M11_g677 T_def_g3955 B Cin ChsIIIb F oxy Chs 3 A fum ChsC $\mathrm{N}$ Cra Chs 1 $\mathrm{C}^{-}$gra-ChsiII B_cin_ChsiIIa A- fum ChsG A_nid_ChsB

\section{T_M11_g677}

T_def_g3955

$B$ Cin Chsirib F_oxy_Chs 3 A_fum_ChsC N_cra_Chs 1 C-gra-ChsiII B_cin_Chsila A_fum_ChsG A nid ChsB

T_M11_g677
T_def_g3955
B_cin_ChsIIIb
F_oxy_Chs3
A_fum_ChsC
N_cra_Chs 1
C_gra_ChsIII
B_cin_ChsIIIa
A_fum_ChsG
A_nid_ChsB

T M11 g677 T_def_g3955 B_cin_ChsIIb $\mathrm{F}^{-}$oxy $\mathrm{Chs} 3$ A_fum_ChsC N_cra_Chs 1 C_gra_ChsIII B_cin_Chsila A fum ChsG
IVVCLVF GIPPCDKGTLDLLATIGIYQDQIMKGKINGKKPTAHI FEYTTTVVVNDRMQI IVVCLVFPGI PCDKGTLDLLATI IGIYQDQIMKGE IDGKKPTAHI FEYTTTQVSVNDNMQL IVVCLVF GGE KADPGVLDLLTTVGVYQDGVRKQDVDGKET TAHVFEETTQLSITPDLQL IVVCLVF GIDKVDKNVFDVLATVGIYQDGVLKKDVNGKETVAHI FEYTSQVSVTPDQQL IVVCLVFPGIEPCDKNTLDVLATIGVYQDGVMKKDVDGRETVAHI FEYTTQLSVTPTQQL IVVCLVFPGLPKTDKNVLDVLATIGVYQDGVIKKDVDGKETVAHIFEYTSQLSVTPNQAL IVVCLVFDGIEKTDKSVLDVLATVGIYQDGVVKKDVDGKETVAHIFEYTSQLSVTPSQQL IVVCLVFPGIPPCDKDTLDVLATIGIYQDGVMKKDVDGKETVAHVFEYTTQLSVTASQQL IVVCLVFDGIDPCDKDTLDVLATI GVYQDGVMKRDVDGKETVAH I FEYTTQLSVTPNQQL IVVCLVFPGIDPCDKDTLDVLATVGIYQDGVMKRDVDGKETVAHI EEYTTQLSVTPNQQL

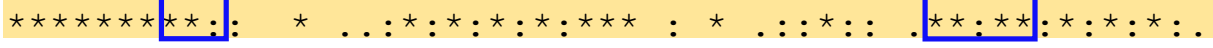

\section{2.}

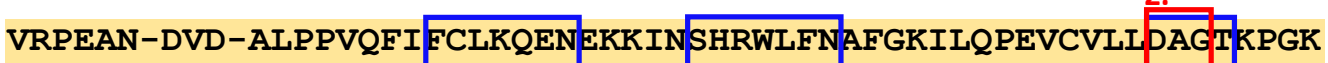
IRPSEN-DPD-ALPPVQFI FCLKQENEKKINSHRWLFNAFGKILQPEVCVLLDAGTKPGK SRPNSDVDDSSNLP PVQLLECLKQKNTKK INSHRWLFNAFGR I LNPEVTILIDAGTKPGP VRPDPD-KPHRNLP PVQFI FCLKQKNSKKINSHRWLFNAFGRILNPEVA ILIDAGTKPAP VRPQPN-DPS-NLPPVQMLECLKQKNSKKINSHRWLFNAFSRILNPEICILLDAGTKPGS IRPVDD-GPQ-TLPPVQF I FCLKQKNFKKINSHRWLFNAFGRI LNPEVC ILLDAGTKPSP IRPVDD-GPS -TLPPVQF I FCLKQKNSKKINSHRWLFNAFGRILNPEVCILIDAGTKPSP IRPTEG-DAN-CLP PVQMMFCLKAKNTKKINSHRWLFNAFGRLLNPEVCILLDAGTKPGP IRPTDD-GPS-TLPPVQMMFCLKQKN SKKINSHRWLFNAFGRILNPEVC ILLDAGTKPGP IRPTDD-GPS-TLPPVQMMFCLKQKNSKKIN SHRWLFNAFGRILNPEVC ILLDAGIKPGP $\star \star$

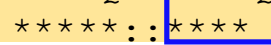

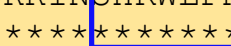

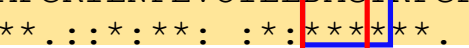

RSIYHLWKAFFNDANLGGACGEIHAMLSNG-RKLVNPLVAT QNFEYKMSNILDKPLESSF RSIYHLWKAFFNDANLGGACGE IHAMLSKG-KKLVNPLVATQNFEY KMSNILDKPLESSF RSLLALWEAFYNDKNLGGA CGE I HAMLGSRNSKLLNP LVAIQNFEYKI SNVLDKPLESSF RALLSLWEGFYNDRDLGGACGE I HVMLGKGGKMLLNP LVAVQNFEYKISNVLDKPLESAF KSLLALWEAFYNDKTLGGA CGEI HAMLGRGWRNVLNPLVAAQNFEYKISNILDKPLESAF RSLLALWEGFYNDKDLGGA CGEIHAMLGKGGKKLLNP LVAVQNFEYKISNILDKPLESAF RSLLALWEGFYNDKDLGGACGE I HAMLGKGGKKLLNPLVAVQNFEYKISNILDKPLESSF KSLLSLWEGFYNDKDLGGACGE IHAMLGKGGKKLLNPLVAGQNEEYKISNILDKPLESSF KSLLSLWEAFYNDKDLGGACGE IHAMLGKGWKNL INP LVAAQNEEYKISNI LDKPLESSF KSLLYLWEAFYNDKDLGGA GGE I HAMLGKGWKKLLNP LVAAQNFEYKISNILDKPLESSF

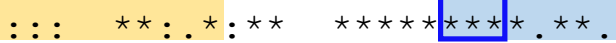

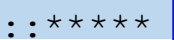

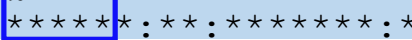
4. GYVSVLPGAFSAYRYRAIQGRPLDQ YFRGDHSLANKLGEKGVNGMGIFKKNMFIAEDRII GYVSVLP GAFSAYR YRAIQGRPLDQ YFRGD HSLAGVLGNKGVNGMGIFR KNMFLAEDRIL GYV TVL PGAFSAYRERA IMGRPLEQ Y YSHGDHTLL--SGKKS INNMNI FKENMFIAEDRIL GYVSVLPGAFSAYRERA IMGRPLEQY FHGDHTLSKSLGKKGIDGMNIFKKNMF LAEDRIL GYVSVLPGAFSAYR YRA IMGRPLE QY FHGD HTLSKRLGKKGIEGMNIFKKNMF LAEDR I L GYVSVLPGAFSAYRERA IMGRPLEQYFHGD HTLSKLLGKKG IEGMNIFKKNMFLAEDRIL GYVSVLPGAFSAYRFRA IMGRP LEQY FHGDHTLSKILGKKG I DGMNIFKKNMF LAEDRIL GYVSVLPGAFSAYRFRA IMGRPLEQYFHGDHTLSKILGKKGIEGMNIFKKNMF LAEDRIL GYVSVLPGAFSAYRERA IMGRPLEQYFHGDHTLSKQLGKKG IEGMNI FKKNMFLAEDRIL
321 322 315 383 304 324 319 318 322 327

379 380 375 442 362 382 377 376 380 385 
A_nid_ChsB

T_M11_g677

T_def_g3955

B_cin_ChsIIIb

F_oxy_Chs 3

A_fum_ChsC

N_cra_Chs 1

C_gra_ChsIII

B_cin_ChsIIIa

A_fum_ChsG

A_nid_ChsB

T_M11_g677

T_def_g3955

B_cin_ChsIIIb

F oxy Chs 3

A_fum_ChsC

N cra Chs 1

C_gra_ChsIII

B cin ChsIIIa

A fum Chs

A_nid_ChsB

T_M11_g677

T_def_g3955

B_cin_Chsilib

F_oxy_Chs 3

A_fum_ChsC

N_cra_Chs 1

C_gra_ChsIII

B_cin_Chsilia

A fum Chs G

A_nid_ChsB

T_M11_g677

T_def_g3955

B_cin_Chsilib

F_oxy_Chs 3

A fum Chs C

N_cra_Chs 1

C_gra_ChsIII

B_cin_Chsilia

A_fum_ChsG

A_nid_ChsB

T_M11_g677

T_def_g3955

B cin Chsilib

F oxy Chs 3

A fum Chs C

N_cra_Chs 1

C_gra_ChsiII

B_cin_ChsIIIa

A_fum_ChsG
GYVSVLPGAFSAYRFRAIMGRPLEQYFHGDHTLSKQLGKKGIEGMNIFKKNMF LAEDRIL

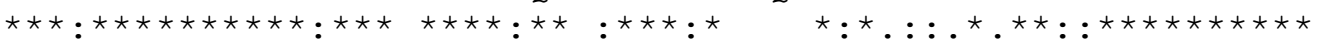

505

5.

CFELVAKAGARWKLTYVKASQAETDVPEQVAEF IS QRRRW LNGSFAASIYSMVHFPRLYR CFELVAKAGAKWKLTYVKASQAETDVPEQAAEFIS QRRRW LNGSFAAS SYSMVHFPRLYR CFELVVKEGQNWHLSYVKAAKGE TDVP EGPAEFLSQRRRW NNGSFAA SLYS L I HFGRMYK CFELVAKASQKWHLSY IKASKGE TDVP EGAAEF I QRRRRW NGS FAM SLYSLMHFGRMYG CFE LVAKAGYKWHLTYVKASKGE TDVP EAAPEYISQRRRW NGSFAA SLYS IMHFGRIYK CFELVAKAGQKWHLSY IKAAKGETDVP EGAPE FISQRRRW NGSFAA SLYSLMHFGRMYK CFELVAKAGQKWHLSY IKAAKGE IDVPEGAAEF ISQRRRW NGSFAA SLYS LMHFGRMYK CFELVAKAGSKWHLTYIKAAKGE T DVP EGAAEF I GQRRRW NNGSFAA GMYS IMHFGRMYK CFELVAKAGSKWHLTYVKASKAE IDVP EGAPEF ISQRRRW NGSFAA GIYS LMHFGRMYK CFELVAKAGSKWHLSYVKASKGE TDVP EGAPEF I SQRRRW NGS FAA GI YS LMHFGRMYK

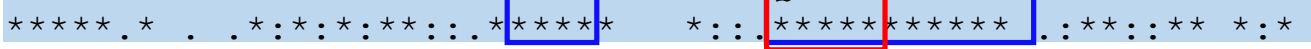

SNHS IARMVIFHLQLLYNI FST IFSWFALANLWLTFSVVIQLTSQQSPFLAPSSCNLCHA SNHSFFRMFVFHVQLVYNI FSTIFSWFALANLWLTFSVVIQLTSQQSPFLGTNSCNTCHA SGHSLLRMIMF HFQLLYNIANVIF SWFSLSSYWLTTTVIMDLVGT PVTASNY-------SGHNLIRLFFLHIQFVYNLVNVLF SWFSLAAFYLTTT I IMKLVGT PQVLSEY------SGHSFVRMF FLHIQMIYNCCQLIMTWFS LASYWLTSSVIMDLVGTPSSHNKY-------SGHNIVRMFFF HVQLIYNIANVIFTWFSLASYWLTTTVIMDLVGT PVTASSS SGHNLVRMI FFH IQLVYNI LQVLFTWFSLGSYYLTTTVIMDLVGNPVVSEDPSGHNIVRMFFLHIQFLYNVFSNELSWFMLSSFWLTTTVIMDLVGTPTAASDT SGHNIVRMFFLHIQMLYNI FSTVLTWFSLASYWLTTTVIMDLVGT PSDNNGNSGHNIVRMFFLHLQMLYNWFSTFLTWFSLASYWLTTSVIMDLVGT PSSSNGY ${ }^{\star} .{ }^{\star} .:{ }^{\star}: \ldots{ }^{\star}{ }^{\star}::{ }^{\star \star}, .::^{\star \star}{ }^{\star} . \quad{ }^{\star \star}::::{ }^{\star} \ldots$

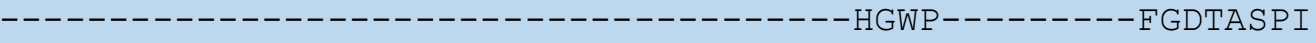
FGDTATPI $-\mathrm{HGWP}$ FGNDASPI

FNLVLQYVYLGALLLSFLLALGQRPKGSIKTYTGAMAVFAVCQVYLLACSFYLAIKALIS FNLVLQYVYLGTILLSFLLALGQRPKGSVKTYLGAMTLFAFCQIYLLACSFYLAITALMT

FNHVIEYIYLAFVITQF ILALGNRPKGSQVTYLVLFVVFGF IQLY I I I LSFYLVYRALRT VNVLIKYIYIAFLVLQFVLALGNRPKGAQYTYVLS FMVFGLIQLYLLVLTGYLVYRAFTG VNF FVKYGYLLVLMLQFVLALGNRPKGTKLAYTMSFLWFSLVQFYVLILSFYLVANAFMG FNAVLKYIYLAFVILQFILALGNRPKGSKWTYITSFFVFSLIQSY ILVLSGYLVARAFSV FNALLKYLYLAFVILQFILALGNRPKGSKYTYIAS FVVFGLIQSY ILILSMYLVVQAFQT INT I LKYLYLGFLLVQF ILALGNRPKGSKATY IVSFVVFGV INLYVLVLSMYLVVRAFSS INT IVKYVYLGFLLLQFILALGNRPKGSKFSYLASFVVFGI IQVYVVIDALYLVVRAFSG INTLVKY IYLAFLLLQF ILALGNR PKGSKLSYLASFVAFGI IQLYVVVDALYLVVRAFTG

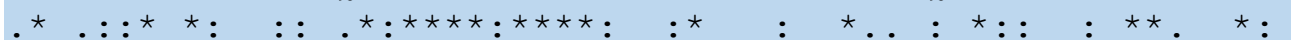
TPIEEQISFESG-KAFFDSFFGG---D-TGVAGLII IALFT IYGLNYIASFLYLDPWHMF GM-I-DFDFDQGVGNFLSSFFS------STGGG IVLIALVSTYGIYIVAS I LYMDPWHIL PLDQ-QLQLDNA-KDAMASLFGG---S--GSAGVILVALVT IYGLYFLAS FMYLDPWHMF PLSQ-QI SLDSG-KDFVQSFFGG---T--NAAGVILVALVT IYGLNF IAS FMYLDPWHMF GDSL-DTSSAK---DFFESFFGD---SSSSGAG I I LALAATFGLYFVAS FMYMDPWHMF SAPM-DFTTDQGVGE FLKSFFS------SSGAGI I I ALAATFGLYFVASFMYLDPWHMF 
bioRxiv preprint doi: https://doi.org/10.1101/2021.09.16.460675; this version posted September 19, 2021. The copyright holder for this preprint (which was not certified by peer review) is the author/funder, who has granted bioRxiv a license to display the preprint in perpetuity. It is made available under aCC-BY-NC-ND 4.0 International license.

A_nid_ChSB GAPM-DFNTDDGIGAFLSSFFG------SSGAGIIIIALAATFGLYFVASFMYLDPWHMF . . : * $\star::::^{\star}::^{\star}:{ }^{\star \star}::^{\star}:{ }^{\star} \star{ }^{\star}::$

T_M11_g677

T_def_g3955

B_cin_ChsIIb

F_oxy_Chs 3

A fum Chs C

N Cra Chs 1

C_gra_ChsIII

B_cin_ChsIIIa

A_fum_ChsG

A_nid_ChsB

HSF PQYLLLAPSYTNI LNVYSFCNTHDV SWGTKGADKPEALPAVEAKKGGHA-SAIVEEN HSLPQYILLAPSYVNI LNVYSFCNTHDV SWGTKGSDKPEAL PALEAKKGD-R-SAIVEEN

HSF PQY I ILASTYINILMVYAFNNWHDVSWGTKG SDESEKLPSANVIKDSKSGVEMVEEE HSF PQYLVLMSTYINILMVYAFNNWHDVSWGTKGSDTAEALPSAMIVKDEKGKEAVVEEI TSSWAYFLGMTTSINI LMVYAFCNWHDVSWGTKGSDKADALPSAQTKKADGSKSNFIEEI HSF PYYMLLMS TYINI LMI YAFNNWHDVSWGTKGSDKAEALPSANVSKGEKD-EAVVEEI TSFPHYLVLMSTYINI LMVYAFNNWHDVSWGTKGSDKTEALPSAQVSKGEKD-EAVVEEI HSFGPYLLLMSSYINILMVYAFSNWHDVSWGTKGSDKAEALPSAKTTKVDGK-AAVIEEI TSEPAYMCVQSSYINILNVYAFSNWHDVSWGTKGSDKADALPSAKTTKDEGK-EVVIEEI TSFPAYMAVQSSYINILNVYAFSNWHDVSWGTKGSDKADALPSAKTTGGKGE-EAVIEEI EQEQEDIDSKFEKVVWRALAPMSEMAEEKPEKKDVEDSYKSFRTGLVILWLLCNIVLIVV DKPQADIDSQFEATVKRALAPYQEP--KEDSTISLDDSYRNFRTSLVLLWILSNLLVSLL N_cra_Chs 1 EKPQEDIDQQFEATVRRALAPYKED--ETPEPKDLEDSYKS FRTMLVVSWLFSNCLLAVV

DKPQADIDSQFEATVKRALTPYVPP--VEKEEKTLEDSYKS FRTRLVTFWIFSNAFLAVC DKPQADIDSQFEATVKRALTPYVPP--EEKEEKSLDDSYKSFRTRLVTLWLFSNGLLAVC FTSSDIQTAFGIGQSTKTRTATYFQFILWSTAVLSFIRFVGCLYFVTQTGIQQIPGFSKR 